UNIVERSIDADE DE SÃO PAULO

INSTITUTO DE PSICOLOGIA

LISLIEE LOPES VIDAL SILVA

ESTILOS E ESTRATÉGIAS DE APRENDIZAGEM DE ESTUDANTES UNIVERSITÁRIOS

SÃO PAULO

MARÇO DE 2012 


\section{ESTILOS E ESTRATÉGIAS DE APRENDIZAGEM DE ESTUDANTES UNIVERSITÁRIOS}

(Versão Original)

Dissertação apresentada ao Instituto de Psicologia da Universidade de São Paulo para obtenção do título de Mestre em Psicologia.

Área de Concentração: Psicologia Escolar e do Desenvolvimento

Orientador: Prof. Dr. José Fernando Bitencourt Lomônaco

SÃO PAULO

MARÇO DE 2012 
AUTORIZO A REPRODUÇÃO E DIVULGAÇÃO TOTAL OU PARCIAL DESTE TRABALHO, POR QUALQUER MEIO CONVENCIONAL OU ELETRÔNICO, PARA FINS DE ESTUDO E PESQUISA, DESDE QUE CITADA A FONTE.

Catalogação na publicação

Biblioteca Dante Moreira Leite

Instituto de Psicologia da Universidade de São Paulo

Silva, Lisliê Lopes Vidal.

Estilos e estratégias de aprendizagem de estudantes universitários / Lisliê Lopes Vidal Silva; orientador José Fernando Bitencourt Lomônaco. -- São Paulo, 2012.

$125 \mathrm{f}$.

Dissertação (Mestrado - Programa de Pós-Graduação em Psicologia. Área de Concentração: Psicologia Escolar e do Desenvolvimento Humano) - Instituto de Psicologia da Universidade de São Paulo.

1. Estilos cognitivos 2. Aprendizagem 3. Estudantes universitários I. Título. 
Nome: SILVA, Lisliê Lopes Vidal

Título: Estilos e estratégias de aprendizagem de estudantes universitários

Dissertação apresentada ao Instituto de Psicologia da Universidade de São Paulo para obtenção do título de Mestre em Psicologia

Aprovado em:

Banca Examinadora

Prof. Dr. José Fernando Bitencourt Lomônaco Instituição: Universidade de São Paulo

Julgamento: Assinatura:

Prof. Dra. Fraülein Vidigal de Paula Instituição: Universidade de São Paulo Julgamento: Assinatura:

Prof. Dra. Acácia Aparecida Angeli Santos Instituição: Universidade São Francisco Julgamento: Assinatura: 
Ao meu orientador,

Prof. Dr. José Fernando Bitencourt Lomônaco, que desde o início acreditou neste trabalho e me conduziu em cada passo do mestrado com serenidade e genuíno interesse por meu crescimento acadêmico. 


\section{AGRADECIMENTOS}

A Deus por me acompanhar e abençoar todos os meus dias.

Ao meu marido Rodrigo por me incentivar, apoiar e dedicar tanto tempo à minha felicidade.

À minha família, meu porto seguro. Lili e Ezequiel, pais que fizeram sempre todo o esforço possível para que eu recebesse a melhor educação. Gleidy e Walace, irmãos que me ensinaram, pelas diferenças e semelhanças, o amor que nos une. Alexandre e Melissa, cunhados que se tornaram como irmãos de sangue. Rayssa, Bruno e Walace Filho, sobrinhos amados.

À minha querida amiga Edna pelo incentivo e apoio constantes desde a inscrição para o mestrado até a conclusão deste trabalho.

Ao meu orientador, Prof. Dr. José Fernando Lomônaco, pela leitura cuidadosa e orientação segura durante todo o processo de elaboração deste trabalho. Meu sincero reconhecimento.

A Profa. Dra. Acácia Santos e Profa. Dra. Fräulein de Paula pelas preciosas colaborações feitas por ocasião da qualificação.

Ao UNASP, Centro Universitário Adventista de São Paulo, pela redução da carga de aulas e auxílio financeiro, que viabilizaram a produção deste trabalho. 
"Eu sempre sonho que uma coisa gera, nunca nada está morto.

O que não parece vivo, aduba. O que parece estático, espera."

Adélia Prado 


\section{RESUMO}

SILVA, L.L.V. Estilos e estratégias de aprendizagem de estudantes universitários. 2012. 125f. Dissertação (mestrado) - Instituto de Psicologia, Universidade de São Paulo, São Paulo, 2012.

Este estudo exploratório buscou investigar os estilos e estratégias de aprendizagem de universitários, com o objetivo de avaliar uma possível interação entre os dois constructos e também comparar o tipo de estilo e de estratégia de aprendizagem dos participantes em função da área de conhecimento, do curso e sexo dos participantes. A pesquisa foi realizada em uma instituição de ensino superior, particular, do interior paulista com 352 estudantes de diversos cursos. Para a coleta de dados foram utilizados dois instrumentos: o Índice de Estilos de Aprendizagem e a Escala de Avaliação de Estratégias de Aprendizagem em Universitários. Quanto aos estilos de aprendizagem, a amostra como um todo se revelou predominantemente sensorial, visual, ativa e sequencial. E no tocante às estratégias de aprendizagem, constatou-se que há uma ordem hierárquica no uso das mesmas: os universitários tenderam a utilizar preferencialmente as estratégias de autorregulação dos recursos internos e contextuais, seguidas pelas de autorregulação cognitiva e metacognitiva $e$, por último, às destinadas à autorregulação social. Os resultados obtidos não apresentaram correlação suficientemente robusta entre estilos e estratégias de aprendizagem. Contudo, as demais comparações realizadas indicaram diferenças significantes quanto as variáveis: área de conhecimento, curso e gênero do participante. Com base nestes resultados, sugere-se que o professor promova diferentes formas de se lidar com a informação, favorecendo o contato do estudante com outros estilos de aprendizagem diferentes daqueles preferidos por este. Aponta-se também para necessidade de programas de ensino para o uso de estratégias de aprendizagem voltados aos estudantes universitários. 


\begin{abstract}
SILVA, L.L.V. Styles and learning strategies of university students. 2012. $125 f$. Dissertação (mestrado) - Instituto de Psicologia, Universidade de São Paulo, São Paulo, 2012.
\end{abstract}

This study aimed to investigate the styles and learning strategies of undergraduate students, searching to evaluate a possible interaction between that two constructs and also to compare the kind of style and learning strategy of the participants regarding the knowledge field, the course and the sex of the participants. The research was conducted at an Private Instituition of higher education, in Sao Paulo State's countryside with 352 students of several courses. For collection data it was used two tools: Index of Learning Styles and Learning Strategies Scale Evaluation. Concerning to learning styles, the sample at all showed itself sensorial, visual, active and sequential. In relation to the learning strategies, it was found that that is a hierarchical sequence in the utilization of that: the undergraduate students tend to use preferably autoregulation strategies of internal and contextual resources, followed by the cognitive and metacongnitive autoregulation strategies and, finally, that strategies fated to the social autoregulation. The reached results didin't show strong correlation between learning styles and strategies. However, the remain comparissons indicated significant differences according to the variables: knowledge field, course and gender of the participant. Based on that results it is suggesting that the professor promote diferent forms to lead with information, favouring the contact of the student with other learning styles different from that other preferred. It indicates also the need of teaching programs for the use of learning swtrategies turned to University Students. 


\section{LISTA DE ILUSTRAÇÕES}

Figura 1. Modelo de Processamento da Informação Humana.

Figura 2. Modelo de Processamento da Informação Humana incluindo os Processos Executivos de Controle e a Metacognição

Figura 3. Esquema representativo da proposta de Curry sobre os componentes dos estilos de aprendizagem com a adição do nível sugerido por Claxton e Murrel 28

Figura 4. Modelo teórico dos componentes dos estilos de aprendizagem e seus efeitos

Figura 5. Modelo representativo da Teoria de Aprendizagem Experiencial de Kolb.33 Figura 6. Questão no. 1 do Inventário de Estilos de Aprendizagem (Learning Style Inventory - LSI)

Figura 7. Esquema representativo do modelo de estilos de aprendizagem de FelderSilverman. 37

Figura 8. Escala de classificação do Índice de Estilos de Aprendizagem (ILS) ........40

Figura 9. Formato das questões na versão original e modificada do ILS 43 


\section{LISTA DE TABELAS}

Tabela1. Distribuição dos participantes da pesquisa por área, cursos, semestre e

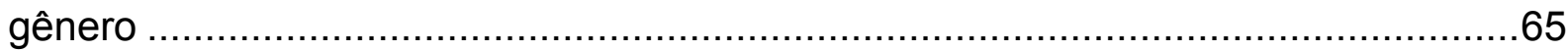

Tabela 2. Estilos de aprendizagem dos participantes em função das dimensões e estilos de aprendizagem ...............................................................................69

Tabela 3. Comparação entre os estilos de aprendizagem de cada dimensão para a amostra total .................................................................................. 70

Tabela 4. Frequência e porcentagem dos estilos de aprendizagem em função das áreas de conhecimento

Tabela 5. Comparação entre os estilos sensorial e intuitivo em função das áreas de conhecimento

Tabela 6. Comparação entre os estilos visual e verbal em função das áreas de conhecimento

Tabela 7. Comparação entre os estilos ativo e reflexivo em função das áreas de conhecimento.

Tabela 8. Comparação entre os estilos sequencial e global em função das áreas de conhecimento

Tabela 9. Frequência e porcentagem dos estilos de aprendizagem em função do curso.

Tabela 10. Comparação entre os estilos sensorial e intuitivo em função dos cursos76

Tabela 11. Comparação entre os estilos visual e verbal em função dos cursos .......77

Tabela 12. Comparação entre os estilos ativo e reflexivo em função dos cursos. ....77

Tabela 13. Comparação entre os estilos seqüencial e global em função dos cursos78

Tabela 14. Frequência em cada estilo de aprendizagem por sexo

Tabela 15. Comparação entre os estilos de cada dimensão em função do sexo .....80

Tabela 16. Estratégias de aprendizagem: médias e desvios padrão de cada fator ..81

Tabela 17. Estratégias de aprendizagem: comparações entre os três fatores.

Tabela 18. Estratégias de aprendizagem: médias e desvios em função da área de conhecimento

Tabela 19. Análise de variância referente ao uso de estratégias de aprendizagem em função da área de conhecimento

Tabela 20. Estratégias de aprendizagem: médias e desvios em função dos cursos 84

Tabela 21. Análise de variância referente ao uso de estratégias de aprendizagem em função dos cursos.

Tabela 22. Estratégias de aprendizagem: médias e desvios em função do sexo .....87

Tabela 23. Resultado do teste t para a comparação entre o uso de estratégias de aprendizagem e o gênero dos participantes.....................................................8 8

Tabela 24. Comparação entre o uso de estratégias e os estilos visual-verbal...........89

Tabela 25. Comparação entre o uso de estratégias e os estilos ativo-reflexivo........89

Tabela 26. Síntese dos resultados que apresentaram diferenças estatisticamente significantes 


\section{SUMÁRIO}

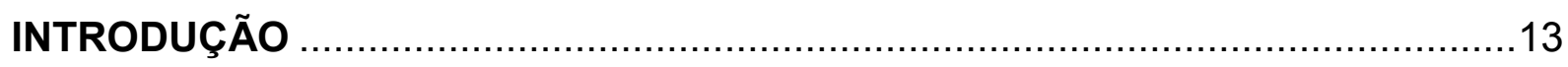

10 PROCESSO DE APRENDIZAGEM: ESTILOS E ESTRATÉGIAS …..............16

1.1 TEORIAS DA APRENDIZAGEM: A TRANSIÇÃO DO BEHAVIORISMO PARA O

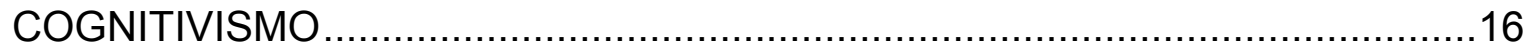

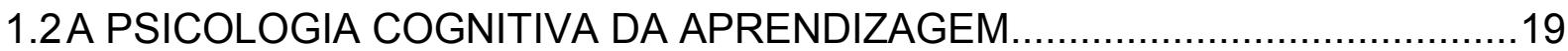

1.2.1 Aprendizagem por Processamento da Informação ........................................20

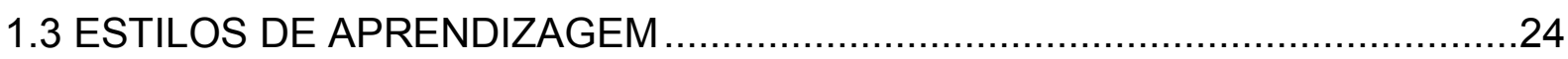

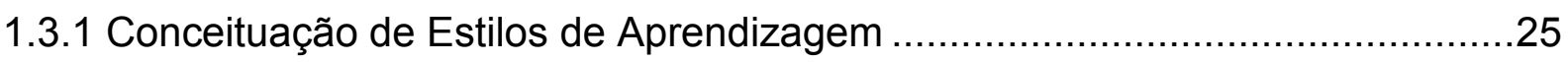

1.3.2 Modelos e Instrumentos de Avaliação dos Estilos de Aprendizagem...............28

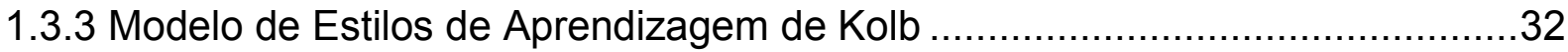

1.3.3.1 Inventário de Estilos de Aprendizagem (Learning Style Inventory - LSI) ......34

1.3.4 O Modelo de Estilos de Aprendizagem de Felder-Silverman ..........................36

1.3.4.1 Índice de Estilos de Aprendizagem de Felder-Soloman (ILS - Index of

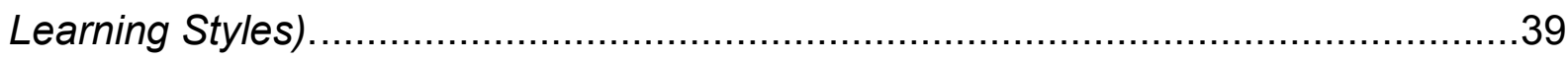

1.3.4.1.1 Evidências de Validade e Confiabilidade do ILS.....................................41

1.3.4.1.2 Pesquidas que utilizaram o ILS no Ensino Superior .................................45

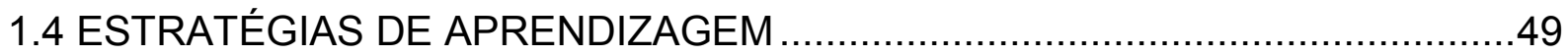

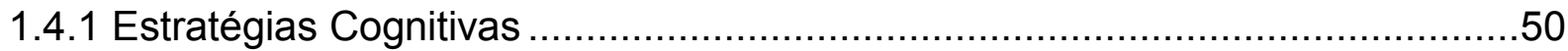

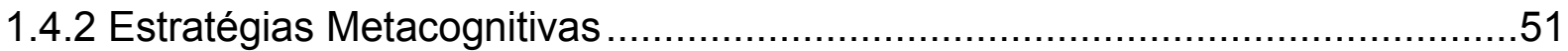

1.4.3 Pesquisas sobre Estratégias de Aprendizagem .........................................51

1.4.4 Instrumentos de Avaliação das Estratégias de Aprendizagem ........................57

1.4.4.1 Escala de Avaliação de Estratégias de Aprendizagem em Universitários

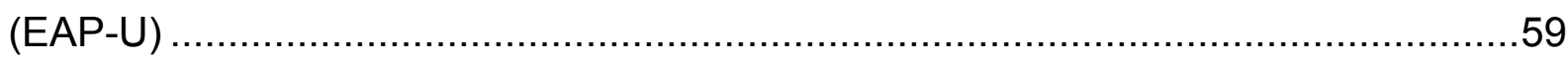

2. MÉTODO

2.1 JUSTIFICATIVA

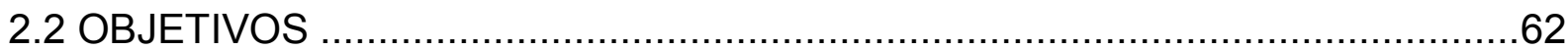

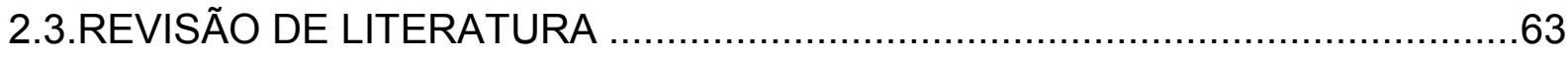

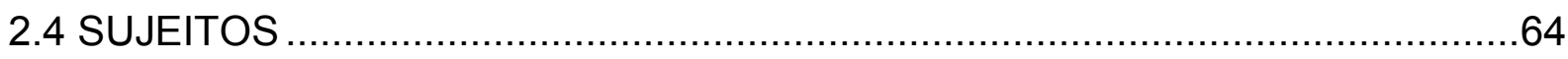

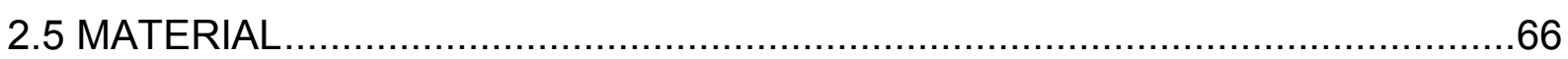

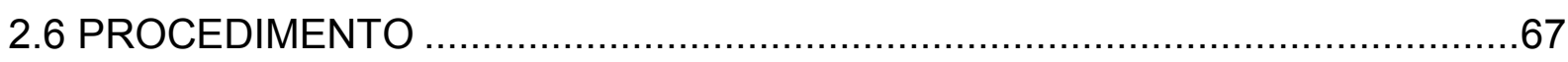

3. RESULTADOS 


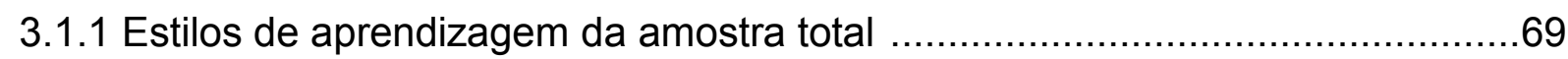

3.1.2 Estilos de aprendizagem de acordo com a área de conhecimento ..................70

3.1.3 Estilos de aprendizagem de acordo com o curso ..........................................74

3.1.4 Estilos de aprendizagem em função do gênero ..........................................78

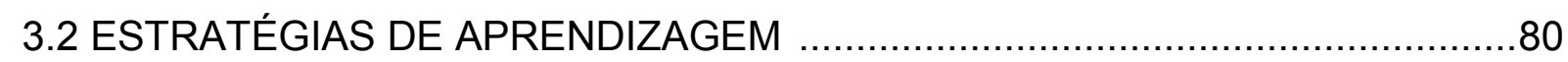

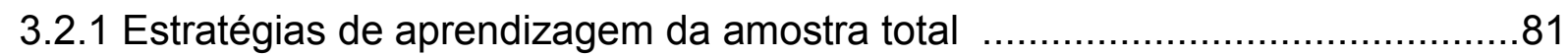

3.2.2 Estratégias de aprendizagem: comparações entre as áreas de

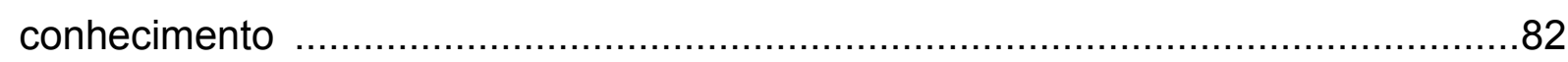

3.2.3 Estratégias de aprendizagem: médias e desvios padrão em função dos

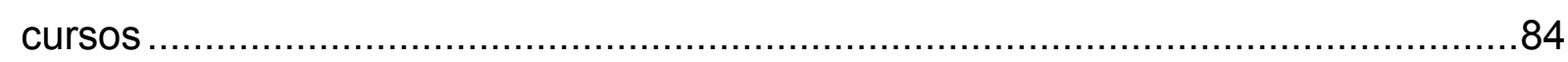

3.2.4 Estratégias de aprendizagem: comparações entre os gêneros ………….......87

3.3 INTERAÇÃO ENTRE ESTILOS E ESTRATÉGIAS DE APRENDIZAGEM...........88

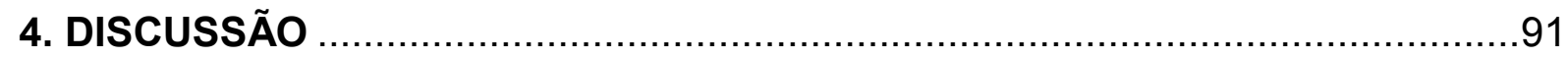

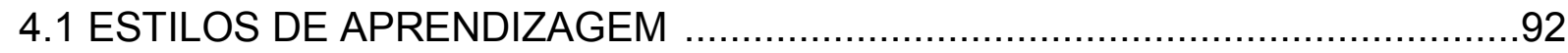

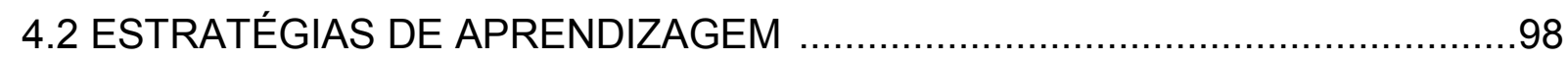

4.3 INTERAÇÃO ENTRE ESTILOS E ESTRATÉGIAS DE APRENDIZAGEM........101

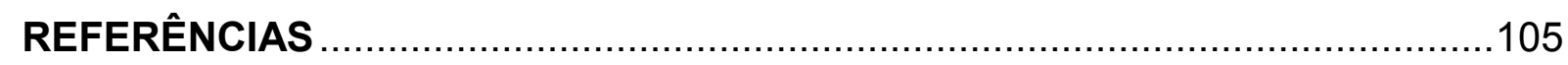

ANEXO A - Índice de estilos de aprendizagem .................................................118

ANEXO B - Escala de avaliação de estratégias de aprendizagem em

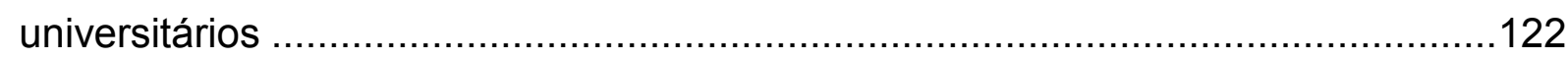

APÊNDICE A - Termo de consentimento livre e esclarecido.................................125 


\section{INTRODUÇÃO}

A sociedade atual está marcada por um novo imperativo: a informação. Novas tecnologias propiciam conservação eficaz e rápida difusão da informação. Pozo (2002, p.35) evidencia que "não é preciso buscar ativamente a informação, desejar aprender algo, para encontrá-la. É, antes, a informação que nos busca através da mediação imposta pelos canais de comunicação."

De acordo com Lazarte (2000), o que deveria ser considerado como um fator positivo tem gerado sérios problemas de memória, de relacionamento social e de saúde, como estresse, doenças cardíacas e depressão dentre outras. Segundo o autor, isto se deve ao descontrole e desequilíbrio com que a informação tem sido recebida e tratada pelos indivíduos contemporâneos.

O principal ambiente onde este descontrole e desequilíbrio podem ser percebidos é o educacional. Para Pozo (2002, p.16-17), a aprendizagem sempre foi uma tarefa difícil, mas a pós-modernidade tem evidenciado seus fracassos e a necessidade de superá-los. "Não é simplesmente que aprendemos pouco, nem que se ensine mal. É que os cenários de aprendizagem e instrução muitas vezes não foram pensados levando em conta as características dos aprendizes e seus mestres."

Pesquisas nacionais e internacionais têm apontado para a relação direta entre os padrões cognitivos de aprendizagem do aluno e suas características, preferências, metas e experiências como aprendiz. Outros estudos ratificam também a importância de que o ensino seja adaptado às características individuais de aprendizagem dos estudantes. Destacam que o processo de ensino-aprendizagem poderá ser ineficaz se houver desencontro entre a forma de ensinar do professor e a maneira preferencial do aluno aprender. (FELDER; SILVERMAN, 1988, 2002; COCCO, 2004; PEREIRA, 2005; BAKER et al., 2005; SILVA, 2006; SOUZA, 2006; FREITAS, 2007; TREVELIN, 2007; GRANITO, 2008; AGUADO; FALCHETTI, 2009;)

Bandura (2008) endossa este pensamento ao afirmar que todo indivíduo possui padrões pessoais, utilizados para realizar qualquer atividade a ele apresentada. A partir de suas intenções, os indivíduos elaboram planos e estratégias para atender suas demandas de 
uma maneira pessoal. Logo, é possível inferir que a aprendizagem, como uma atividade humana tão comum e necessária, é abordada de acordo com um padrão pessoal desenvolvido pelo próprio indivíduo, fruto de suas interações e experiências. Há, portanto, diferenças na forma de cada pessoa aprender. Compreendê-las pode ser o primeiro passo que as instituições de ensino, e mesmo o próprio aprendiz, devam dar rumo à aprendizagem eficaz.

Os teóricos dedicados ao estudo dos estilos de aprendizagem afirmam que estas distintas formas de aprender podem ser agrupadas de acordo com algumas características pessoais do indivíduo, com a forma pela qual ele interage com o ambiente de aprendizagem. Vários modelos têm sido apresentados nas últimas décadas com a intenção de identificar os diferentes estilos de aprendizagem. São exemplos os modelos apresentados por Kolb, DunnDunn, Honey-Alonso-Gallego e Felder-Silverman. (FELDER; SILVERMAN, 1988, 2002; BAKER; JENSEN; KOLB, 2005; ALONSO, 2008;)

Para Cerqueira (2000), que procurou sintetizar as diferentes definições encontradas, estilo de aprendizagem é a maneira pela qual as pessoas interagem com as condições de aprendizagem, abrangendo aspectos cognitivos, afetivos, físicos e ambientais que podem favorecer o processamento de informações. Os estilos de aprendizagem podem ser compreendidos como uma tendência de abordar as atividades e situações pertinentes ao processo de aprender. O modo com que o aluno percebe e capta as informações, assim como a forma escolhida para processar e reter este conhecimento indica seu estilo individual de aprender. Contudo, os estilos não são os únicos elementos referentes às diferenças individuais no processamento da informação. Os resultados recentes de pesquisas têm indicado também a importância e a eficácia do uso de estratégias frente ao aprendizado. (BORUCHOVITCH, 1995, 1999; RIBEIRO, 2003; TEIXEIRA, 2004; SANTOS, 2005; BRANDÃO, 2006; VIANA, 2006, FONSECA, 2006; FREITAS, 2007; LOPES, 2007; MANZINI, 2007; RABELLO, 2007; MAGALHÃES, 2008; SOSSAI, 2009).

Na perspectiva da Psicologia Social Cognitiva, baseada na Teoria do Processamento de Informação, estratégias de aprendizagem são as sequências de procedimentos ou atividades que os indivíduos empregam para adquirir, armazenar e utilizar a informação. (DEMBO, 1991; BORUCHOVITCH, 1999; POZO, 2002) Referem-se não somente ao comportamento, mas também aos pensamentos desenvolvidos pelo aprendiz durante seu 
processo de codificação, memorização e resgate das informações recebidas. (WEINSTEIN; MAYER, 1985)

Aceitando que o indivíduo possui diferentes estilos de abordar as situações de aprendizagem, e que, para realizar as demandas destas, são necessárias estratégias de aprendizagem, é possível perguntar se a cada estilo de aprendizagem, não corresponderia uma tendência a escolher preferencialmente certos tipos de estratégias? É esta, em resumo, a principal pergunta que este estudo exploratório procurará responder. 


\section{CAPÍTULO 1}

\section{O PROCESSO DE APRENDIZAGEM: ESTILOS E ESTRATÉGIAS}

\subsection{TEORIAS DA APRENDIZAGEM: A TRANSIÇÃO DO BEHAVIORISMO PARA O COGNITIVISMO}

Através dos tempos a aquisição do conhecimento sempre foi um tema bastante discutido e considerado. Provavelmente a primeira teoria elaborada sobre a aprendizagem seja a de Platão, em IV a.C...Na verdade, o filósofo ressalta a irrelevância da aprendizagem, pois para ele todo o indivíduo nasce com ideias inatas e são estas que constituem a sua racionalidade. O conhecimento humano é fruto destas ideias pré-existentes, bastando ao homem apenas recuperar o que sempre esteve em sua alma. Para Platão, a recuperação do conhecimento se dá através da dialética, um caminho de purificação da alma para ascender ao verdadeiro conhecimento. (PLATÃO, 1956; LOMÔNACO, 1997; POZO, 2002)

Opostas ao racionalismo platônico estão as ideias empiristas, propostas por Aristóteles e aprimoradas por Locke, Berkeley e Hume nos séculos XVII e XVIII. De acordo com Aristóteles, todo indivíduo é uma tabula rasa, uma folha em branco, na qual as experiências vividas vão marcando impressões que se associam de acordo com a sua aproximação, semelhança ou contraste, derivando-se destas formas de relacionamento as conhecidas leis de associação, que muito contribuíram no embasamento de futuras teorias da aprendizagem, em especial, o comportamentalismo. (LOMÔNACO, 1997; POZO, 2002)

O comportamentalismo, ou behaviorismo tal como conhecemos hoje, foi profundamente influenciado pelos estudos de Ivan Petrovich Pavlov (1849-1936) que, no início do século passado, desenvolveu vários experimentos comprovando que reflexos inatos aos seres humanos e animais podem ser associados a estímulos que naturalmente não os eliciam. Sua famosa experiência sobre o condicionamento clássico demonstrou que um cachorro é capaz de salivar (reflexo inato) mesmo quando o alimento não está à vista, 
bastando ouvir o som da campainha que costumeiramente precedia o alimento. Ou seja, o animal passou a dar uma resposta condicionada a um estímulo diferente do natural (alimento), pois aprendeu a antecipá-lo. Por isso o condicionamento clássico é também denominado de aprendizagem por substituição de estímulo.

O trabalho de Pavlov influenciou o pensamento de Jonh B. Watson (1878-1958) que, em 1913, posicionou-se como um behaviorista, dando nome à ciência que se dedicaria ao estudo do comportamento humano. Compreendia que todo ser humano nascia com reflexos inatos, físicos e emocionais. Do espirro ao amor, qualquer tipo de reflexo poderia ser condicionado a um estímulo que estivesse frequentemente presente no momento de uma resposta reflexa. Para Watson não havia diferenças individuais, a aprendizagem deveria ser considerada como uma resposta gerada por estímulos. As diferenças existentes nos indivíduos eram originadas exclusivamente pelas experiências e oportunidades vivenciadas ao longo da vida. Por razões metodológicas, consciência ou introspecção não eram consideradas na explicação do comportamento. Toda aprendizagem teria a ver somente com a formação de hábitos, que Watson entendia como sendo o condicionamento de sequências de estímulo-resposta. (SCHULTZ; SCHULTZ, 2007; LEFRANÇOIS, 2008)

Seguidor das ideias de Watson, Burrhus F. Skinner (1904-1990), que veio a se tornar o mais conhecido dos behavioristas, procurou distinguir claramente suas premissas daquelas esposadas por outros pensadores que consideravam a influência de eventos interiores e subjetivos sobre o comportamento. Para ele, o behaviorismo radical se pautava na objetividade dos fenômenos observáveis. A autonomia humana não existe, e todo comportamento pode ser controlado por reforçamentos e punições produzidas pelo ambiente. (SKINNER, 2002; LEFRANÇOIS, 2008; SCHULTZ; SCHULTZ, 2007)

Apesar da firme posição behaviorista de não considerar os eventos subjetivos ou fisiológicos, os estudos de pensadores neobehavioristas, como Thorndike (1874-1949) e Tolman (1886-1959), terminaram por disseminar críticas ao comportamentalismo e contribuir para o surgimento do cognitivismo. Estes pensadores encararam a aprendizagem como um fenômeno mais complexo do que somente uma associação entre estímulo e resposta ou reforçamentos e punições. Edward L. Thorndike admitiu a motivação como um fator interferente na aprendizagem, no que chamou de lei do efeito. Para ele toda ação causa um efeito satisfatório ou desagradável no indivíduo; consequentemente, aquelas que 
levam a um estado satisfatório tendem a ser repetidas e reforçadas, ao contrário daquelas que provocam resultados aversivos. Passou também a compreender a aprendizagem como uma formação de conexões fisiológicas entre estímulos e respostas. Em face dos resultados dos seus estudos, Thorndike veio a considerar a importância das ideias e do pensamento para a aprendizagem. Denominou de "aprendizagem ideacional" um tipo de aprendizagem superior que requeria análise, abstração e significação. Chegou a afirmar que a tarefa mais importante da escola era promover a habilidade de raciocinar. (SANTROCK, 2004; SCHULTZ; SCHULTZ, 2007; LEFRANÇOIS, 2008)

Edward C. Tolman rejeitou a lei do efeito de Thorndike. Para ele a recompensa ou o reforço em nada interferiam na aprendizagem. Acreditava, porém, que haviam cinco variáveis intervenientes que determinavam o comportamento humano: o estímulo ambiental, os impulsos fisiológicos, a hereditariedade, o treinamento prévio e a idade. Seus estudos admitiam que processos internos do organismo interferiam na resposta comportamental. Neste sentido Tolman é considerado um dos precursores da psicologia cognitiva. (SCHULTZ; SCHULTZ, 2007; LEFRANÇOIS, 2008)

A importância dos processos mentais, da estrutura física e biológica, assim como da percepção também passou a ser enfatizada por meio dos estudos realizados por psicólogos evolucionistas e gestaltistas. Merecem destaque os trabalhos de Donald Hebb (1904-1985), realizados nas décadas de 30 e 40, que vieram dar embasamento ao que viria a se constituir como psicologia cognitiva. A transição do behaviorismo para o cognitivismo, todavia não implicou na extinção desta primeira vertente teórica, que muito contribuiu para a construção da teoria cognitiva e ainda é amplamente utilizada nos contextos psicológicos e educacionais. Na verdade, as ideias rejeitadas do behaviorismo não foram as que se relacionavam com o associacionismo, mas as que postulavam atenção exclusiva aos fatores observáveis do comportamento. Daí uma das principais características da psicologia cognitiva: o interesse também pelo que não é passível de observação direta, tais como: o pensamento, a linguagem, a memória, o processo de tomada de decisão, a formação de conceitos, o processamento da informação etc., sem desconsiderar ou menosprezar a importância dos fatores ambientais. (POZO, 2002; LEFRANÇOIS, 2008; STERNBERG, 2008) 


\subsection{A PSICOLOGIA COGNITIVA DA APRENDIZAGEM}

De acordo com Casteñon (2007) a consciência é um dos aspectos que melhor diferencia o behaviorismo e o cognitivismo. Para o primeiro trata-se de um fenômeno imensurável e irrelevante ao comportamento humano. Na concepção cognitivista, é a consciência quem dirige e controla a maioria das ações do indivíduo. Outro importante conceito da psicologia cognitiva é a visão do homem como um processador de informação. Para representar suas concepções sobre como a aprendizagem acontecia na mente do aprendiz os psicólogos cognitivos recorreram à metáfora do computador. Resguardada a artificialidade da comparação, assim como o computador a mente humana recebe, manipula, armazena e recupera dados. (MAYER, 1985; PENNA, 1984; GARDNER, 2003; CASTEÑON, 2007)

O surgimento do computador e a Teoria da Informação, influenciaram a Psicologia Cognitiva no sentido de compreender a aprendizagem como um processo por meio do qual o indivíduo percebe, seleciona, manipula, significa e armazena as informações disponibilizadas pelo ambiente. Este processo se torna possível por meio de atividades mentais e motoras planejadas e empreendidas pelo próprio sujeito. $\mathrm{O}$ modelo computacional input-programa-output passou a ser largamente adotado para explicar o processo de aprendizagem, ou seja, de transformação da informação que entra no organismo naquela que sai em forma de resposta. (CASTEÑON, 2007) 


\subsubsection{Aprendizagem por Processamento da Informação}

A aprendizagem por processamento da informação é caracterizada basicamente por três elementos: entrada (input), processamento de informações e saída (output) sob a forma de respostas. A informação é compreendida como qualquer estímulo recebido do ambiente (som, imagem, texto etc.). Nessa teoria a memória é composta sequencialmente de três tipos: sensorial, de trabalho (ou de curto prazo) e de longo prazo. (GAGNÉ, 1985; MAYER, 1985; DEMBO, 1991; BZUNECK, 2004; STERNBERG, 2008)

Este trabalho utilizará o modelo formulado por Mayer $(1985$, p.43), representado na Figura 1, para ilustrar o processamento da informação humana.

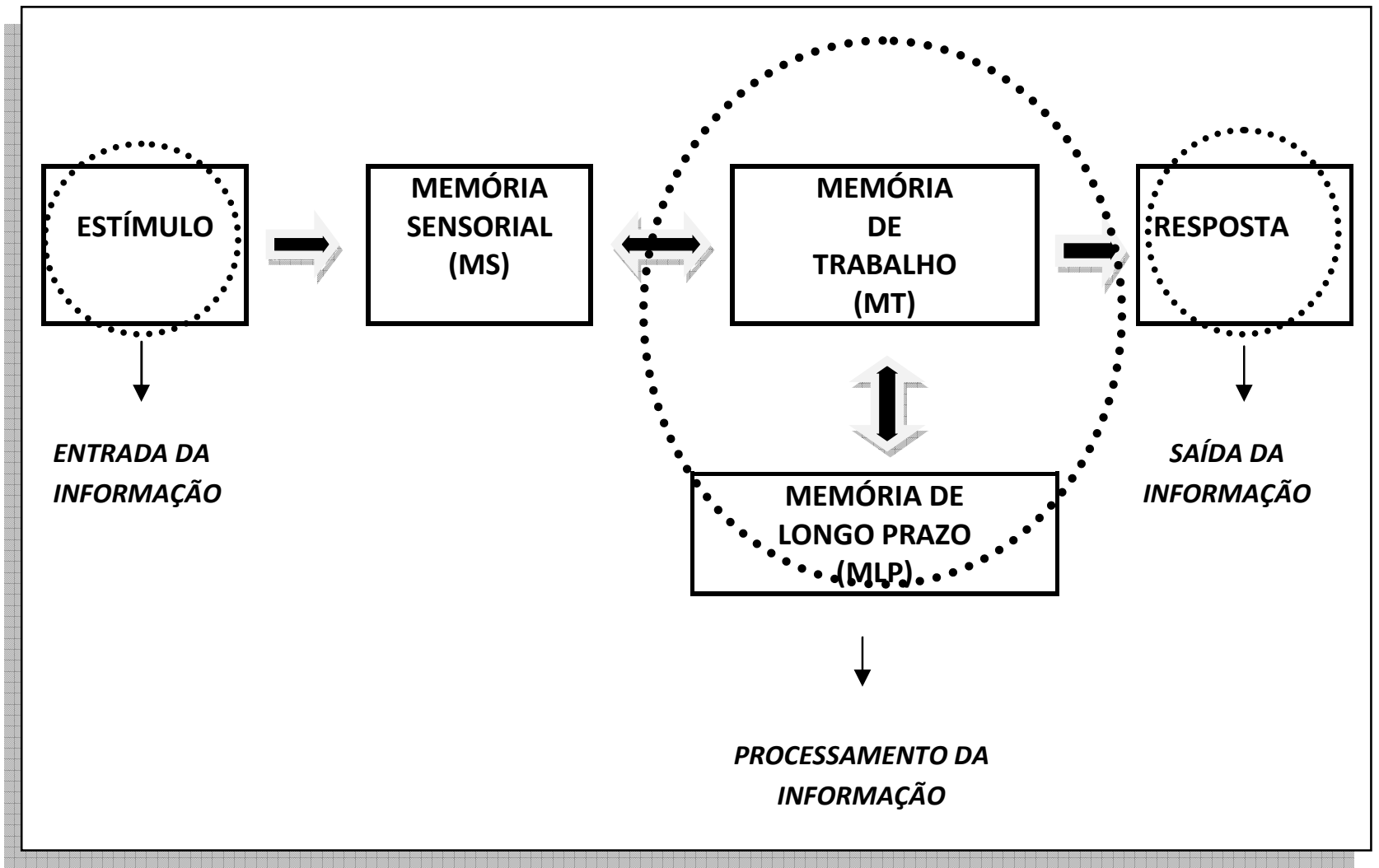

Figura 1. Modelo de Processamento da Informação Humana (Traduzido e adaptado de Mayer, 1985)

A informação proveniente do exterior é captada pelos sentidos humanos e armazenada na memória sensorial (MS). O período de armazenamento é extremamente 
curto, no máximo 250 milésimos de segundo. Nesse estágio a informação pode ser transferida para a próxima fase ou apagada. Se outra informação se sobrepõe, antes que haja tempo para a transferência, a primeira informação será esquecida. (BZUNECK, 2004; STERNBERG, 2008)

Dembo (1991) destaca que, em nenhum outro estágio, a atenção é tão necessária quanto na memória sensorial, pois a informação só será transferida para a memória de trabalho se o aprendiz prestar atenção ao estímulo sensorial armazenado na MS. Por isso, nem todos os estímulos recebidos passam para a próxima fase: a memória de trabalho.

A memória de trabalho (MT), também chamada de memória de curto prazo, possui uma capacidade limitada de armazenamento, variando entre 5 e 9 unidades. Uma informação contendo uma sequência de letras ou números de 5 itens com significado será lembrada e poderá ser repetida com facilidade. Entretanto, uma sequência com um número superior a 9 unidades provavelmente não poderá ser repetida. É muito difícil lembrar a seguinte sequência de 21 números: 101001000100001000100 , mas se esta for separada em 6 unidades, que evoquem algum significado, como por exemplo: 10, 100, 1000, 10000, 1000 e 100, sua reprodução será facilitada. (MILLER ${ }^{1}, 1956$ apud STERNBERG, 2008)

A informação processada na memória de trabalho é transferida para a memória de longo prazo (MLP). Mas, para que seja consolidada na MLP, a informação "deve ser classificada, organizada, conectada e armazenada com outras informações que já estão na MLP." (DEMBO, 1991, p. 270) Isso implica em diversas ações mentais, empreendidas estrategicamente pelo aprendiz para que a nova informação consiga ser estabelecida de forma mais duradoura. Mayer (1985) chama de codificação o processo de transferência de informação da memória de curto prazo para a memória de longo prazo. Gagné (1985) amplia esta definição ao dizer que a codificação acontece quando a nova informação é integrada de várias maneiras a outras informações já conhecidas.

De acordo com Dembo (1991) há um último aspecto a ser considerado no processamento da informação: os processos executivos de controle. Tratam-se de ações responsáveis por avaliar, controlar e dirigir todos os elementos cognitivos envolvidos no ato de aprender. Os processos executivos de controle determinam quais estratégias serão

\footnotetext{
${ }^{1}$ MILLER, G. A. The magical number seven, plus or minus two: some limits on our capacity for processing information. Psychology Review, no. 63, p.81-97, 1956.
} 
usadas para se alcançar o êxito na aprendizagem. E também avaliam se as estratégias empregadas foram eficazes ou não, definindo sua manutenção ou alteração. Os processos de controle operam na memória de curta e de longa duração, são eles que garantem a atenção, manipulação e organização da informação. Parte destas ações é automática e parte é controlada conscientemente pelo aprendiz. Esta parte consciente implica em metacognição e controla todo o armazenamento e recuperação da informação na memória de longa duração. A Figura 2 representa esses processos.

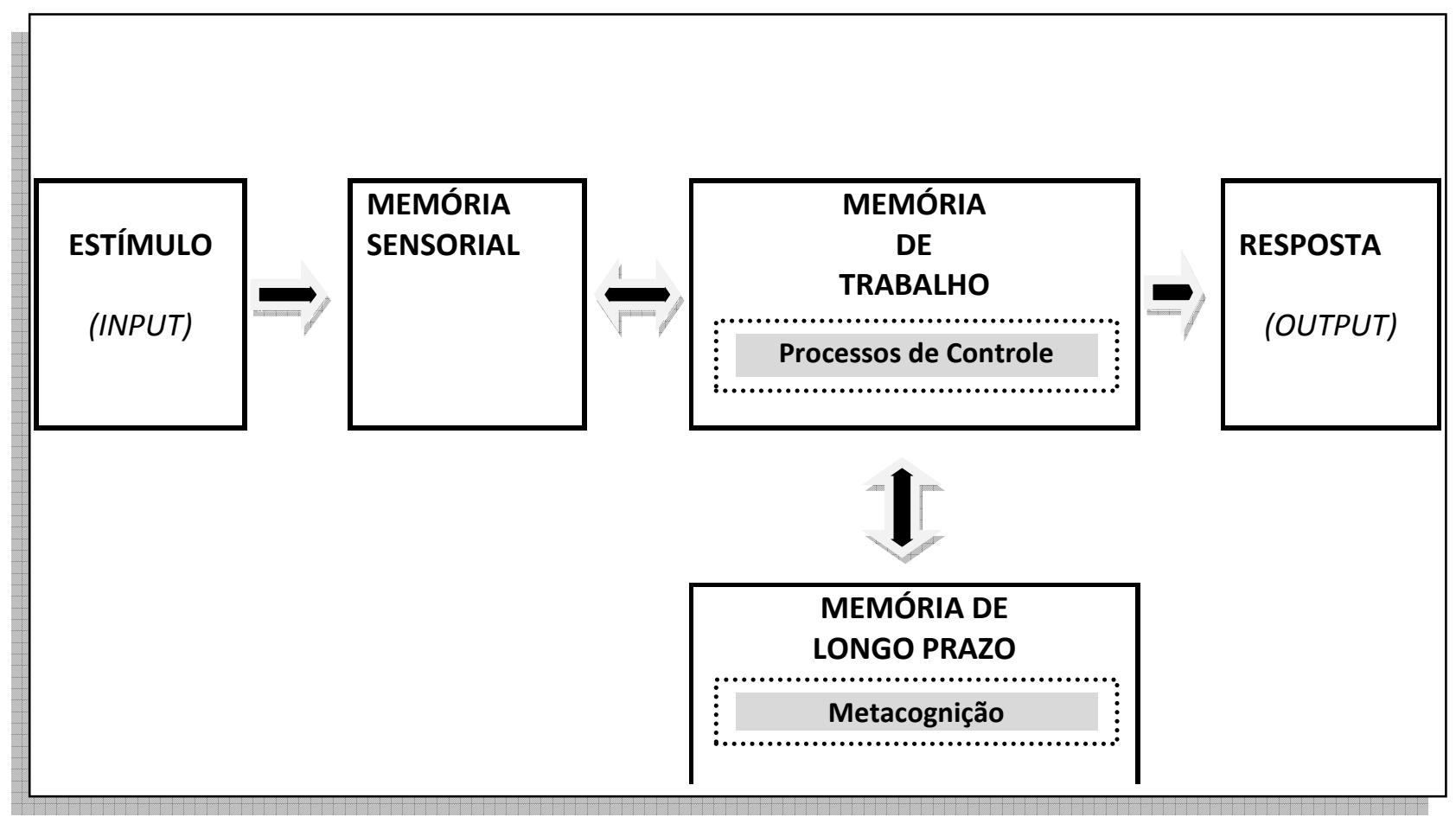

Figura 2. Modelo de Processamento da Informação Humana incluindo os Processos Executivos de Controle e a Metacognição (Adaptação de Dembo, 1991 ao modelo de Mayer, 1985)

De acordo com Flavell ${ }^{2}$ (1976), autor do termo citado por Dembo (1991), a metacognição refere-se à consciência que o aprendiz tem de seus próprios processos cognitivos e de tudo o que se refere a eles. É o conhecimento sobre o próprio conhecimento. Trata-se, também, de uma autorregulação ativa do processo de aprender. Dembo (1991, p.272) sintetiza a visão de outros autores destacando três aspectos essenciais da metacognição: 1) "a habilidade de reconhecimento das próprias limitações cognitivas ou do nível de dificuldade da tarefa exigida"; 2) "a regulação e o controle do próprio

\footnotetext{
${ }^{2}$ FLAVELL, J.H. Metacognitive aspects of problem solving. In: RESNICK, L. (ed.) The nature of intelligence. Hillsdale, NJ: Erlbaum, 1976.
} 
comportamento cognitivo" e 3) "a administração do próprio pensamento durante a situação de aprendizagem". Tudo isso com o objetivo de criar estratégias adequadas para a tarefa, monitorar o próprio progresso e avaliar o resultado obtido.

As estratégias de aprendizagem constituem elementos imprescindíveis ao processamento da informação. São elas as ferramentas utilizadas pelo aprendiz para lidar com as informações visando a melhor forma de armazená-las e recuperá-las quando necessário. Vários pesquisadores têm apontado a relevância das estratégias de aprendizagem e a necessidade do papel ativo do aprendiz em sua seleção e aplicação. (GAGNÉ, 1985; MAYER, 1985; DEMBO, 1991; MADRUGA; LACASA, 1995; BORUCHOVITCH, 1999, 2007; POZO, 2002; POZO; MONEREO, 2003; MONEREO; CASTELLÓ, 2004; MONEREO, 2007; PERRAUDEAU, 2009).

Para Monereo (2007) o grau de autonomia do aprendiz pode ser mensurado de acordo com o domínio que possui do uso de estratégias. O autor também declara que essas ações exigem uma tomada de consciência por parte do indivíduo, pois devem ser adaptadas por este ao seu próprio contexto de aprendizagem, fazendo de sua aprendizagem algo personalizado e único. Este pensamento confirma o que foi ressaltado por Mayer (1985) de que as pessoas não possuem a mesma forma de processar a informação. Existem diferenças individuais no aprender.

Esta forma individualizada de interagir com as condições da aprendizagem têm sido denominada por diversos autores como estilo de aprendizagem (SCHMECK, 1988; DEBELLO, 1990; FELDER; SILVERMAN, 1988; CERQUEIRA, 2000; RINCÓN; CUÉ; GALLEGO, 2008; PUPO; TORRES, 2009). De acordo com Galego e Garcia (2008) o aprendiz escolhe as estratégias de aprendizagem em conformidade com o seu estilo individual para aprender. $O$ estilo é mais estável que a estratégia, pois esta última pode ser alterada para adequar o material de aprendizagem ao estilo do aprendiz. Nesta compreensão, a estratégia não atende apenas às demandas da tarefa, mas também às características do indivíduo que a realiza. Uma mesma tarefa pode ser realizada com sucesso por meio de estratégias de aprendizagem diferentes, pois foram escolhidas por aprendizes de estilos diferentes.

Considerando que o presente trabalho tem como principal objetivo analisar a relação existente entre estas duas variáveis - estilos e estratégias de aprendizagem - os próximos tópicos serão dedicados a um estudo mais detalhado sobre os dois temas. 


\subsection{ESTILOS DE APRENDIZAGEM}

São várias as teorias que se propõem a explicar os estilos de aprendizagem. Grande parte delas apresenta conceitos e modelos com significativas diferenças entre si. Isto torna difícil um consenso sobre o que realmente vem a ser estilo de aprendizagem. Há, no entanto, uma premissa comum a todos os autores: existem diferenças individuais ante a aprendizagem. Cada indivíduo reage de maneira particular diante da tarefa exigida.

De acordo com Riding e Cheema (1991), estilo cognitivo foi o primeiro termo utilizado para denominar as diferenças individuais na aprendizagem, por volta da década de 30 do século passado. Já nos anos sessenta, segundo Martinez (2007) ${ }^{3}$, citado por Pupo e Torres (2009), em paralelo com as pesquisas sobre estilos cognitivos, foram realizados trabalhos voltados especificamente à aprendizagem no contexto educacional e estes cunharam um novo termo: estilo de aprendizagem. Como a noção de estilo cognitivo não estava bem especificada, o novo constructo contemplou melhor as características das descobertas no âmbito educativo. Mesmo assim, ainda hoje, o dois termos aparecem ora como sinônimos, ora com denominações distintas entre si. Após uma extensa pesquisa sobre os estudos desta temática, Gallego e Garcia (2008) conseguiram identificar duas tendências que distinguem as investigações sobre estilos: 1) os autores que se concentram nos aspectos cognitivos da aprendizagem usam o termo estilo cognitivo; 2) aqueles que enfocam o processo de aprendizagem usam estilos de aprendizagem. Contudo, os autores deixam claro que esta distinção representa uma tendência, pois há pesquisas, assim como a presente, que compreendem ambos os termos como sinônimos.

\subsubsection{Conceituação de Estilos de Aprendizagem}

\footnotetext{
${ }^{3}$ MARTINEZ, G.P. Aprender y eseñar: los estilos de aprendizaje y de enseñaza desde la práctica del aula. Bilbao: Mensajero, 2007.
} 
Existe certa dificuldade em se definir o constructo estilo de aprendizagem. Várias investigações do tipo estado da arte buscaram organizar os principais conceitos e modelos existentes sobre estilos de aprendizagem. Com base em alguns destes estudos (DEBELLO, 1990; CASSIDY, 2004; PUPO, TORRES, 2009; CERQUEIRA, 2000, 2008) serão apresentados conceitos dos vários autores, com destaque para os mais reconhecidos atualmente: Kolb, Dunn e Dunn, Schmeck, Felder e Silverman, Alonso Garcia, Keefe e Jenkins.

Kolb iniciou seus estudos em 1971, tendo como sujeitos de pesquisa estudantes universitários. Segundo este autor, fatores hereditários, experiências passadas e demandas do ambiente fazem com que as pessoas dêem preferência a certos estilos em detrimento de outros. Esta é a base de sua Teoria de Aprendizagem Experiencial. (DEBELLO, 1990; CERQUEIRA, 2000, 2008; KOLB; BOYATZIS; MAINEMELIS, 2000)

Cerqueira (2008, p. 110), cita a definição de estilo de aprendizagem dada por Kolb ${ }^{4}$ (1984): um estado duradouro e estável que deriva de configurações consistentes das transações entre o indivíduo e o seu meio ambiente.

Kolb e Kolb (2005, p.194) afirmam que "o conceito de estilo de aprendizagem descreve as diferenças individuais na aprendizagem com base na preferência de gerenciamento do aluno para trabalhar nas diferentes fases do ciclo da aprendizagem".

Rita e Keneth Dunn tornaram-se reconhecidos por se dedicarem à pesquisa sobre os estilos de aprendizagem nos níveis de ensino fundamental e médio. Para eles há variáveis que interferem na forma pela qual os estudantes aprendem. Estas variáveis podem ser classificadas em ambientais, emocionais, sociológicas, fisiológicas e psicológicas. (DEBELLO, 1990; DUNN, R.; DEBELLO, 1999; AVILES, 2008 )

Dunn, Dunn e Price ${ }^{5}$, citado por Cerqueira (2000, p. 41), definiram estilo de aprendizagem como "a maneira pela qual dezoito elementos diferentes, procedentes de quatro estímulos básicos (ambiental, emocional, sociológico e físico), afetam a habilidade de uma pessoa para absorver e reter informação". Posteriormente, segundo Aviles (2008), eles aumentaram para 24 o número de elementos interferentes na aprendizagem.

\footnotetext{
${ }^{4}$ KOLB, D.A. Experimental learning: experience as the source of learning and development. New Jersey: Prentice-Hall

${ }^{5}$ DUNN, R.; DUNN, K.; PRICE, G. Learning Style Inventory (LSI) for students in grades 3-12. Lawrence, Kansas: Price Systems, 1979.
} 
Já de acordo com Schmeck $(1982)^{6}$, também citado por Cerqueira $(2000$, p.36), estilo de aprendizagem é "uma predisposição do aluno em adotar uma estratégia particular de aprendizagem, independentemente das exigências específicas das tarefas."

Entwistle (1988) prefere usar o termo orientação, ao invés de estilo de aprendizagem, para se referir à maneira regularmente utilizada pelo estudante para lidar com as situações de aprendizagem. Essa orientação resulta das percepções do aprendiz, mediadas por sua motivação, e controla os métodos, técnicas e atitudes frente à tarefa.

Já para Felder e Silverman, que iniciaram suas primeiras investigações entre os estudantes de engenharia, os estilos de aprendizagem referem-se à maneira preferencial que as pessoas escolhem receber e processar a informação. (FELDER; SILVERMAN, 1988)

Para Keefe e Jenkins (1997, p.30) estilo de aprendizagem é "um composto de características cognitivas, afetivas e fatores fisiológicos que serve como um indicador relativamente estável de como um aprendiz percebe, interage e responde ao seu ambiente de aprendizagem". (KEEFE; JENKINS, 1997, p.30)

Catalina Alonso Garcia, cujos estudos têm influenciado significativamente as pesquisas sobre estilos de aprendizagem em países como Espanha, Portugal, Brasil, Argentina, Chile e Peru, não elaborou uma definição própria para estilos de aprendizagem, mas em suas produções adotou a concepção de Keefe e Jenkins (1997) como sendo a mais elucidativa delas. (GARCIA, 2008; RINCÓN; CUÉ; GALLEGO, 2008; CUÉ; RINCÓN; GARCIA, 2009)

Berings et. al. (2005, p.378) definem estilo de aprendizagem como uma tendência para usar uma determinada combinação de atividades de aprendizagem que uma pessoa pode, e gosta, de realizar. De acordo com a demanda requerida, cada estilo de aprendiz realiza uma combinação de atividades, também denominadas como estratégias de aprendizagem.

Cada conceito de estilos de aprendizagem referese-a um modelo explicativo deste, no qual cada tipo de aprendiz é denominado e suas características frente ao ato de aprender são descritas. Cada modelo apresenta um instrumento de mensuração dos estilos que

\footnotetext{
${ }^{6}$ SCHMECK, R.R. Inventory of learning process. In: NASSP. Student learning styles and brain behavior. Reston, Virginia: National Association of Secundary School Principals, 1982.
} 
propõe. A diversidade de modelos gera dificuldades de chegar-se a um consenso neste campo de investigação. Coffield (2004) encontrou 71 modelos existentes atualmente para explicar os estilos de aprendizagem. Rincón et. al. (2009) ao investigar somente os instrumentos de mensuração mais utilizados, listou 38 deles em seu trabalho. 


\subsubsection{Modelos e Instrumentos de Avaliação dos Estilos de Aprendizagem}

Ao elaborarem seus modelos explicativos sobre estilos de aprendizagem, os autores salientam em suas teorias as variáveis constituintes destes estilos. Na tentativa de promover uma melhor compreensão e organização das variáveis explicitadas e mensuradas nos diversos modelos teóricos e seus instrumentos, Lynn Curry, em 1983, apresentou uma proposta de classificação em três níveis: estilo cognitivo da personalidade, estilo de processamento da informação e preferências instrucionais. Posteriormente, Curry (1991) inclui em sua proposta um quarto nível - preferência de interação social sugerido por Claxton e Murrell (1987).

Curry utiliza a metáfora das camadas da cebola para exemplificar sua classificação. Cada camada representa os elementos constituintes do estilo de aprendizagem. E a posição da camada indica o nível de interferência ou mutabilidade na formação dos estilos.

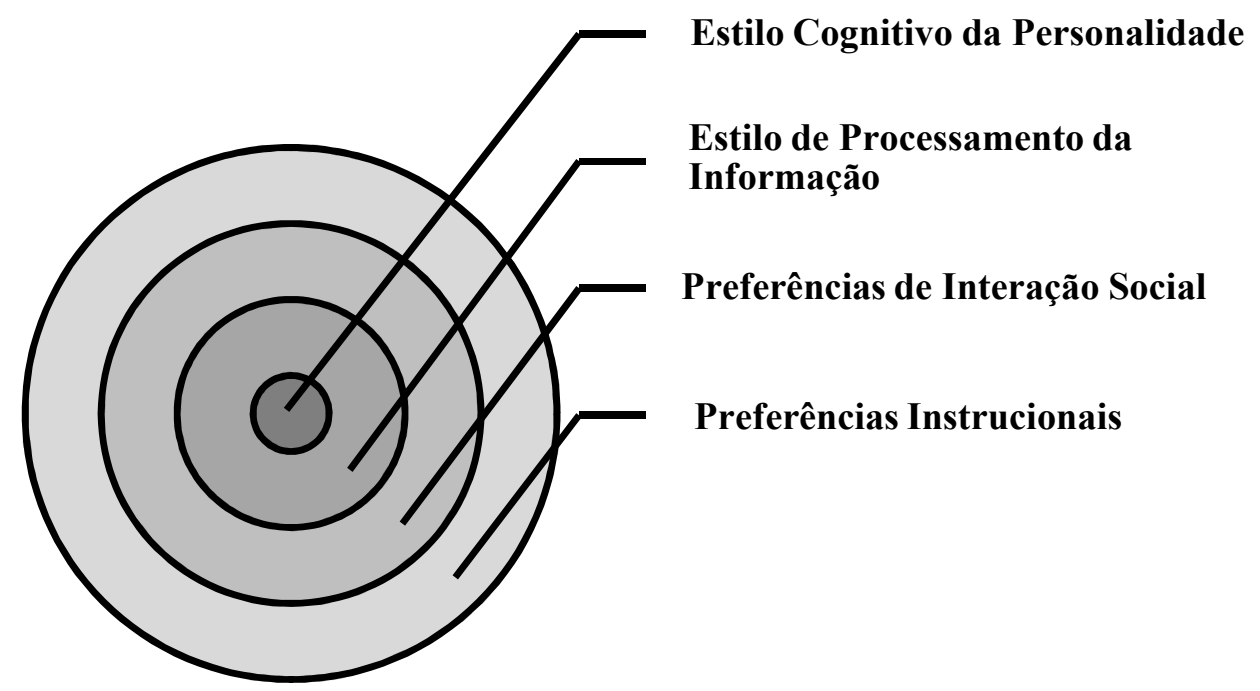

Figura 3. Esquema representativo da proposta de Curry (1991) sobre os componentes dos estilos de aprendizagem com a adição do nível sugerido por Claxton e Murrell (1987)

Na proposta de Curry (1991), a camada mais externa da cebola representa as preferências do aprendiz pelo modo de instrução recebido, ou seja, pela metodologia do professor. Este nível é mais susceptível a mudar do que o próximo, referente às predileções do aprendiz em sua interação social. Na terceira camada da cebola encontra-se a maneira 
preferencialmente escolhida para a aproximação e tratamento da informação. O estilo de processamento da informação é composto das estratégias de aprendizagem escolhidas pelo aprendiz. Este nível é menos mutável que os dois anteriores, mas pode ser modificado com mais facilidade que o último: o estilo cognitivo da personalidade que, segundo Lago et. al. (2008, p.4), é entendido como "a aproximação individual aos processos de adaptação e assimilação da informação, tratando-se de uma dimensão relativamente permanente da personalidade".

Em 1990, sob influência de suas próprias pesquisas e das de outros pesquisadores que destacaram a importância da motivação e da metacognição na aprendizagem, Curry apresentou um novo esquema teórico com a intenção de representar os elementos constituintes dos estilos e suas conseqüências na aprendizagem. Após intensa revisão dos estudos internacionais, publicados por 14 teóricos de estilos de aprendizagem (Biggs, Dunn, Entwistle, Friedman-Stritter, Grasha-Riechmann, Hunt, Kagan, Keefe, Kolb, Myers-Briggs, Rezler, Schmeck, Tamir, Witkin), Curry ressalta quatro elementos como sendo os principais na formação do estilo individual para aprender: preferências por condições do ambiente, preferências por condições sociais, nível de compromisso com a tarefa e as preferências no processamento cognitivo da informação. (CURRY, 1991)

A Figura 4 representa o modelo atual proposto por Cury (1991). 


$\uparrow$

Habilidade

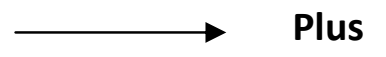

Conhecimento

Metacognitiva

Específico e Habilidades

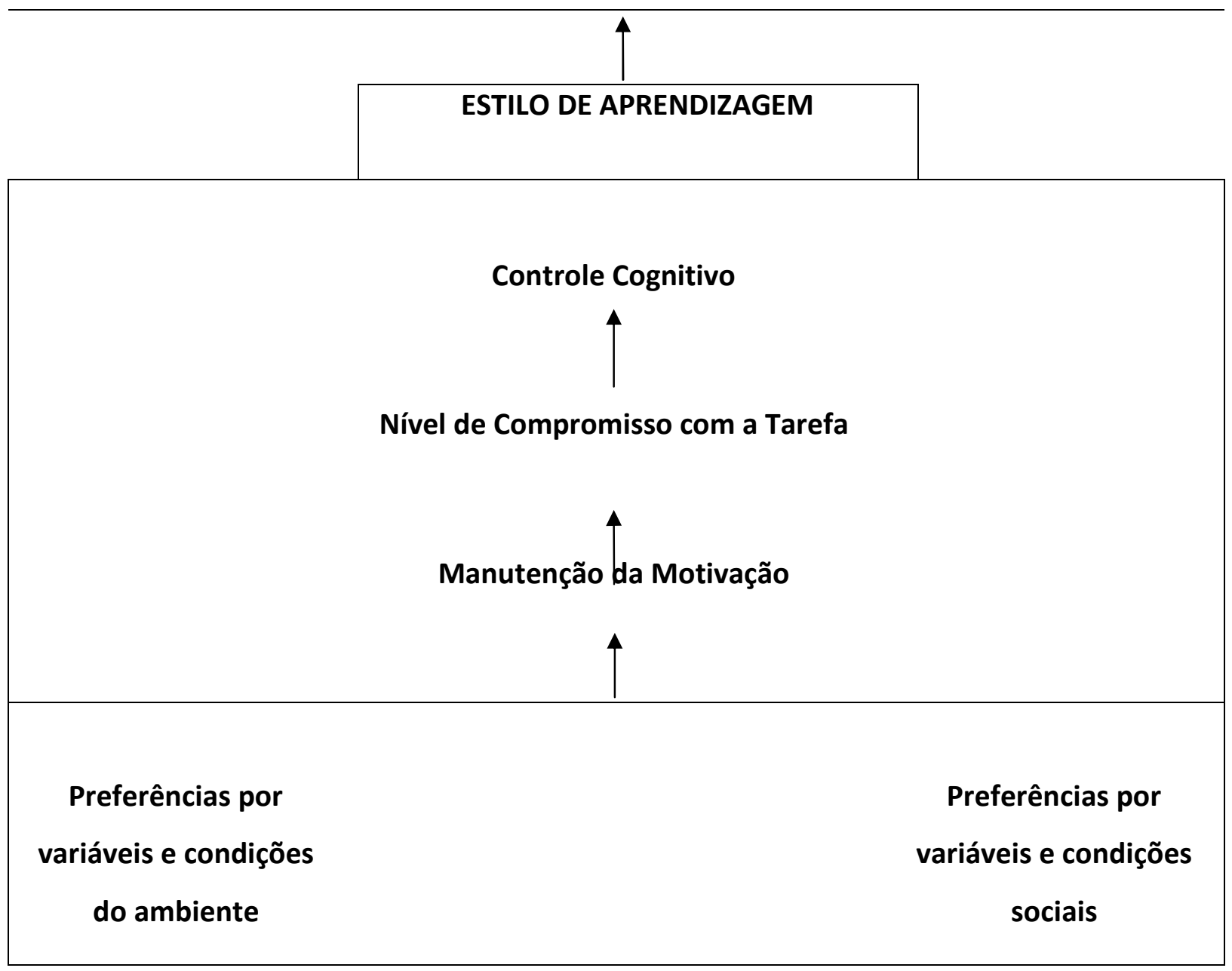

Figura 4. Modelo teórico dos componentes dos estilos de aprendizagem e seus efeitos (Curry, 1991)

A pesquisa sobre estilos de aprendizagem de estudantes universitários brasileiros tem aumentado na última década. As teses e dissertações encontradas têm correlacionado os estilos individuais de aprender a diferentes focos temáticos como as estratégias de ensino utilizadas pelos professores e o impacto no desempenho dos alunos (KURI, 2004; PEREIRA, 2005; ROSÁRIO, 2006; SANTOS, 2005; SILVA, 2006; SOUZA, 2006; TREVELIN, 2007; 
LINDEMAN, 2008; NAKASHIMA, 2008; PERNOMIAN, 2008; CATHOLICO, 2009; PIMENTEL, 2009), o ensino-aprendizagem de língua estrangeira (FUTER, 2007), a formação de equipes (FREITAS, 2007) e o contexto de trabalho (SALLES, 2007). Outras pesquisas dedicaram-se a compreender as relações existentes entre o estilo de aprendizagem do professor e as estratégias de ensino utilizadas por estes (MURAD, 2004; CURY, 2008). Vários outros pesquisadores se preocuparam em investigar os estilos de aprendizagem no ambiente didático-virtual da educação à distância (JACOBSOHN, 2003; COCCO, 2004; DINIZ, 2007; PEREIRA, 2007; SANTOS, 2007; AMARAL, 2008; FERRAZ, 2008; GRANITO, 2008; KALATZIS, 2008).

Quanto aos instrumentos de pesquisa adotados, apenas um dos trabalhos encontrados não fez uso de instrumento psicométrico (PEREIRA, 2005). Todos os outros utilizaram instrumentos para avaliar os estilos de aprendizagem. O modelo teórico mais adotado e, consequentemente, o instrumento mais utilizado foi o Índice de Estilos de Aprendizagem de Felder-Silverman (1988) e Felder-Soloman (1991) (LOPES, 2002; KURI, 2004; SANTOS, 2005; ROSÁRIO, 2006; SILVA, 2006; DINIZ, 2007; FREITAS, 2007; TREVELIN, 2007; GRANITO, 2008; KALATZIS, 2008; LINDEMAN, 2008; PERNOMIAN, 2008; CATHOLICO, 2009; PIMENTEL, 2009).

Dois outros instrumentos dividiram o segundo lugar na preferência dos pesquisadores: o Inventário de Estilos de Aprendizagem de Kolb (CERQUEIRA, 2000; SOUZA, 2006; CURY, 2008) e o Índice de Estilos de Aprendizagem de Keirsey - Bates (DINIZ, 2007; FREITAS, 2007; TREVELIN, 2007) foram usados cada um em três pesquisas. Outros seis instrumentos foram utilizados em um ou no máximo dois trabalhos. São eles: VICS-E-CSA-WA - Verbal - Imagery Cognitive Style - Extended Cognitive Style Analysis - Wholist/Analitic (SANTOS, 2007); CHAEA - Cuestionario Honey-Alonso de Estilos de Aprendizaje (SANTOS, 2005; NAKASHIMA, 2008); Inventário Brasileiro sobre Diferenças Individuais (JACOBSOHN, 2003); Questionário de Felder \& Silverman; MBTI - Myers-Briggs Type Inventory (MURAD, 2004); Estilos Cognitivos de Kathleen A. Butler e PLSPQ - Perceptual Learning-Style Preference Questionnaire (FUTER, 2007). As demais investigações se utilizaram de instrumentos construídos pelo próprio autor e sem histórico de evidências de validade (COCCO, 2004; PEREIRA, 2007; SALLES, 2007; AMARAL, 2008; FERRAZ, 2008), exceto o 
trabalho de Silva (2011) que elaborou e também apresentou evidências de validade de um novo instrumento: Escala de Estilos de Aprendizagem em Universitários.

Dentre os diversos modelos teóricos e instrumentos existentes que se propõem a explicar e mensurar a formação dos estilos de aprendizagem, serão descritos, a seguir, os propostos pelos pesquisadores Kolb e Felder-Silverman-Soloman. Os dois modelos foram escolhidos como referência para este trabalho por três razões: 1) adotam a mesma concepção dimensional para explicar a formação de estilos de aprendizagem: percepção e processamento da informação; 2) são os únicos a ter os seus instrumentos validados no Brasil e 3) ambos elaboraram seus modelos explicativos e aplicaram seus instrumentos de mensuração no mesmo público alvo da presente pesquisa: estudantes universitários. Contudo, dentre os dois teóricos, o modelo e o instrumento de Felder-Silverman-Soloman foram escolhidos para esta pesquisa por serem os de melhor aceitação e utilização no cenário acadêmico brasileiro.

\subsubsection{Modelo de Estilos de Aprendizagem de Kolb}

Em sua Teoria de Aprendizagem Experiencial, Kolb concebe a aprendizagem como um processo cíclico baseado na experiência. A experiência modifica o indivíduo e o orienta na escolha de novas experiências. Desenvolvemos uma melhor maneira de aprender ao escolher entre quatro possíveis modos de encarar a situação de aprendizagem. Nossos conflitos cognitivos podem ser resolvidos ao sermos concretos ou abstratos, ativos ou reflexivos. (KOLB et. al., 2000, 2005; CERQUEIRA, 2000; LOO, 2004)

Seu modelo teórico, infuenciado pela teoria dos tipos psicológicos de Jung ${ }^{7}$, propõe duas formas de perceber a informação: experiência concreta e observação reflexiva. E duas formas de processar a informação: conceituação abstrata e experimentação ativa. Para Kolb a aprendizagem passa pelas quatro etapas descritas na Figura 5. As experiências concretas, através do uso dos sentidos, são a base para as observações e reflexões. Por sua vez, o que

\footnotetext{
${ }^{7}$ Carl Gustav Jung distinguia as pessoas segundo quatro funções psicológicas básicas: pensamento, sentimento, sensação e intuição. Cada um desses tipos pode se mostrar tanto introvertido quanto extrovertido, dependendo da orientação preferencial e inconsciente do indivíduo.
} 
foi assimilado através da observação reflexiva transforma-se em conceitos abstratos, que implicarão em novas experimentações. (KOLB et. al., 2000)

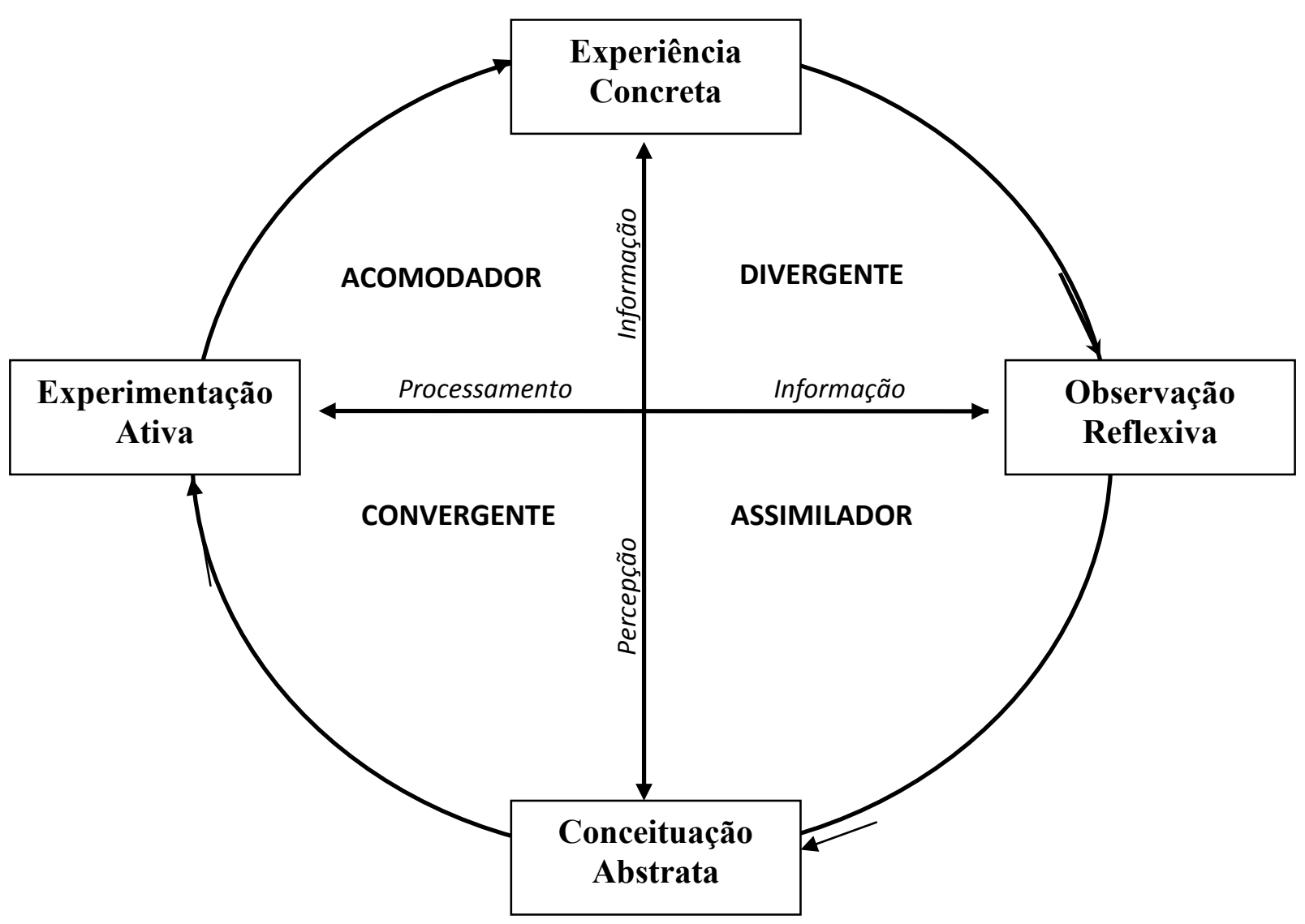

Figura 5. Modelo representativo da Teoria de Aprendizagem Experiencial de Kolb. Adaptado de Loo (2004) e Ferraz (2008)

De acordo com Kolb, a situação de aprendizagem gerará diferentes demandas que exigirão do aprendiz uma determinada maneira de tratar a informação. Caberá a este decidir qual aplicar e quando. As duas dimensões da aprendizagem (percepção e processamento), representadas no modelo de Aprendizagem Experiencial, geram quatro quadrantes que indicam os possíveis modos (estilos) de conduta perante a tarefa: acomodador, divergente, assimilador e convergente.

O aprendiz eficaz é aquele que se utiliza dos quatro estilos, gerenciando-os conforme a demanda da tarefa, visando o sucesso na aprendizagem, independente de sua maneira preferencial de aprender. Porém, este tipo de aprendiz é raro. As pessoas têm preferências 
na maneira de perceber e processar as experiências vividas. $E$ tendem a repeti-las indiferentes à natureza da tarefa. Para Kolb a essa forma padronizada de atender às demandas é tarefa denominada estilos de aprendizagem. (KOLB et. al., 2000, 2005; LOO, 2004)

Os quatro estilos de aprendizagem proposto por Kolb são compreendidos a partir da perspectiva bidimensional de seu modelo (percepção-processamento):

- Acomodador (EA-EC) - este estilo de aprendiz prefere perceber a informação de maneira concreta e processá-la de maneira ativa. Aprendem fazendo, aceitando desafios, imergem na realidade concreta e guiam sua aprendizagem mais pelos sentidos do que pela reflexão.

- Divergente (EC-OR) - a preferência deste tipo de aprendiz está na aprendizagem por meio da experiência concreta e da observação reflexiva. São chamados de divergentes, pois se destacam pela elaboração de novas ideias. Possuem muita criatividade e soluções inovadoras.

- Assimilador (OR-CA) - situado no quadrante inferior direito, os assimiladores baseiam sua aprendizagem na observação reflexiva e na conceitualização abstrata. Preferem pensar, refletir e planejar. Dificilmente deixamse guiar por seus sentidos, confiam nos modelos teóricos.

- Convergente (CA-EA) - o indivíduo convergente consegue por meio da conceituação abstrata e da experimentação ativa colocar as ideias teóricas em prática. (KOLB et. al., 2000; CERQUEIRA, 2000)

\subsubsection{O Inventário de Estilos de Aprendizagem (Learning Style Inventory - LSI)}

Em 1971, David Kolb elaborou um instrumento visando avaliar os estilos individuais de aprender. De acordo com as pesquisas do autor, o LSI foi capaz de identificar estatisticamente a existência dos quatro tipos de estilos: acomodador, divergente, assimilador e convergente. Entre os anos de 1985 e 1993, o instrumento sofreu uma série de revisões e a versão atual é composta por 12 séries de frases que devem ser completadas de 
acordo com a preferência do respondente, o qual deverá ordenar as respostas hierarquicamente. Para cada frase há quatro opções de respostas, cada uma delas refletindo a postura padrão de cada estilo. (KOLB et. al., 2000; CERQUEIRA, 2000)

\begin{tabular}{|c|c|c|c|c|}
\hline $\begin{array}{l}\text { 1. Enquanto } \\
\text { aprendo: }\end{array}$ & $\begin{array}{l}\text { Gosto de lidar com } \\
\text { meus } \\
\text { sentimentos. }\end{array}$ & $\begin{array}{l}\text { Gosto de pensar } \\
\text { sobre ideias. }\end{array}$ & $\begin{array}{l}\text { Gosto de estar } \\
\text { fazendo } \\
\text { coisas. }\end{array}$ & $\begin{array}{l}\text { Gosto de } \\
\text { observar e } \\
\text { escutar. }\end{array}$ \\
\hline
\end{tabular}

Figura 6. Questão no. 1 do Inventário de Estilos de Aprendizagem (Learning Style Inventory - LSI) (CERQUEIRA, 2000)

De acordo com Kolb et. al. (2000) o instrumento LSI foi utilizado em mais de 990 estudos até o ano de 1999. Quanto à avaliação de suas propriedades psicométricas, o LSI recebeu algumas críticas a sua validade de constructo (PANAYIOTA; PLATSIDOU, 2008; COFFIELD, 2004; GARNER, 2000). Outros estudos, porém, confirmaram a validade e confiabilidade do instrumento (RENNIE, 2004; COKER; PEDERSEN, 2004; KAYES, 2005).

No Brasil, o primeiro estudo das evidências de validade do instrumento foi realizado por Sobral (1992) com 474 alunos de medicina. Os resultados sugeriram que o LSI possui valor limitado para explicar a variabilidade da aprendizagem em contexto real.

Cerqueira $(2000,2008)$ realizou outro trabalho dedicado às evidências de validade do instrumento, com 2552 estudantes universitários de 40 cursos diferentes, abrangendo as cinco regiões brasileiras. Os resultados obtidos com esta amostra não permitiram uma clara identificação dos quatro fatores mensurados pelo LSI. A pesquisadora optou, então, pela validação de definição do instrumento através de uma análise lingüística dos itens. Para isso contou com a ajuda de 30 juízes formados em Psicologia e com experiência na área educacional. De acordo com os resultados da análise dos juízes, o LSI passou a contar com a validação de definição. 


\subsubsection{O Modelo de Estilos de Aprendizagem de Felder-Silverman}

Richard Felder e Linda Silverman publicaram seu primeiro trabalho sobre estilos de aprendizagem em 1988. Para eles a aprendizagem depende em parte da capacidade e preparação prévia do aluno, mas também da compatibilidade entre seu estilo de aprendizagem e o estilo de ensino do professor. (FELDER; SILVERMAN, 1988)

Influenciados pela teoria de aprendizagem experiencial de Kolb e pela teoria dos tipos psicológicos de Jung, elaboraram um modelo explicativo sobre os estilos de aprendizagem a partir da maneira pela qual os indivíduos se relacionam com a informação. Dessa forma, procuraram contribuir para a adequação dos estilos de ensino aos estilos de aprendizagem dos estudantes. (FELDER; SILVERMAN, 1988; LOPES, 2002; SENRA et. al, 2008)

Numa primeira proposta o modelo era constituído por cinco dimensões de estilos de aprendizagem. Cada uma das dimensões correspondia ao modo preferencial do aprendiz de perceber (sensorial/intuitivo); reter (visual/auditivo); organizar (indutivo/dedutivo); processar (ativo/reflexivo) e compreender a informação (sequencial/global). Após revisões, o modelo sofreu duas alterações: em 1993 a dimensão indutivo/dedutivo foi excluída e, em 1995, a dimensão visual/auditivo foi renomeada para visual/verbal. (FELDER; SILVERMAN, 1988, 2002; FELDER; HENRIQUES, 1995)
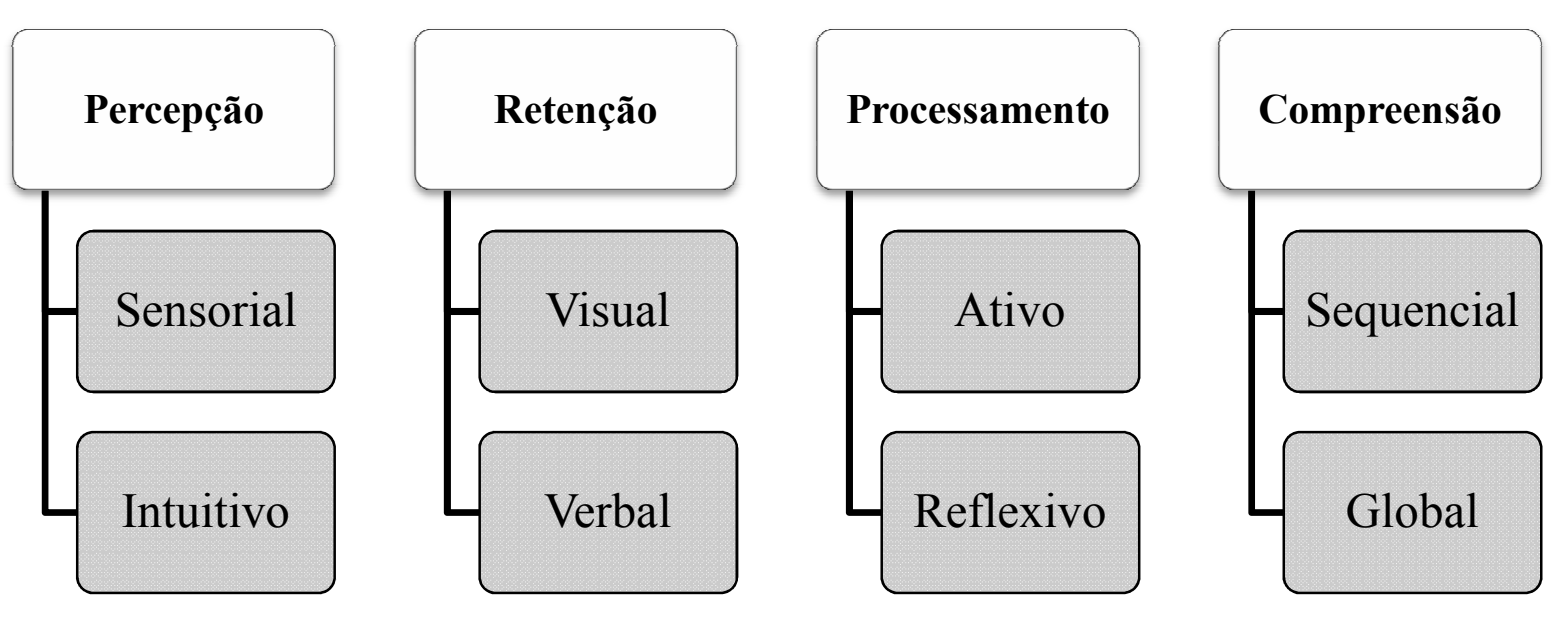

Figura 7. Esquema representativo do modelo de estilos de aprendizagem de FelderSilverman. Adaptado de Felder e Silverman (1988). 
Cada dimensão proposta no modelo é constituída por dois pólos contrários, que caracterizam as preferências do aprendiz (FELDER; SILVERMAN, 1988, 2002; FELDER; BRENT, 2005; GRANITO, 2008):

- Dimensão Sensorial/Intuitivo - esta dimensão corresponde à forma preferencialmente utilizada no momento de perceber a informação. Indica a maneira pela qual o indivíduo percebe o ambiente que o cerca.

Aprendizes Sensoriais: apreciam fatos e dados, tendem a ser concretos, práticos e metódicos na resolução de problemas. São pacientes com detalhes o que pode levá-los a apresentar um ritmo um pouco mais lento que os intuitivos.

Aprendizes Intuitivos: sentem-se mais confortáveis em aprender com símbolos, diagramas, modelos e teorias. A abstração é o seu ponto forte, mas a impaciência com os detalhes pode fazer com que tenham uma postura descuidada frente à tarefa. Gostam de inovações e são criativos na solução de problemas.

- Dimensão Visual/Verbal - indica quais canais sensoriais são mais utilizados na recepção da informação.

Aprendizes Visuais: as representações visuais (diagramas, imagens, gráficos, filmes, etc) causam maior impacto e assim facilitam a entrada da informação para este tipo de estudante.

Aprendizes Verbais: apresentam boa memória auditiva e possuem também facilidade no trato com a palavra, quer seja escrita ou falada, por isso gostam de utilizar anotações.

Apesar de não 38atisfató a modalidade cinestésica nesta dimensão, Felder e Silverman (1988) admitem sua existência. Porém, como se refere à preferência pelo movimento e experimentações (sabor, toque, cheiro etc) os autores optaram por relacioná-la à dimensão ativo/reflexivo.

- Dimensão Ativo/Reflexivo - corresponde à predileção do aluno ao processar a informação.

Aprendizes Ativos: demonstram preferência por uma maneira extrovertida de processamento. Gostam de estudar em grupo. Procuram situações dinâmicas 
capazes de proporcionar experimentações e evitam aquelas que exigem certa passividade do aprendiz, como palestras etc.

Aprendizes Reflexivos: elegem a reflexão como forma preferencial de processamento. Por isso, sentem-se mais confortáveis em trabalhos individuais. Aprendem melhor em situações que promovam tempo e espaço para a abstração e levantamento de alternativas e hipóteses. Tendem a ser teóricos.

- Dimensão Sequencial/Global - indica a forma de organização do pensamento usada pelo aprendiz no caminho para a compreensão.

Aprendizes Sequenciais: compreendem melhor através de uma sequência lógica de etapas. Conseguem trabalhar mesmo que tenham apenas um conhecimento fragmentado e superficial do todo. É a partir de pequenas peças que constrói a visão geral sobre o assunto a ser aprendido. Seu ponto forte é o pensamento convergente e analítico.

Aprendizes Globais: tratam a informação de maneira holística. Necessitam de uma visão geral do conteúdo para poder compreendê-lo, após isto conseguirá facilmente interrelacionar os fragmentos descontextualizados da informação. Possuem pensamento divergente e sintético.

Estudos posteriores, que utilizaram o modelo Felder-Silverman de estilos de aprendizagem, confirmaram os benefícios do conhecimento sobre estilos de aprendizagem para as práticas educacionais, principalmente no que se refere à melhoria dos métodos de ensino; à qualificação das ações do professor e ao aumento do desempenho do aluno. (KURI, 2004; BELHOT, 2005; PEREIRA, 2005; SILVA, 2006; LINDEMAN, 2008; CATHOLICO, 2009; NEEL E GRINDEM, 2010; HALBERT et. al., 2011)

Em 1991, Felder, juntamente com outra pesquisadora, Barbara Soloman, desenvolveu um instrumento com o propósito de mensurar quão próximo estava o aprendiz de cada pólo dimensional do seu modelo. Dessa forma, o resultado obtido através do Índice de Estilos de Aprendizagem (ILS - Index of Learning Styles) seria capaz de indicar as maneiras preferenciais do respondente em situação de aprendizagem, ou seja, o seu estilo próprio de aprender. Este instrumento, por ser o escolhido para a coleta de dados deste estudo, será descrito a seguir. 


\subsubsection{1 Índice de Estilos de Aprendizagem de Felder-Soloman (ILS - Index of Learning Styles)}

Trata-se de uma escala dicotômica contendo 44 afirmativas incompletas, cabendo ao respondente completá-las optando entre as duas alternativas apresentadas (a ou b). Cada questão visa identificar as preferências dos estudantes universitários quanto à sua aprendizagem. Estas preferências são demonstradas segundo a forma pela qual a informação é percebida e processada pelo estudante (FELDER; SOLOMAN, 2004).

O Índice de Estilos de Aprendizagem, citado a partir deste momento por sua abreviatura, ILS, avalia as características do aprendiz de acordo com o modelo de estilo de aprendizagem elaborado por Richard M. Felder e Linda K. Silverman. As combinações das quatro dimensões previstas no modelo: ativo-reflexivo, sensorial-intuitivo, visual-verbal e seqüencial-global caracterizam a maneira pela qual o estudante lida com as demandas de sua própria aprendizagem. Ou seja, constitui o seu estilo de aprendizagem. (FELDER; SILVERMAN, 1988, 2002; FELDER; HENRIQUES, 1995).

Cada dimensão do modelo de Felder-Silverman é avaliada no ILS por meio de 11 questões. A diferença entre os escores, referentes aos dois estilos que compõem cada dimensão, indica qual destes é preferido pelo estudante de forma leve (1 e 3), moderada (5 e 7) ou forte (9 e 11). Por exemplo, ao responder às questões destinadas à dimensão seqüencial-global, o sujeito obteve como resultado a seguinte pontuação: seqüencial 8 e global 3. A diferença entre os dois estilos é 5 , sendo marcada na escala de classificação do ILS no lado destinado ao estilo com maior pontuação. Isso indica que este estudante possui uma predileção moderada pelo estilo seqüencial. Ou seja, quanto à compreensão do conteúdo, sua aprendizagem é facilitada quando o conteúdo é exposto e estudado de forma linear, passo-a-passo, enfatizando primeiro os detalhes para construir o todo.

A Figura 8, a seguir, mostra a escala de classificação utilizada pelo instrumento e destaca o resultado mencionado no exemplo dado acima. 


\begin{tabular}{l|l|l|l|l|l|l|l|l|l|l|l|l|l}
\hline Estilo & 11 & 9 & 7 & 5 & 3 & 1 & 1 & 3 & 5 & 7 & 9 & 11 & Estilo \\
\hline
\end{tabular}

\begin{tabular}{lccccccccccccc}
\hline Sensorial & 11 & 9 & 7 & 5 & 3 & 1 & 1 & 3 & 5 & 7 & 9 & 11 & Intuitivo \\
\hline Visual & 11 & 9 & 7 & 5 & 3 & 1 & 1 & 3 & 5 & 7 & 9 & 11 & Verbal \\
\hline Ativo & 11 & 9 & 7 & 5 & 3 & 1 & 1 & 3 & 5 & 7 & 9 & 11 & Reflexivo \\
\hline Sequencial & 11 & 9 & 7 & 5 & 3 & 1 & 1 & 3 & 5 & 7 & 9 & 11 & Global \\
\hline
\end{tabular}

Figura 8. Escala de classificação do Índice de Estilos de Aprendizagem (ILS)

Atualmente o ILS é disponibilizado pelos autores, em sua página na internet: www.ncsu.edu/felder-public/ILSpage.html. Podem ter acesso gratuito ao índice os estudantes interessados em conhecer seu perfil de aprendizagem, os professores motivados a aperfeiçoar sua prática pedagógica e os pesquisadores, bastando a estes últimos concordar com o termo de utilização do ILS para que a licença de aplicação seja concedida. Somente as instituições sem fins educacionais devem pagar pelo uso do instrumento. (FELDER, 2001)

\subsection{Evidências de Validade e Confiabilidade do ILS}

Quanto às evidências de validade e confiabilidade, foram encontrados sete trabalhos internacionais e dois nacionais, exclusivamente dedicados à avaliação das propriedades psicométricas do ILS. Seis destes estudos o apontaram como um instrumento estatisticamente confiável e válido para identificar os estilos de aprendizagem. Contudo, como é comum a todo instrumento, foi sugerida a realização de novas pesquisas, com diferentes amostras.

Em 1994, centenas de questionários da versão inicial do índice, criado em 1991, foram submetidos a uma análise fatorial. Alguns itens, que não apresentaram carga fatorial 
significativa, foram descartados e novos itens foram acrescentados, compondo a atual versão do ILS. A partir daí, o instrumento foi traduzido para várias línguas e passou a ser utilizado em diversas pesquisas. (FELDER; SPURLIN, 2005).

Questionando a validade do ILS foram encontrados dois estudos internacionais. O primeiro, realizado por Van Zwanenberg et al. (2000), em duas universidades de Newcastle, Reino Unido, com 139 estudantes de engenharia e 145 estudantes de administração. Após a análise dos dados, os pesquisadores expressaram preocupação com a validade de conteúdo do instrumento e com a baixa confiabilidade interna de suas escalas. No segundo estudo desfavorável ao ILS, Viola et al. (2006) apontam problemas na capacidade do instrumento de avaliar as dimensões propostas no modelo de Felder-Silverman.

Por sua vez, indicando a validade e confiabilidade do ILS no exterior, foram localizados os estudos de Zwyno (2003), Felder e Spurlin (2005), Cook (2005), Cook e Smith (2006), Litzinger et all. (2007) e de Hosford e Siders (2010).

Zwyno (2003), no período de três anos, realizou uma pesquisa longitudinal com estudantes e professores de engenharia na Ryerson University, Toronto, Canadá. A cada ano o participante da pesquisa respondia a uma nova aplicação do ILS. Foram coletados 557 questionários válidos e a análise dos dados incluiu teste e re-teste de confiabilidade, confiabilidade interna, correlação item total e correlação inter-escala. Seus resultados concordaram com os encontrados por Linvesay ${ }^{8}$ et al. , citado por Zywno (2003) que, ao avaliar 255 estudantes de engenharia, por meio de medições repetidas, também constatou que o ILS é confiável como ferramenta psicométrica.

Como resposta às críticas de Van Zwanenberg et al. (2000), anteriormente citadas, Zwyno destaca seus resultados: a confiabilidade de moderada a forte e o coefeciente 42 atisfatório de confiabilidade interna das escalas. E sugere que os baixos escores encontrados por Van Zwanenberg devem-se a falta de re-teste.

Felder e Spurlin (2005) realizaram um estudo a partir dos resultados de várias pesquisas que utilizaram o ILS como instrumento de medida. Por meio destes dados, responderam a diversas questões sobre sua aplicação, evidências de validade e

\footnotetext{
${ }^{8}$ LIVESAY, G.; DEE, K.; FELDER, R.; HITES, L.; NAUMAN, E.; O'NEAL, E. Statistical Evaluation of the Index of Learning Styles, Session 2430, ASEE Annual Conference and Exposition, Montreal, Quebec, Canada, 2002.
} 
confiabilidade. Confirmando as propriedades psicométricas do ILS e incentivando novas aplicações do instrumento.

Cook (2005) aplicou o ILS em 139 residentes de medicina, nos Estados Unidos. Encontrou, por meio de teste e re-teste, correlações significantes e escores que indicaram a confiabilidade do índice. Cook e Smith (2006), em outra pesquisa com médicos residentes e estudantes de medicina, compararam o ILS com três instrumentos destinados a medir estilos de aprendizagem: o Inventário de Estilos de Aprendizagem (LSI), a Análise de Estilos Cognitivos (CSA) e o Indicador de Tipos de Estilos de Aprendizagem (LSTI). Os dados encontrados confirmaram a validade do ILS.

Litzinger et all. (2007) avaliaram o efeito de uma mudança no tipo de escala do ILS em sua confiabilidade e validade. Aplicaram duas versões do índice em estudantes de engenharia, educação e artes. A primeira foi a versão original, dicotômica, contendo questões de escolha forçada entre as alternativas apresentadas (a ou b). A segunda versão continha as mesmas questões da versão original, mas a resposta era dada em uma escala likert de cinco pontos. Esse formato permitia ao respondente tanto expressar a intensidade de sua preferência quanto optar por uma posição neutra.

A Figura 9 apresenta um modelo contendo o formato das questões na versão original e modificada.

\section{ILS ( versão original):}

Eu compreendo melhor alguma coisa depois de:

( a ) experimentar

(b) refletir sobre ela

\section{ILS ( versão modificada):}

Eu compreendo melhor alguma coisa depois de:

Experimentar

L

Refletir sobre ela 

2007)

Figura 9. Formato das questões na versão original e modificada do ILS. (LITZINGER et all.,

Após a aplicação das duas versões, os alunos ainda deveriam opinar sobre quão bem os instrumentos descreviam seus estilos de aprendizagem. A conclusão do estudo indicou que a versão original do ILS gera dados com níveis aceitáveis de consistência interna, e que as provas advindas da análise fatorial e da opinião dos alunos confirmaram uma forte validade de constructo. A modificação da escala de resposta dicotômica para a escala likert de cinco pontos não resultou em mudanças significativas, quer na confiabilidade interna das escalas, quer na validade de conteúdo ou na estrutura fatorial do instrumento. Contudo, os pesquisadores apontam que seria interessante aprofundar a investigação sobre a tendência percebida nas respostas de posição neutra, uma vez que na escala dicotômica não é possível tal manifestação. Porém, por ser o ILS um instrumento com longo histórico de aplicação, evidências de validade e confiabilidade os autores não recomendam uma alteração no formato de resposta do índice.

Entre os anos de 2002 a 2007, Hosford e Siders (2010) realizaram um estudo com o objetivo de avaliar a consistência interna e a estabilidade temporal das respostas de estudantes de medicina ao ILS e, assim, verificar sua confiabilidade como instrumento de medida. Os participantes responderam ao índice duas vezes com um intervalo de dois a quatro anos entre a primeira e segunda aplicação. Os resultados indicaram o ILS como instrumento adequado para mensurar as preferências dos estudantes quanto ao seu perfil dominante para aprender.

No Brasil, o instrumento foi introduzido pelos estudos de Kuri e Giorgetti (1996), citados por Rosário (2006), responsáveis pela tradução e adaptação do instrumento para o português. Quanto às evidências de validade, Lopes (2002) realizou um trabalho com o objetivo de validar o ILS utilizando uma amostra de 449 estudantes do estado de Minas Gerais. Porém, não conseguiu um resultado que confirmasse a validade de conteúdo do instrumento, nem pela amostra investigada nem pela avaliação de juízes. Contudo, em 2004, um novo estudo foi realizado, desta vez com 840 estudantes paulistas. Kuri (2004), autora do 
trabalho, comprovou a confiabilidade e validade do ILS em medir as preferências dos estudantes investigados. Em resumo, a maior parte dos trabalhos encontrados mostra evidências de validade do ILS.

Conforme apontado anteriormente, foram localizadas 14 teses e dissertações brasileiras que objetivaram investigar os estilos individuais de aprendizagem de alunos do Ensino Superior, por meio deste instrumento. Nesses trabalhos, além das variáveis demográficas, foram correlacionados aos estilos vários outros fatores: o estilo preferencial do professor, o desempenho acadêmico do aluno, o procedimento e rendimento em cursos de educação à distância, as estratégias de ensino e a formação de equipes. Ao todo, foram investigados aproximadamente 2800 sujeitos, entre estudantes e professores de diversos cursos do ensino superior: ciências da computação, pedagogia, contabilidade, tecnologia de produção, tecnologia em processamento de dados, engenharia de produção mecânica, computação, sistemas de informação, engenharia elétrica, engenharia civil e administração de empresas. (LOPES, 2002; KURI, 2004; SANTOS, 2005; ROSÁRIO, 2006; SILVA, 2006; DINIZ, 2007; FREITAS, 2007; TREVELIN, 2007; GRANITO, 2008; KALATZIS, 2008; LINDEMAN, 2008; PERNOMIAN, 2008; CATHOLICO, 2009; PIMENTEL, 2009).

Em face dos dados anteriormente considerados optou-se pelo emprego do ILS nesta pesquisa com base nos seguintes elementos:

1. A facilidade de acesso ao instrumento, de uso livre e gratuito para pesquisas educacionais.

2. A significativa aplicação no contexto brasileiro. Os dados coletados nesses trabalhos poderão contribuir para a análise e discussão dos resultados desta pesquisa.

3. Estudos anteriores que comprovaram sua confiabilidade e validade.

4. A falta de instrumentos nacionais validados.

5. A escassez de instrumentos internacionais traduzidos, adaptados e validados para a avaliação de estilos de aprendizagem no Brasil.

De acordo com Felder e Silverman (1988) não há um aprendiz puro em termos de estilo, cada indivíduo poderá apresentar características tanto de um pólo como de outro em cada dimensão. O estilo é definido pelo tipo de ação e postura mais costumeiramente adotado pelo estudante. 


\subsection{Pesquisas que utilizaram o ILS no Ensino Superior}

Várias pesquisas utilizaram o ILS para identificar os estilos de aprendizagem de estudantes universitários e relacioná-los a outras variáveis como gênero e curso dos participantes. No âmbito nacional, as pesquisas em sua grande maioria focaram a investigação de cursos nas áreas de Ciências Exatas e Engenharias. Foi encontrado apenas um trabalho que abordou cursos das áreas de Ciências Humanas e da Saúde (SANTOS; MOGNON, 2010).

Os trabalhos cujos participantes eram alunos de cursos da área de Ciências Exatas, como Ciências da Computação (DINIZ, 2007; LINDEMAN, 2008), Tecnologia de Processamentos de Dados (TREVELIN, 2007), Tecnologia da Informação (SANTOS E MOGNON, 2010), Contabilidade (SILVA, 2006; PIMENTEL, 2009) e Matemática (LINDEMAN, 2008) relataram que o perfil dominante dos estudantes desta área é sensorial, visual, ativo e seqüencial. Com exceção dos alunos de Matemática, que, na dimensão seqüencial-global, demonstraram preferência pelo estilo global (LINDEMAN, 2008).

Já os diversos cursos da área de Engenharias: Engenharia da Produção (KURI, 2004; BELHOT, 2005; FREITAS, 2007), Engenharia Civil (KURI, 2004; PEREIRA, 2005; KALATZIZ, 2008), Engenharia Elétrica (KURI, 2004; PERNOMIAN, 2008), Engenharia Mecânica (KURI, 2004; SANTOS E MOGNON, 2010), Engenharia de Alimentos e Engenharia Química (ROSÁRIO, 2006) apresentaram concordância em três dimensões dos estilos: ativo, sensorial e visual. Assim como nos cursos de Ciências Exatas, houve diferenciação na dimensão seqüencial-global. Algumas das pesquisas relatam a preferência dos alunos pelo estilo seqüencial (ROSÁRIO, 2006; KALATZIZ, 2008; PERNOMIAN, 2008) já outras relatam que os participantes preferem compreender de forma global (PEREIRA, 2005; BELHOT, 2005; FREITAS, 2007). Por sua vez, Kuri (2004) descreve que, apesar do perfil dominante de sua amostra ser sensorial, visual, ativo e global, ao considerar separadamente os resultados por habilitação (Civil, Mecânica, Elétrica e de Produção), não encontrou diferença estatisticamente significante entre o estilo sequencial e o global. 
Santos e Mognon (2010) investigaram 242 estudantes de vários cursos das Ciências Humanas (Pedagogia), Ciências da Saúde (Fisioterapia e Educação Física), Ciências Exatas (Tecnologia da Informação), Ciências Sociais Aplicadas (Administração), Engenharias (Engenharia Mecânica) e Linguística, Letras e Artes (Letras). Sem considerar a natureza do curso, os resultados indicaram que os estilos preferencialmente elegidos pelos participantes foram: sensorial, visual, ativo e seqüencial. A análise dos estilos por curso indicou diferenças significantes nas dimensões ativo-reflexivo e visual-verbal. Os estudantes do curso de Letras usam predominantemente o estilo reflexivo no processamento da informação. Com exceção do curso de $\mathrm{TI}$, que apresentou resultado neutro, os demais cursos preferem o estilo ativo. Na dimensão visual-verbal, novamente o curso de Letras distingue-se. Enquanto apresenta preferência pelo estilo verbal, todos os demais estudantes pesquisados relataram preferência pelo estilo visual de recepção da informação.

Em resumo, independente do curso as pesquisas apontam que, quanto à percepção da informação, os estudantes brasileiros têm preferência por aprender de forma mais prática, elegendo as representações visuais para facilitar a entrada da informação. Já quanto ao processamento tendem a escolher situações dinâmicas capazes de promover maior experimentação do conteúdo. Contudo, quanto à compreensão há divergência na preferência nacional, parte dos alunos indica que para compreenderem melhor necessitam antes de uma visão geral sobre o conteúdo, outros, porém, aprendem melhor através de uma sequência lógica de etapas.

No tocante às pesquisas internacionais, os trabalhos encontrados foram realizadaos em cursos da área de Engenharia (FELDER,1988; ALLEN; MOURTOS, 2000) e de Ciências da Saúde (DEE ET. AL., 2002; HOLTZCLAW ET. AL.,2006; ZHANG; LAMBERT, 2008; HUGHES ET. AL. 2009; NEEL; GRINDEM, 2010; PRAJAPATI ET. AL.,2011).

Felder (1988) e Allen e Mourtos (2000) em trabalhos desenvolvidos com estudantes de Engenharia obtiveram resultado similar ao encontrado nos trabalhos nacionais: o mesmo perfil dominante em três das quatro dimensões medidas pelo ILS - sensorial, visual e ativo e divergência na dimensão seqüencial-global.

Estudantes de Engenharia Biomédica da Universidade de Tulane, EUA, demonstraram preferir perceber o ambiente de aprendizagem sensorialmente, receber as informações de forma visual, processar de maneira ativa e compreender globalmente (DEE ET. AL., 2002). Já 
os estudantes de Genética da Universidade de Atlanta exibiram três estilos de aprendizado predominantes: sensorial, visual e seqüencial. Apenas na dimensão ativo-reflexivo não foi percebida uma predominância significativa, pois a amostra apresentou $54 \%$ de participantes ativos e $46 \%$ de reflexivos (HOLTZCLAW Et. al.,2006).

O único trabalho encontrado com participantes orientais foi realizado por Zhang e Lambert (2008) com 100 estudantes chineses do curso de Enfermagem. O perfil dominante da amostra foi: sensorial, visual, reflexivo e global. Interessante ressaltar que foi também o único estudo encontrado que apresenta o estilo reflexivo como dominante em uma amostra, sem considerar a variável gênero. Isso indica que os estudantes chineses de enfermagem elegem a reflexão como forma preferencial de processamento, valorizando o tempo e o espaço dedicado à abstração.

Os resultados encontrados por Hughes et. al. (2009), em um levantamento realizado com 261 alunos de Ortodontia, indicam que estes são altamente visuais e mostram preferência pelos estilos sensorial e seqüencial. Já os alunos de Medicina Veterinária classificaram-se como: sensorial, visual, ativo e sequencial (NEEL; GRINDEM, 2010). Por sua vez, os duzentos e sessenta alunos europeus de Optometria, investigados por Prajapati et. al. (2011) indicaram preferencialmente os estilos sensorial, visual, ativo e seqüencial como as melhores abordagens à própria aprendizagem.

Quanto à relação entre os estilos de aprendizagem e o gênero do estudante, as pesquisas nacionais apontam evidências de que os estilos de aprendizagem são influenciados pelo gênero. Segundo pesquisa realizada por Rosário (2006) com estudantes de Engenharia Química e de Alimentos, os homens tendem a ser mais intuitivos, visuais e globais. Por sua vez as mulheres representam melhor o estilo verbal.

Diniz (2007) não encontrou diferença de perfil de estilo entre os alunos de Ciências da Computação. Mulheres e homens apresentaram o mesmo perfil: sensorial, visual, ativo e seqüencial. Contudo, a autora detectou uma tendência mais forte entre as mulheres de serem ativas e sensoriais, já que todas as participantes do sexo feminino apresentaram perfil ativo e sensorial.

Ao pesquisar alunas e alunos dos cursos de Ciências da Computação e de Matemática, Lindemann (2008) encontrou resultado similar a Diniz (2007), ambos os sexos 
apresentaram o mesmo perfil dominante: sensorial, visual, ativo e seqüencial. Porém, novamente entre os estudantes ativos e sensoriais houve maior representatividade do sexo feminino. Os homens por sua vez apresentaram tendência maior a serem visuais.

Belhot (2005) e Freitas (2007) relatam que, quanto à percepção e ao processamento, os estilos de aprendizagem das alunas coincide com o perfil dos alunos do curso de Engenharia da Produção, ambos são sensoriais e ativos. Contudo, quanto à retenção e compreensão, as estudantes do sexo feminino tendem a ser mais verbais e seqüenciais.

Pimentel (2009) também aponta divergência entre os sexos, mas apenas na dimensão seqüencial-global: os homens apresentaram o estilo global e as mulheres o sequencial. Nas demais dimensões o perfil predominante do grupo pesquisado (ativo, sensorial e visual) coincide em ambos os sexos. Todavia, a maior parte dos alunos de estilo intuitivo e visual são mulheres.

Santos e Mognon (2010) encontraram diferenças significantes em duas dimensões: ativo-reflexivo e visual/verbal. Em comparação com as mulheres, os homens apresentaram maior preferência pelo estilo ativo de processamento. Já quanto à retenção da informação, os homens tendem a ser mais visuais do que as mulheres.

Estudos internacionais também indicam que homens e mulheres apresentam diferenças em seus estilos de aprendizagem. Dee et. al. (2011) encontrou entre os alunos de Engenharia Biomédica uma percentagem significativamente maior de estudantes do sexo feminino que apresentaram preferência pelo estilo sensorial e ativo. Já na pesquisa de Prajapati et. al. (2011) as alunas de Optometria apresentaram maior preferência pelo estilo reflexivo e visual do que seus colegas do sexo masculino.

\subsection{ESTRATÉGIAS DE APRENDIZAGEM}

Na perspectiva da Psicologia Social Cognitiva, baseada na Teoria do Processamento de Informação, as estratégias de aprendizagem são seqüências de procedimentos ou atividades que os indivíduos usam para adquirir, armazenar e 
utilizar a informação. (GAGNÉ, 1985; DEMBO, 1991; BORUCHOVITCH, 1999; POZO, 2002)

Ser um aprendiz estratégico implica em dominar as técnicas necessárias ao empreendimento das estratégias. As estratégias de aprendizagem referem-se não somente ao comportamento, mas também aos pensamentos desenvolvidos pelo aprendiz durante seu processo de codificação, memorização e resgate das informações recebidas. Não são, porém, todos os alunos que conseguem realizar um bom planejamento para o uso das estratégias. (WEINSTEIN; MAYER, 1985)

Bzuneck (2001) ressalta que o esforço de muitos alunos para aprender torna-se frustrante, pois não sabem como aprender. A falta de conhecimento sobre adequadas estratégias de aprendizagem pode levá-los a um baixo desempenho escolar e, consequentemente, desmotivá-los já que não percebem como reverter o resultado obtido. Vários autores consideram que a solução está no ensino tanto para a aquisição das habilidades quanto para o uso tático delas. Ou seja, o ideal não seria somente a instrução para o conhecimento das estratégias possíveis, mas também para o metaconhecimento, capacidade necessária para que o aluno saiba quando e quais estratégias utilizar. (HATTIE; BIGGS; PURDIE, 1996; BZUNECK, 2001; MONEREO, 2003; MUNEIRO, 2008)

De acordo com o que foi historiado por Boruchovitch (1999) e Muneiro (2008), muitas são as classificações e nomenclaturas usadas para distinguir os tipos de estratégias de aprendizagem: cognitivas, metacognitivas, de administração de recursos, primárias, de apoio, superficiais e de profundidade. Contudo, segundo Santos (2008, p. 27) "o comum à maioria destas definições e classificações é dividilas em duas grandes esferas: estratégias cognitivas e metacognitivas".

\subsubsection{Estratégias Cognitivas}

As estratégias de aprendizagem cognitivas ou primárias estão mais direcionadas a ajudar o estudante a organizar, elaborar e integrar a informação. Podem ser divididas em ensaio, elaboração e organização. As estratégias de ensaio 
são marcadas pela repetição da informação aprendida. Por exemplo: repetir palavras-chave em voz alta ou por escrito, sublinhar ou destacar partes importantes do texto, tomar notas etc. As estratégias de elaboração objetivam associar a informação nova com informações já aprendidas. Envolvem ações como: reescrever, resumir, parafrasear, elaborar anotações sobre a própria compreensão do assunto, criar rimas, abreviaturas, palavras-chave, analogias, criar e responder questionários sobre o assunto. Já as estratégias de organização estruturam as informações a serem aprendidas e requerem procedimentos como formar categorias, criar redes de conceitos, fazer mapas conceituais. (WEINSTEIN; MAYER, 1985; BORUCHOVITCH, 1999; POZO, 2002).

\subsubsection{Estratégias Metacognitivas}

A metacognição apresenta-se tanto na forma de reflexão como de ação, pois compreende a capacidade do aprendiz de tomar consciência do próprio conhecimento, refletir sobre este e os fatores que o influenciam. E, a partir daí, empreender ações que propiciem seu desenvolvimento. Por isso as estratégias de aprendizagem metacognitivas estão orientadas para o planejamento, monitoramento, regulação do próprio pensamento e manutenção de um estado interno satisfatório à aprendizagem do indivíduo. (BORUCHOVITCH, 1999, 2007; POZO, 2002, 2004; RIBEIRO, 2003)

As estratégias metacognitivas podem ser divididas em dois tipos: de monitoramento e afetivas. Quando um aluno, por exemplo, consegue administrar o próprio tempo, rever as estratégias usadas e perceber quais foram adequadas ou não à tarefa executada ele empreendeu habilidades de monitoramento. Se este mesmo aprendiz foi capaz de lidar com seus sentimentos, crenças e controlar sua motivação, ele fez uso das estratégias afetivas. (WEINSTEIN; MAYER, 1985; BORUCHOVITCH, 1999, 2007) 


\subsubsection{Pesquisas sobre Estratégias de Aprendizagem}

As estratégias de aprendizagem são um foco recente de pesquisa, mas tem sido um assunto bastante estudado no âmbito escolar. No levantamento de pesquisas nacionais, foram encontrados 30 trabalhos, entre teses e dissertações, na última década, que se dedicaram ao estudo das estratégias de aprendizagem no ensino superior. De acordo com o seu foco temático principal estas pesquisas formam três agrupamentos: $1^{\circ}$.) avaliação das estratégias metacognitivas - referente àquelas que se dedicaram exclusivamente à mensuração das estratégias metacognitivas; (RUIZ, 2005; SANTOS, 2005; BRANDÃO, 2006; SANTOS, 2006; BENCKE, 2008; SILVA, 2008 ${ }^{\mathrm{a}} 2^{\circ}$.) avaliação das estratégias cognitivas e metacognitivas - as que mensuraram estratégias cognitivas e metacognitivas de forma conjunta (BARTALO, 2006; MARINI FILHO, 2006; SILVA, 2006; QUINTANA, 2006; VIANA JÚNIOR, 2006; ANDRADE, 2007; GALVÃO, 2007; LIMA, 2007; PEREIRA, 2007; RABELLO, 2007; DEMOLINER, 2008; MUNEIRO, 2008; SILVA, 2008b; SOSSAI, 2009; e $3^{\circ}$.) intervenção em estratégias de aprendizagem - as que apresentaram propostas de ensino, promoção e desenvolvimento de estratégias cognitivas e metacognitivas. (FONSECA, 2006; GAIGNOUX , 2006; MORITA, 2006; CARVALHO, 2007; MAGALHÃES, 2009; MOTTA, 2009; TAKEUCHI, 2009; VILAÇA, 2009; ALVES, 2010)

Estas pesquisas trouxeram importantes contribuições para uma melhor compreensão das estratégias de aprendizagem e de seus efeitos no âmbito do ensino superior brasileiro.

Em estudo realizado com 191 estudantes do curso de Letras com o objetivo de identificar as estratégias de estudo individual e suas percepções sobre o contexto de ensino e aprendizagem, Galvão (2007) verificou que a estratégia cognitiva mais utilizada é a de realizar anotações. Estratégias cognitivas mais complexas como fazer exercícios, resumo ou esquemas são usadas ocasionalmente por estes estudantes. Quanto ao uso das estratégias metacognitivas, os participantes relataram utilizá-las para a manutenção da concentração em sala. No entanto estas pareceram não ser empregadas para a organização do tempo, já que os alunos 
relataram não ter rotina diária de estudo individual e consideraram insuficiente 0 tempo que dedicam a este. De acordo com o estudo, esta ausência de rotina não pôde ser relacionada à disponibilidade de tempo dos alunos, logo foi associada à questão estratégica.

Em outras duas pesquisas realizadas com os mesmos objetivos de Galvão (2007) e utilizando também igual instrumento de levantamento, foram encontradas semelhanças e diferenças quanto à utilização das estratégias de aprendizagem pelos estudantes de Matemática (PEREIRA, 2007) e de Pedagogia (DEMOLINER, 2008). Em comparação com os alunos de Pedagogia, os estudantes de Matemática elegem estratégias cognitivas mais diversificadas e complexas como fazer exercícios, revisar, anotar, resumir e pesquisar em fontes diferentes daquelas abordadas em sala. Contudo, com exceção da estratégia "fazer exercícios", utilizada sempre pelos alunos, as demais estratégias foram apontadas apenas como de uso freqüente. Por sua vez, os estudantes de Pedagogia declararam como preferida a estratégia cognitiva de ensaio "fazer anotações". Apenas cerca de um terço dos futuros pedagogos relataram utilizar outro tipo de estratégia que exige processamento mais profundo da informação, como resumo ou elaboração de esquemas.

Os mesmos estudos indicaram que estratégias metacognitivas não são adequadamente utilizadas para a organização do tempo, pois a grande maioria dos estudantes de ambos os cursos declararam dedicar tempo insuficiente para o estudo extra-classe. Já quanto à rotina de estudo há uma divergência: enquanto mais da metade dos alunos de Matemática afirma ter rotina diária de estudo, a maioria dos estudantes de Pedagogia declarou não possuir rotina de estudo individual. No entanto, parece haver utilização de estratégias metacognitivas quanto à escolha do ambiente de estudo, pois os estudantes dos dois cursos reconheceram as características de um ambiente adequado à aprendizagem e elegeram a própria casa como o local mais propício para o estudo eficaz. Outra diferença entre os cursos aparece no monitoramento da atenção em sala de aula: os participantes do curso de matemática relataram fazer grande uso das estratégias metacognitivas para controlar a própria atenção durante as aulas. Por sua vez, menos da metade dos alunos de Pedagogia declararam prestar atenção às explicações do professor, 
alegando que a monotonia e a conversa paralela em classe dificultam a concentração. (PEREIRA, 2007; DEMOLINER, 2008).

Ruiz (2005) em estudo realizado com 185 universitários dos cursos de Educação Física, Ciências da Computação e Administração apontou a influência da natureza do curso na utilização de estratégias metacognitivas direcionadas à manutenção da motivação. Os alunos de Educação Física e Administração relataram maior crença de autoeficácia em comparação aos estudantes de Ciência da Computação. Por sua vez, os estudantes deste curso apresentaram maior controle de ansiedade frente às provas. Como resultado geral, o estudo apontou que, independente do curso, os participantes apresentaram um grau satisfatório de motivação, o que indica a utilização de estratégias metacognitivas.

De acordo com Silva (2006), estudantes formandos do curso de Letras tendem a empreender mais estratégias cognitivas do que metacognitivas. E entre as metacognitivas, preferem as destinadas ao automonitoramento. Já as estratégias afetivas, aplicadas ao controle dos sentimentos ligadas à aprendizagem, são menos empregadas por estes alunos.

Bartalo (2006) realizou uma pesquisa com 833 universitários de 21 cursos diferentes das áreas de Ciências Exatas, Ciências da Saúde, Ciências Humanas e Ciências Sociais. Ressalte-se, porém, que neste estudo o curso de Engenharia Civil foi considerado como parte do grupo de Ciências Exatas. Os resultados apontaram diferenças no uso de estratégias de acordo com o gênero e com a natureza do curso. Os estudantes do sexo masculino relataram utilizar menos estratégias afetivas no controle da ansiedade do que as colegas do sexo feminino. As mulheres também apresentaram maior uso das estratégias metacognitivas para a administração do tempo e manutenção da motivação. Quanto ao curso, a distinção apareceu tanto na aplicação das estratégias cognitivas quanto das metacognitivas: os estudantes de Ciências da Saúde e Ciências Humanas pareceram adotar melhores estratégias cognitivas do que os alunos de Ciências Sociais, com destaque para os alunos de Ciências Humanas que apresentaram maior adoção da estratégia de elaboração "identificar as ideias principais". Resultado similar ocorre quando a capacidade de manter a concentração é avaliada: os estudantes de Ciências Humanas e Exatas se mostraram mais estratégicos do que os de Ciências Sociais. Quanto à organização do tempo, tanto os alunos de Ciências Sociais quanto os de 
Exatas utilizaram menos estratégias metacognitivas em comparação aos de Ciências Humanas. Já com respeito à manutenção da motivação, os alunos de Ciências da Saúde empreenderam mais estratégias metacognitivas que os estudantes das outras áreas.

Muneiro (2008) investigou 160 alunos de Engenharia Elétrica e de Serviço Social, com objetivos semelhantes às pesquisas anteriores: conhecer e comparar o uso de estratégias de aprendizagem de alunos do ensino superior em dois cursos de natureza diferente. Em geral, os resultados indicaram a preferência da maioria dos estudantes pelo uso de estratégias cognitivas de ensaio, que apresentam pouca complexidade e maior familiaridade, pois são requisitadas desde o início da vida escolar. Quanto às estratégias metacognitivas, as mais relatadas pelos participantes estavam relacionadas ao controle do material exigido à tarefa, ao monitoramento da compreensão e manutenção da motivação. Na comparação entre os participantes dos dois cursos, houve pequena diferença na utilização de estratégias cognitivas e metacognitivas. Os estudantes de Serviço Social relataram usar mais as estratégias cognitivas de ensaio do que os estudantes de Engenharia. Por sua vez, em relação aos alunos de Serviço Social, os estudantes de Engenharia indicaram utilizar mais estratégias metacognitivas de controle da ansiedade frente à avaliação e tarefas difíceis.

Outras pesquisas apontam que as principais dificuldades dos alunos do Ensino Superior consistem em empreender estratégias de gerência da própria aprendizagem, como a administração do tempo de estudo e o controle dos sentimentos ligados à aprendizagem. Estes estudos também indicam a falta de conhecimento e adequação de técnicas de estudos como uma possível causa de insucesso na aprendizagem. (ANDRADE, 2007; LOPES, 2007; RABELLO, 2007; SILVA, 2008b).

Vários trabalhos indicaram a importância da metacognição e sua repercussão positiva no desempenho do estudante. Brandão (2006) verificou que a metacognição pode se apresentar como um instrumento capaz de facilitar a interação do aluno de educação à distância, contribuindo para o controle e monitoramento durante a tarefa. Silva $\left(2008^{a}\right)$ afirma que estudantes que fazem uso das estratégias metacognitivas são mais autônomos e comprometidos com a própria aprendizagem, demonstrando capacidade de reelaborar as estratégias a fim de servir-lhes em contextos mais 
específicos, na sua vida acadêmica e, consequentemente, na sua vida pessoal. Dessa forma, conseguem atribuir significado ao ato de aprender.

Viana Júnior (2006) concluiu que as estratégias de aprendizagem, especialmente as metacognitivas, colaboram para que o aluno consiga lidar de uma forma melhor com as atividades orais, no momento em que estas estão sendo realizadas. Os resultados obtidos por Sossai (2009) apontam as estratégias metacognitivas como auxílio na resolução do problema de compreensão de leitura no ensino superior. E, também, como eficazes no controle das estratégias cognitivas. Contudo, Galvão (2007) indica que os alunos não são incentivados ou preparados para o desenvolvimento da metacognição

Esta é outra relevante questão ressaltada nas pesquisas encontradas: a importância da instrução para o uso de estratégias de aprendizagem. O professor é destacado como elemento imprescindível para que o aluno aumente o seu conjunto de estratégias cognitivas e metacognitivas. (SANTOS, 2005; MORITA, 2006; SILVA, 2006; QUINTANA, 2006; MOTTA, 2009). Por isso a prática docente deve promover tanto o conhecimento sobre as estratégias cognitivas possíveis para a resolução da tarefa proposta, quanto a reflexão metacognitiva sobre o próprio processo de aprendizagem. Mas, essa não é a realidade atual do ensino universitário (LIMA, 2007; DEMOLINER, 2008). Assim sendo, discute-se a necessidade urgente de que o ensino de estratégias de aprendizagem faça parte da educação superior (MUNEIRO, 2008).

Os autores que desenvolveram pesquisas interventivas sobre o uso de estratégias confirmaram que o ensino para a metacognição é capaz de aumentar o repertório de estratégias do aprendiz e promover a autorregulação da própria aprendizagem. Gaignoux (2006) comprovou que a instrução para o uso de estratégias pode ser um meio eficaz de proporcionar aos aprendizes de língua estrangeira um desenvolvimento mais bem sucedido no que se refere a sua produção oral. Carvalho (2007) mostrou que, por meio de tarefas de pesquisa, é possível oportunizar o desenvolvimento de estratégias metacognitivas do aluno. Vilaça (2009) verificou que a adoção de materiais didáticos, capazes de instruir em estratégias de aprendizagem, aumenta o repertório e o uso destas pelos estudantes. Em pesquisas similares, Magalhães (2009) com estudantes de Ciência da Computação e Takeuchi (2009) com alunos de Enfermagem, constataram que a 
utilização de estratégias cognitivas de elaboração, como os mapas conceituais, aumenta o conjunto de estratégias, inclusive metacognitivas. $E$ influencia positivamente o desempenho dos alunos com respeito à atenção, percepção, simbolização, seleção, memória e avaliação da informação. Alves (2010), por sua vez, aponta que o ensino de estratégias cognitivas de elaboração melhoram o desempenho dos alunos quanto à compreensão leitora.

Fonseca (2006), através de pesquisa realizada com alunos ingressantes no curso de Letras, confirmou que as estratégias metacognitivas puderam promover o controle consciente do processo de aprendizagem, permitindo ao grupo de intervenção compreender e guardar mais informação do texto estudado que o grupo de controle.

Um elemento que merece atenção no estudo de estratégias de aprendizagem é o instrumento utilizado para a mensuração das mesmas. Foi observado que as propriedades psicométricas do instrumento nem sempre são alvo de análise ou descrição por parte do autor, podendo assim trazer vieses para a pesquisa.

A seguir será realizada uma apresentação geral dos instrumentos utilizados nas pesquisas sobre estratégias de aprendizagem e, com maior detalhamento, o escolhido para o presente estudo: EAP-U - Escala de Avaliação de Estratégias de Aprendizagem em Universitários.

\subsubsection{Instrumentos de Avaliação das Estratégias de Aprendizagem}

Boruchovitch (2006) ressalta que, mesmo na literatura estrangeira, são poucos os instrumentos propostos para a avaliação de estratégias de aprendizagem. Segundo a autora, os principais instrumentos internacionais existentes atualmente 
são: o LASSI - Learning and Study Strategies Inventory 9 , o MSLQ - Motivated Strategies for Learning Questionaire ${ }^{10}$ e a Self-Regulated Interview Schedule ${ }^{11}$.

Somente o LASSI e o MLSQ foram utilizados em pesquisas brasileiras. Os demais instrumentos não possuem histórico de aplicação no país. Quanto ao Learning and Study Strategies Inventory (LASSI), Bartalo (2006) realizou um levantamento de suas propriedades psicométricas, que indicou a necessidade de reformulações para que fosse utilizado como medida confiável. A autora elaborou uma proposta reformatada do instrumento, que veio a se mostrar útil em seu estudo. O MSLQ foi aplicado por Ruiz (2005) para analisar as variáveis motivacionais que influenciam a aprendizagem de estudantes universitários. Os resultados sugeriram a continuidade dos estudos de validade do instrumento, já que foram encontradas poucas correlações entre as suas escalas.

As pesquisas nacionais, anteriormente citadas, utilizaram diversos tipos de instrumentos para a avaliação de estratégias de aprendizagem no ensino superior. Conforme os objetivos propostos em cada estudo, os instrumentos foram elaborados pelos autores ou adaptados de outras medidas já existentes. O principal formato utilizado foi o questionário estruturado ou semi-estruturado, sendo a maioria deles utilizada uma única vez. Com exceção dos trabalhos de Galvão (2007); Lima (2007), Pereira (2007) e Demoliner (2008) que utilizaram o mesmo instrumento: Questionário sobre estratégias de estudo deliberado e percepções sobre o ensino em contexto universitário.

Outros trabalhos, principalmente os voltados para estratégias de aprendizagem de uma segunda língua, optaram pela tradução e adaptação de instrumentos internacionais como o MARSI - Inventário de Consciência de Estratégias Metacognitivas de Leitura (FONSECA, 2006); o SILL - Strategy Inventory for Language Learning (GAIGNOUX, 2006; SILVA, 2006; VIANA JÚNIOR, 2006; LOPES, 2007) e o Inventário BraBELT (LOPES, 2007).

\footnotetext{
${ }^{9}$ WEINSTEIN, C. E.; ZIMMERMAN, B. J.; PALMER, D. R. Assessing learning strategies: the design and development of the LASSI. In: GOETZ, E.T.; ALEXANDER, P.A. Learning and study strategies. Issues in assessment, instruction and evaluation. San Diego: Academic Press. 1988.

${ }^{10}$ PINTRICH, P. R.; GROOT, E.V. Motivacional and self-regulated learning components of classroom academic performance. Journal of Educational Psychology. Vol. 82 (1), p.33-40, 1989.

${ }^{11}$ ZIMMERMAN, B. J.; MARTINEZ-PONZ, M. Development of a structured interview for assessing student use of self-regulated learning strategies. American Educational Research Journal. Vol. 23, p. 614-628, 1986.
} 
Dois outros autores elaboraram e iniciaram a busca por evidências de validade de instrumentos próprios, denominados de Escala de Avaliação das Habilidades para a Aprendizagem Auto-dirigida (MARINI FILHO, 2006) e Escala de Estratégias de Aprendizagem (MOTTA, 2009). Contudo, não foram encontrados outros estudos que utilizaram os referidos instrumentos. Muneiro (2008) também faz uso de uma escala produzida no contexto nacional, mas de autoria de Boruchovitch e Santos (2006): a Escala de Avaliação de Estratégias de Aprendizagem em Universitários (EAP-U), também a escolhida para o presente estudo. No próximo item ela será descrita e sua escolha será justificada. 


\subsubsection{Escala de Avaliação de Estratégias de Aprendizagem em Universitários (EAP-U)}

Em 2001, motivadas pela pequena quantidade de instrumentos existentes, Evely Boruchovitch e Acácia Aparecida Angeli dos Santos desenvolveram uma escala para avaliar as estratégias de aprendizagem de estudantes universitários. A versão atual do instrumento é composta por 36 itens, organizados em uma escala do tipo likert, de quatro pontos. As questões apresentam quatro opções de respostas: sempre, às vezes, raramente e nunca. (BORUCHOVITCH; SANTOS, 2006)

A escala pretende identificar e medir a frequência de utilização das estratégias de aprendizagem por estudantes universitários. O respondente é introduzido à escala da seguinte forma: “As próximas questões referem-se às estratégias que você pode utilizar para aprender. Pense na(s) forma(s) como você, em geral, costuma estudar ou se preparar para uma avaliação, um concurso ou preparar uma aula." A partir daí, as afirmativas apresentadas sugerem ações nas quais vários tipos de estratégias são executadas, cabendo ao participante revelar com qual frequência faz uso de cada uma delas.

Na busca por evidências de validade, a primeira versão da escala foi aplicada em 436 universitários de diversos cursos. A consistência interna das escalas atingiu um nível desejável estatisticamente (SANTOS et. al., 2004). Porém, foram reveladas "discrepâncias relacionadas às categorias tradicionais do construto e contradições em relação ao desempenho acadêmico, utilizado como critério externo de evidência de validade." (SANTOS; BORUCHOVITCH, 2006, p.115)

A primeira versão da escala era composta por 30 itens, cuja análise fatorial indicou o agrupamento destes em cinco fatores: estratégias cognitivas simples; estratégias metacognitivas; estratégias metacognitivas de regulação; estratégias cognitivas complexas de elaboração e organização e estratégias de apoio afetivo (SANTOS et. al., 2004). Após revisões foi apresentada a segunda versão da EAP-U, composta por 49 itens (SANTOS, informação pessoal ${ }^{12}$ ) e, após pesquisa realizada com 1490 alunos universitários, foi elaborada a versão atual do instrumento que conta com 36 itens divididos em três fatores: o fator 1 - autorregulação cognitiva e metacognitiva - é composto pelas estratégias cognitivas

\footnotetext{
${ }^{12}$ SANTOS, A.A.A. Versão recente da EAP-U. Mensagem recebida por lislie.silva@usp.br em 23 de maio de 2011.
} 
de ensaio, elaboração e organização, como também pelas estratégias metacognitivas destinadas à automotivação e à percepção da própria falta de compreensão. O fator 2 autorregulação dos recursos internos e contextuais - reúne as estratégias metacognitivas "orientadas para o controle e manejo dos estados internos e das variáveis contextuais que interferem na aprendizagem autorregulada", como por exemplo, o controle da ansiedade, a administração do tempo e a organização de estudo. O fator 3 - autorregulação social "inclui estratégias orientadas às formas de aprendizagem que envolvem a relação e a interação com o outro", como pedir ajuda aos colegas ou estudar em grupo. (SANTOS, informação pessoal ${ }^{13}$ )

Além dos estudos voltados à busca de evidências de validade, foram encontrados dois trabalhos que utilizaram a EAP-U. Santos (2008) a aplicou em 35 professoras do Ensino Fundamental com o objetivo de compreender o quanto conheciam sobre estratégias de aprendizagem e qual uso faziam destas. Muneiro (2008) usou a referida escala para identificar quais as estratégias mais usadas numa amostra de 160 alunos de engenharia e serviço social.

Considerando todos os instrumentos levantados, cujo objetivo é mensurar tanto estratégias cognitivas quanto metacognitivas, a Escala de Avaliação de Estratégias de Aprendizagem em Universitários (EAP-U) é o instrumento com o melhor histórico de evidências de validade no país.

Conforme visto anteriormente, tantos os autores que estudam estilos de aprendizagem quanto os que estudam estratégias apontam para a importância de ambos na prática educacional. Segundo eles, o conhecimento sobre os estilos e estratégias de aprendizagem pode ter repercussões positivas tanto na forma de ensino do professor, que passa a considerar as diferenças individuais na aprendizagem de cada aluno, quanto no próprio estudante que começa a refletir não somente sobre o conteúdo a ser adquirido, mas também sobre o processo de aquisição de seu conhecimento.

Ambos os construtos podem ser compreendidos dentro de uma mesma perspectiva cognitivista, com base na teoria do processamento da informação, já que estilos e

\footnotetext{
${ }^{13}$ SANTOS, A.A.A. Explicação dos fatores da EAP-U. Mensagem recebida por lislie.silva@usp.br em 19 out. 2011.
} 
estratégias se enquadram como constituintes dos processos executivos de controle. Ou seja, são responsáveis pelas maneiras e técnicas pelas quais as informações são percebidas, codificadas e resgatadas. Contudo, são escassos os estudos que se dedicam a relacionar esses dois construtos. Após levantamento de estudos internacionais realizados sobre estilos e estratégias de aprendizagem, Salles (2007) os sintetiza em dois grupos. Uma parte dos autores compreende as estratégias como elementos integrantes dos estilos de aprendizagem; a outra parte os toma como construtos distintos sem qualquer relação entre eles.

Schmeck (1988), Entwistle (1988) e Berings et. Al. (2005) concordam que estilos e estratégias possuem uma relação indissociável, já que os estilos são definidos justamente pela preferência na escolha das estratégias de aprendizagem. Em pesquisa realizada para determinar as pautas estratégicas de tipos diferentes de estilo, Aguado e Falcheti (2009) encontraram correlação positiva entre os estilos e as estratégias escolhidas. Alunos do mesmo tipo de estilo apresentaram as mesmas estratégias de aprendizagem. Halbert et. al. (2011) constataram que alunos universitários com determinado perfil de estilo apresentaram-se mais propensos a utilizar certos recursos de aprendizagem em comparação a seus colegas de estilos diferentes.

Não foi encontrado nenhum estudo semelhante no contexto do ensino superior brasileiro, o que justifica esta pesquisa cujo objetivo é investigar a relação entre a escolha de estratégias em função de diferentes estilos de aprendizagem. 


\section{CAPÍTULO 2}

\section{MÉTODO}

\subsection{JUSTIFICATIVA}

A motivação para uma maior compreensão dos estilos e estratégias de aprendizagem não deve ter a intenção de salientar as limitações ou inadequações dos estudantes em determinadas atividades de aprendizagem. Estudar a maneira preferencialmente escolhida por estes deve ter como justificativa adequar e diversificar as propostas de ensino, de forma que todas as diferenças individuais sejam consideradas e promovida entre os estudantes uma melhor compreensão de seus processos individuais de aprendizagem. Além disso, o entendimento sobre a existência de uma maneira própria de aprender, poderá aumentar no aluno o automonitoramento e a eficácia na escolha das estratégias de aprendizagem.

Por conseguinte, compreende-se que os estilos de aprendizagem devam ser estudados considerando as estratégias por estes utilizadas. Nos estudos sobre o assunto, é comum os dois construtos serem abordados separadamente. Não foi localizado nenhum estudo no país que relacionasse estilos e estratégias de aprendizagem. O presente trabalho entende ambos como conceitos indissociáveis para a compreensão da aprendizagem.

\subsection{OBJETIVOS}

O interesse em aprofundar o estudo sobre as diferenças individuais dos estudantes determinou, como objetivo geral desta pesquisa, verificar se, a cada tipo de estilo de aprendizagem, correspondem preferencialmente certos tipos de estratégias. 
Para se atingir o objetivo geral proposto entende-se necessário uma investigação profunda sobre as características e preferências dos alunos. Assim sendo, são elencados os seguintes objetivos específicos:

a) identificar os estilos de aprendizagem mais comuns entre os participantes;

b) relacionar os estilos a cada uma das áreas de conhecimento amostradas;

c) relacionar os estilos a cada tipo de curso estudado;

d) relacionar o gênero dos participantes a seus estilos de aprendizagem;

e) identificar os tipos de estratégias de aprendizagem mais frequentemente usados pelos participantes em situação de aprendizado;

f) relacionar os tipos de estratégias a cada uma das áreas de conhecimento;

g) relacionar as estratégias a cada tipo de curso estudado;

h) relacionar o gênero dos participantes às suas estratégias aprendizagem.

\subsection{REVISÃO DE LITERATURA}

A revisão bibliográfica foi realizada no banco de teses da CAPES (Coordenação e Aperfeiçoamento de Pessoal de Nível Superior) e nas bibliotecas digitais das Instituições de Ensino Superior, como também nos principais bancos de dados da área: BVS-Psi, Psicodoc e Psyc Info. De acordo com Gil (2002), considerando seus objetivos, essa pesquisa se caracteriza como exploratória, já que busca explicitar as relações existentes entre estilos e estratégias de aprendizagem. O problema será abordado de forma quantitativa, fazendo-se uso de recursos e técnicas estatísticas. Quanto à natureza dos seus procedimentos, a pesquisa será de levantamento. Por meio de dois instrumentos psicométricos, aplicados em uma amostra da população alvo, serão obtidos os dados a serem analisados e discutidos. 


\subsection{SUJEITOS}

A amostra da pesquisa foi constituída por universitários de dez diferentes cursos. Optou-se por realizar a pesquisa em cursos distintos com a intenção de investigar uma possível variação nos estilos e estratégias de aprendizagem. Os cursos foram escolhidos em razão de sua natureza. Foram pesquisadas as seguintes áreas e cursos: Ciências Humanas: psicologia, história e pedagogia; Ciências da Saúde: educação física, enfermagem e nutrição; Ciências Exatas: ciência da computação, ciências contábeis e matemática; Engenharias: engenharia civil.

Foram selecionados como sujeitos da pesquisa apenas estudantes do 4 e 60 semestre, pois se presume que estes já estão familiarizados com a natureza e as demandas próprias de seu curso. Assim, a avaliação do estudante sobre seus estilos e estratégias de aprendizagem é passível de ocorrer de forma mais precisa. O total de participantes foi de 352 estudantes, sendo que 218 são do sexo feminino e 133 do sexo masculino. Apenas um dos participantes não informou o seu gênero no questionário dos dados demográficos.

Os locais escolhidos para a aplicação da pesquisa foram dois campi de uma instituição de ensino superior, particular, localizada no estado de São Paulo. Um campus está situado no interior e o outro na capital. A escolha foi baseada na facilidade de acesso, já que a pesquisadora trabalha na referida instituição.

Antes da coleta, através de informações cedidas pela secretaria da IES, foi possível levantar o número aproximado dos participantes. Uma vez que o número dos prováveis participantes não foi elevado, optou-se por não utilizar uma amostra probabilística, mas aplicar os instrumentos em todos os estudantes, caracterizando este trabalho como um censo. Segue na Tabela 1 a distribuição dos sujeitos por área, curso, semestre e gênero. 
Tabela 1. Distribuição dos participantes da pesquisa por área, cursos, semestre e gênero

\begin{tabular}{|c|c|c|c|c|c|}
\hline Área & Curso & Semestre & Gênero & $\begin{array}{l}\text { Quantidade de } \\
\text { participantes }\end{array}$ & $\%$ \\
\hline \multirow{6}{*}{$\begin{array}{l}\text { Ciências } \\
\text { Humanas }\end{array}$} & Psicologia & 40. & Fem.: 34 & 42 & $12 \%$ \\
\hline & & & Masc.: 08 & & \\
\hline & História & 40. & Fem.: 18 & 32 & $9 \%$ \\
\hline & & & Masc.: 13 & & \\
\hline & Pedagogia & 40. & Fem.: 30 & 33 & $9 \%$ \\
\hline & & & Masc.: 03 & & \\
\hline \multirow{6}{*}{$\begin{array}{l}\text { Ciências } \\
\text { da Saúde }\end{array}$} & Educação Física & 40. & Fem.: 21 & 46 & $13 \%$ \\
\hline & & & Masc.: 25 & & \\
\hline & Enfermagem & 40. & Fem.: 34 & 37 & $11 \%$ \\
\hline & & & Masc.: 03 & & \\
\hline & Nutrição & 40. & Fem.: 39 & 42 & $12 \%$ \\
\hline & & & Masc.: 03 & & \\
\hline \multirow[t]{6}{*}{ Ciências Exatas } & Ciências & $4 \div$. & Fem.: 20 & 32 & $9 \%$ \\
\hline & Contábeis & & Masc.: 12 & & \\
\hline & Ciência da & 60 & Fem.: 00 & 34 & $10 \%$ \\
\hline & Computação & & Masc.: 34 & & \\
\hline & Matemática & 40. & Fem.: 12 & 26 & $7 \%$ \\
\hline & & & Masc.: 14 & & \\
\hline \multirow[t]{2}{*}{ Engenharias } & Engenharia Civil & 40. & Fem.: 10 & 28 & $8 \%$ \\
\hline & & & Masc.: 18 & & \\
\hline \multirow{3}{*}{\multicolumn{2}{|c|}{ Total Participantes }} & & Fem.: & 218 & $38 \%$ \\
\hline & & & Masc.: & 133 & $62 \%$ \\
\hline & & & & 352 & $100 \%$ \\
\hline
\end{tabular}




\subsection{MATERIAL}

Com o objetivo de identificar os estilos de aprendizagem dos participantes foi utilizado o Índice de Estilos de Aprendizagem de Felder-Soloman (ILS - Index of Learning Styles) (Anexo A) (FELDER; SOLOMAN, 1991). Trata-se de uma escala dicotômica contendo 44 afirmativas incompletas, cabendo ao respondente completálas optando entre as duas alternativas apresentadas (a ou b). Cada uma das quatro dimensões de estilo são avaliadas por 11 itens e as opções de resposta (a ou b) revelam as características distintas dos estilos que compõem cada dimensão. A resposta selecionada vale 1 ponto e após a soma dos pontos relativos a cada estilo o participante obtém um escore referente à sua preferência.

Com o intuito de melhor transmitir o significado da questão 18 do ILS, realizou-se uma nova versão da tradução do item 18, passando este a apresentar a seguinte constituição:

\section{Prefiro as ideias}

a) objetivas.

b) teóricas.

Para identificar as estratégias utilizadas pelos participantes foi aplicada a Escala de Avaliação de Estratégias de Aprendizagem em Universitários (Santos; Boruchovitch, 2001) em sua versão de 49 itens (Anexo B). Contudo, após a comunicação de Santos (informação pessoal ${ }^{14}$ ) sobre a atual versão do instrumento, que sofreu redução de 13 itens, foram considerados apenas os 36 itens que compõem a versão final.

Esta escala apresenta quatro possibilidades de resposta para cada um dos itens: sempre, às vezes, raramente e nunca. A categoria sempre vale 4 pontos, às vezes, 3 pontos, raramente, 2 pontos e nunca, 1 ponto. $O$ total da pontuação possível varia de no mínimo 36 pontos ao máximo de 144 pontos.

Juntamente com os instrumentos foi aplicado um questionário inicial com objetivo de levantar os dados demográficos do participante como idade, sexo, curso e semestre.

\footnotetext{
${ }^{14}$ SANTOS, A.A.A. Nova versão da EAP-U. Mensagem recebida por lislie.silva@usp.br em 04 out. 2011.
} 


\subsection{PROCEDIMENTO}

Visando a coleta de dados, primeiramente foi obtida a permissão formal para a pesquisa da Reitoria da IES e dos coordenadores dos cursos selecionados. Posteriormente, o projeto foi submetido ao Comitê de Ética em Pesquisas da instituição e considerado aprovado (processo no. 046/2011), de acordo com os quesitos do Conselho Nacional de Saúde na Resolução 196/96.

Após a aprovação do CEP, a pesquisa foi realizada em dia normal de aula. Os estudantes foram informados dos objetivos do estudo e convidados pela pesquisadora a participar voluntariamente. Após assinarem ao Termo de Consentimento Livre e Esclarecido (Apêndice A), os participantes responderam ao questionário inicial, com informações gerais (como sexo, idade, curso e semestre), juntamente com o Índice de Estilos de Aprendizagem (ILS) e a Escala de Avaliação de Estratégias de Aprendizagem em Universitários (EAP-U). Estes dois instrumentos foram apresentados aos sujeitos aleatoriamente anexados em ordem diferente, ora primeiro o ILS, ora a EAP-U. Este procedimento foi adotado com o objetivo de evitar algum possível viés nas respostas aos instrumentos de coleta de dados. 


\section{CAPÍTULO 3}

\section{RESULTADOS}

Os resultados serão apresentados em três tópicos. No primeiro serão apresentados os resultados relacionados aos estilos de aprendizagem: a) identificar os estilos de aprendizagem mais comuns entre os participantes, b) relacionar os estilos a cada tipo de curso estudado, c) relacionar o gênero dos participantes a seus estilos de aprendizagem. No segundo serão considerados os objetivos alusivos às estratégias de aprendizagem: d) identificar os tipos de estratégias de aprendizagem mais frequentemente usados pelos participantes em situação de aprendizado, e) relacionar as estratégias a cada tipo de curso estudado, f) relacionar o gênero dos participantes às suas estratégias aprendizagem. Por fim, será analisada a interação entre estilos e estratégias de aprendizagem.

A análise estatística se dará em dois momentos dentro de cada tópico acima mencionado. Num primeiro momento, os dados serão apresentados em termos da estatística descritiva: distribuições de frequência, escores, médias e desvios padrões. A análise inferencial ocorrerá num segundo momento, quando se procurará explorar as relações existentes entre às variáveis: curso, gênero, estilos e estratégias de aprendizagem.

\subsection{ESTILOS DE APRENDIZAGEM}

Os dados apresentados nesta parte do estudo foram coletados por meio das respostas dadas pelos participantes ao Índice de Estilos de Aprendizagem (ILS), que objetiva identificar o estilo dominante do participante em quatro dimensões da aprendizagem: percepção (estilo sensorial ou intuitivo); retenção (estilo visual ou verbal); processamento (estilo ativo ou reflexivo) e compreensão (estilo sequencial ou global). 
Vale esclarecer que a soma dos participantes em cada estilo que compõem uma dimensão pode não corresponder ao número total da amostra, já que alguns sujeitos, ao não responder à totalidade das questões referentes a determinado estilo, impossibilitaram sua identificação como pertencente ou não a este estilo.

\subsubsection{Estilos de aprendizagem da amostra total}

Os dados referentes ao Índice de Estilos de Aprendizagem (ILS) são apresentados na Tabela 2 em termos de frequência e porcentagem.

Tabela 2. Estilos de aprendizagem dos participantes em função das dimensões e estilos de aprendizagem

\begin{tabular}{llll}
\hline Dimensão & Estilo & N & \% \\
\hline Percepção & Sensorial & 276 & $78 \%$ \\
& Intuitivo & 75 & $21 \%$ \\
Retenção & Visual & 226 & $64 \%$ \\
& Verbal & 124 & $35 \%$ \\
Processamento & Ativo & 203 & $58 \%$ \\
& Reflexivo & 147 & $42 \%$ \\
Compreensão & Sequencial & 239 & $68 \%$ \\
& Global & 110 & $31 \%$ \\
\hline
\end{tabular}

Como pode ser observado a maior diferença entre os estilos, tanto em termos de frequência absoluta quanto em termos percentuais, ocorreu entre o estilo sensorial e o intuitivo. A menor diferença, também em ambas as comparações, foi identificada entre o estilo ativo e o reflexivo. No tocante às dimensões visual-verbal $e$ ativo-reflexivo as diferenças são menos pronunciadas. Consideradas como um todo e em termos percentuais, a amostra de sujeitos pode ser considerada como predominantemente sensorial, visual, ativa e sequencial. 
A análise do $X^{2}$ (Qui-Quadrado) revelou que as diferenças entre os estilos de aprendizagem são estatisticamente significantes. Os resultados estão apresentados na Tabela 3.

Tabela 3. Comparação entre os estilos de aprendizagem de cada dimensão para a amostra total

\begin{tabular}{lcccc}
\hline Estilos de & \multicolumn{3}{c}{ Estatística } \\
Aprendizagem & g.l & $\mathbf{X}^{2}$ crítico & $\mathbf{X}^{2}$ observado & Sig. \\
\hline Sensorial - Intuitivo & 1 & 10,83 & 113,64 & 0,000 \\
Visual - Verbal & 1 & 10,83 & 28,41 & 0,000 \\
Ativo - Reflexivo & 1 & 3,84 & 8,28 & 0,004 \\
Sequencial - Global & 1 & 10,83 & 45,10 & 0,000 \\
\hline
\end{tabular}

De acordo com esta análise pode-se inferir que a amostra se divide em oito tipos distintos de estilos de aprendizagem, sendo quatro destes predominantes.

\subsubsection{Estilos de aprendizagem de acordo com a área de conhecimento}

A Tabela 4 apresenta a distribuição dos estilos de aprendizagem em função da área do conhecimento a que o curso pertence. Os grupos investigados pertencem a quatro áreas distintas. Educação Física, Enfermagem e Nutrição integram a área das Ciências da Saúde. Ciências da Computação, Matemática e Ciências Contábeis a área de Ciências Exatas. Psicologia, História e Pedagogia pertencem às Ciências Humanas e Engenharia Civil à área das Engenharias. 
Tabela 4. Frequência e porcentagem dos estilos de aprendizagem em função das áreas de conhecimento

\begin{tabular}{|c|c|c|c|c|c|c|c|c|c|}
\hline \multirow{3}{*}{ Areas } & \multirow[t]{3}{*}{$\mathbf{N}$} & \multicolumn{8}{|c|}{ Estilos de Aprendizagem } \\
\hline & & \multicolumn{2}{|c|}{ Percepção } & \multicolumn{2}{|c|}{ Retenção } & \multicolumn{2}{|c|}{ Processamento } & \multicolumn{2}{|c|}{ Compreensão } \\
\hline & & Sensorial & Intuitivo & Visual & Verbal & Ativo & Reflexivo & Sequencial & Global \\
\hline \multirow{2}{*}{$\begin{array}{l}\text { Ciências da } \\
\text { Saúde }\end{array}$} & \multirow{2}{*}{125} & 103 & 22 & 85 & 39 & 79 & 44 & 82 & 44 \\
\hline & & $(82,4 \%)$ & $(17,6 \%)$ & $(68,0 \%)$ & $(31,2 \%)$ & $(63,2 \%)$ & $(35,5 \%)$ & $(65,6 \%)$ & $(34,4 \%)$ \\
\hline \multirow{2}{*}{$\begin{array}{l}\text { Ciências } \\
\text { Exatas }\end{array}$} & \multirow{2}{*}{92} & 80 & 12 & 64 & 27 & 57 & 35 & 71 & 20 \\
\hline & & $(87 \%)$ & $(13,0 \%)$ & $(69,6 \%)$ & $(29,3 \%)$ & $(62,0 \%)$ & $(38,0 \%)$ & $(77,2 \%)$ & $(21,7 \%)$ \\
\hline \multirow{2}{*}{$\begin{array}{l}\text { Ciências } \\
\text { Humanas }\end{array}$} & \multirow[t]{2}{*}{107} & 72 & 34 & 53 & 54 & 54 & 53 & 69 & 36 \\
\hline & & $(67,3 \%)$ & $(31,8 \%)$ & $(49,5 \%)$ & $(50,5 \%)$ & $(50,5 \%)$ & $(49,5 \%)$ & $(64,5 \%)$ & $(33,6 \%)$ \\
\hline \multirow[t]{2}{*}{ Engenharias } & \multirow[t]{2}{*}{28} & 21 & 07 & 24 & 04 & 13 & 15 & 17 & 11 \\
\hline & & $(75,0 \%)$ & $(25,0 \%)$ & $(85,7 \%)$ & $(14,3 \%)$ & $(46,4 \%)$ & $(53,6 \%)$ & $(60,7 \%)$ & $(39,3 \%)$ \\
\hline
\end{tabular}

No que se refere à dimensão sensorial-intuitivo, os sujeitos sensoriais compõem mais de dois terços da amostra dividida por área. Quanto à retenção das informações, a área de Engenharias $(85,7 \%)$ apresenta a maior concentração de aprendizes visuais. No tocante à Ciências Humanas (50,5\%) visual e verbal se equivalem. Quanto à dimensão ativo-reflexivo, à exceção da área de Engenharias (46,4\%), a maior parte dos participantes das outras três áreas é identificada como ativa: 63,2\% em Ciências da Saúde, 62\% em Ciências Exatas e 50,5\% em Ciências Humanas.

Com o objetivo de verificar se há diferenças significantes entre as áreas de conhecimento e os estilos de aprendizagem destes, utilizou-se novamente a análise estatística do qui-quadrado para cada área separadamente, como pode ser visto nas tabelas seguintes.

$\mathrm{Na}$ Tabela 5 visualizam-se as comparações realizadas entre o estilo sensorial e intuitivo em função das áreas de conhecimento. Todas as comparações foram significantes, indicando predominância do estilo sensorial sobre o intuitivo nas quatro áreas estudadas. 
Tabela 5. Comparação entre os estilos sensorial e intuitivo em função das áreas de conhecimento

\begin{tabular}{lcccc}
\hline Áreas & \multicolumn{4}{c}{ Estatística } \\
& g.I & $\mathbf{X}^{2}$ crítico & $\mathbf{X}^{2}$ observado & Sig. \\
\hline Ciências da Saúde & 1 & 10,83 & 52,49 & 0,000 \\
Ciências Exatas & 1 & 10,83 & 50,26 & 0,000 \\
Ciências Humanas & 1 & 10,83 & 12,80 & 0,000 \\
Engenharias & 1 & 6,64 & 7,00 & 0,008 \\
\hline
\end{tabular}

Na dimensão visual-verbal (Tabela 6), apenas na área de Ciências Humanas não ocorreu diferença significante, sendo que nas demais áreas o estilo visual predominou sobre o verbal.

Tabela 6. Comparação entre os estilos visual e verbal em função das áreas de conhecimento

\begin{tabular}{lcccc}
\hline Areas & \multicolumn{4}{c}{ Estatística } \\
& g.I & $\mathbf{X}^{2}$ crítico & $\mathbf{X}^{2}$ observado & Sig. \\
\hline Ciências da Saúde & 1 & 10,83 & 16,20 & 0,000 \\
Ciências Exatas & 1 & 10,83 & 14,08 & 0,000 \\
Engenharias & 1 & 10,83 & 14,29 & 0,000 \\
\hline
\end{tabular}

Os resultados referentes ao estilo ativo e reflexivo (Tabela 7) apontam diferenças significantes apenas nas áreas de Ciências da Saúde e Ciências Exatas. Nestas áreas há o predomínio do estilo ativo para o processamento da informação. 
Tabela 7. Comparação entre os estilos ativo e reflexivo em função das áreas de conhecimento

\begin{tabular}{lcccc}
\hline Areas & \multicolumn{4}{c}{ Estatística } \\
& g.I & $\mathbf{X}^{2}$ crítico & $\mathbf{X}^{2}$ observado & Sig. \\
\hline Ciências da Saúde & 1 & 7,88 & 8,71 & 0,003 \\
Ciências Exatas & 1 & 5,26 & 5,02 & 0,000 \\
\hline
\end{tabular}

Os resultados da Tabela 8 revelam que na dimensão sequencial-global apenas a área de Engenharia não apresentou diferença significante entre os estilos. Nas três outras áreas, Ciências da Saúde, Ciências Exatas e Ciências Humanas o estilo sequencial foi predominante.

Tabela 8. Comparação entre os estilos sequencial e global em função das áreas de conhecimento

\begin{tabular}{lcccc}
\hline Areas & \multicolumn{4}{c}{ Estatística } \\
& g.I & $\mathbf{X}^{2}$ crítico & $\mathbf{X}^{2}$ observado & Sig. \\
\hline Ciências da Saúde & 1 & 10,83 & 12,17 & 0,000 \\
Ciências Exatas & 1 & 10,83 & 27,17 & 0,000 \\
Ciências Humanas & 1 & 7,88 & 8,98 & 0,003 \\
\hline
\end{tabular}

Os resultados apontam para a rejeição da hipótese nula, levando à inferência de que a área de conhecimento, a que pertence o curso realizado pelos sujeitos, difere significativamente do estilo de aprendizagem destes. 


\subsubsection{Estilos de aprendizagem de acordo com o curso}

A Tabela 9 apresenta a distribuição dos estilos de aprendizagem em função do curso. No tocante à dimensão perceptual, à exceção do curso de Psicologia $(59,5 \%)$, a porcentagem dos sujeitos que foram identificados como sensoriais foi superior a dois terços da sub-amostra considerada, variando desde o mínimo de $68,8 \%$ no curso de História até $90,6 \%$ no curso de Ciências Contábeis. Já quanto à dimensão visual-verbal, em oito dos dez cursos estudados, é maior a proporção de alunos que declararam preferir o canal visual para a retenção da informação, exceto no grupo de Psicologia $(54,8 \%)$ e Pedagogia (60,6\%), que é composto em sua maioria de estudantes verbais.

No que diz respeito ao processamento da informação, apenas os cursos de Psicologia (66,7\%) e Engenharia Civil (53,6\%) possuem maior concentração de seus alunos no estilo reflexivo. Os demais cursos apresentam a porcentagem dos sujeitos ativos acima de 50\%. Destaque para o curso de Matemática que apresenta a mesma distribuição de seus participantes entre os estilos ativo (50\%) e o reflexivo $(50 \%)$. $\mathrm{Na}$ dimensão referente à forma pela qual o aprendiz organiza o pensamento para a compreensão da informação, a tabela demonstra que a proporção dos estudantes seqüenciais é superior que os globais em todos os cursos, variando desde o mínimo de $52,4 \%$ no curso de Nutrição até $87,5 \%$ no curso de Ciências Contábeis.

Observando-se a distribuição dos sujeitos em função do estilo e do curso é possível destacar os cursos que apresentam o maior contingente de representantes em cada estilo de aprendizagem: Ciências Contábeis é o curso com a maior proporção de alunos sensoriais $(90,6 \%)$ e sequenciais $(87,5 \%)$; Psicologia é o que melhor representa o estilo intuitivo $(40,5 \%)$ e reflexivo $(66,7 \%)$; Engenharia Civil apresenta a maior concentração de sujeitos visuais $(85,7 \%)$ e Pedagogia dos verbais (60\%); Educação Física possui a maior porcentagem de alunos ativos $(73,9 \%)$ e Nutrição de globais $(47,6 \%)$.

Comparando-se a amostra total, cujos estilos predominantes foram 0 sensorial, visual, ativo e sequencial, os alunos de Psicologia, Pedagogia e Engenharia Civil, em duas dimensões, apresentam estilo dominante distinto. $\mathrm{Na}$ dimensão referente à retenção da informação, em Psicologia $(54,8 \%)$ e Pedagogia 
$(60,6 \%)$ predomina o estilo verbal. E na dimensão processamento, em Psicologia $(67,6 \%)$ e Engenharia Civil $(53,6 \%)$ o estilo reflexivo é dominante.

Tabela 9. Frequência e porcentagem dos estilos de aprendizagem em função do curso

\begin{tabular}{|c|c|c|c|c|c|c|c|c|c|}
\hline \multirow{3}{*}{ Curso } & \multirow[t]{3}{*}{$\mathrm{N}$} & \multicolumn{8}{|c|}{ Estilos de Aprendizagem } \\
\hline & & \multicolumn{2}{|c|}{ Percepção } & \multicolumn{2}{|c|}{ Retenção } & \multicolumn{2}{|c|}{ Processamento } & \multicolumn{2}{|c|}{ Compreensão } \\
\hline & & Sensorial & Intuitivo & Visual & Verbal & Ativo & Reflexivo & Sequencial & Global \\
\hline Educação Física & 46 & $\begin{array}{c}39 \\
(84,8 \%)\end{array}$ & $\begin{array}{c}7 \\
(15,2 \%)\end{array}$ & $\begin{array}{c}37 \\
(80,4 \%)\end{array}$ & $\begin{array}{c}9 \\
(19,6 \%)\end{array}$ & $\begin{array}{c}34 \\
(73,9 \%)\end{array}$ & $\begin{array}{c}11 \\
(23,9 \%)\end{array}$ & $\begin{array}{c}32 \\
(69,6 \%)\end{array}$ & $\begin{array}{c}14 \\
(30,4 \%)\end{array}$ \\
\hline Enfermagem & 37 & $\begin{array}{c}27 \\
(73,0 \%)\end{array}$ & $\begin{array}{c}10 \\
(27,0 \%)\end{array}$ & $\begin{array}{c}22 \\
(59,5 \%)\end{array}$ & $\begin{array}{c}15 \\
(40,5 \%)\end{array}$ & $\begin{array}{c}23 \\
(62,2 \%)\end{array}$ & $\begin{array}{c}13 \\
(35,1 \%)\end{array}$ & $\begin{array}{c}28 \\
(75,7 \%)\end{array}$ & $\begin{array}{c}9 \\
(24,3 \%)\end{array}$ \\
\hline Nutrição & 42 & $\begin{array}{c}37 \\
(88,1 \%)\end{array}$ & $\begin{array}{c}5 \\
(11,9 \%)\end{array}$ & $\begin{array}{c}26 \\
(61,9 \%)\end{array}$ & $\begin{array}{c}15 \\
(35,7 \%)\end{array}$ & $\begin{array}{c}22 \\
(52,4 \%)\end{array}$ & $\begin{array}{c}20 \\
(47,6 \%)\end{array}$ & $\begin{array}{c}22 \\
(52,4 \%)\end{array}$ & $\begin{array}{c}20 \\
(47,6 \%)\end{array}$ \\
\hline $\begin{array}{l}\text { Ciências da } \\
\text { Computação }\end{array}$ & 34 & $\begin{array}{c}30 \\
(88,2 \%)\end{array}$ & $\begin{array}{c}4 \\
(11,8 \%)\end{array}$ & $\begin{array}{c}26 \\
(76,5 \%)\end{array}$ & $\begin{array}{c}8 \\
(23,5 \%)\end{array}$ & $\begin{array}{c}22 \\
(64,7 \%)\end{array}$ & $\begin{array}{c}12 \\
(35,3 \%)\end{array}$ & $\begin{array}{c}26 \\
(76,5 \%)\end{array}$ & $\begin{array}{c}7 \\
(20,6 \%)\end{array}$ \\
\hline Matemática & 26 & $\begin{array}{c}21 \\
(80,8 \%)\end{array}$ & $\begin{array}{c}5 \\
(19,2 \%)\end{array}$ & $\begin{array}{c}19 \\
(73,1 \%)\end{array}$ & $\begin{array}{c}6 \\
(23,1 \%)\end{array}$ & $\begin{array}{c}13 \\
(50,0 \%)\end{array}$ & $\begin{array}{c}13 \\
(50,0 \%)\end{array}$ & $\begin{array}{c}17 \\
(65,4 \%)\end{array}$ & $\begin{array}{c}9 \\
(34,6 \%)\end{array}$ \\
\hline $\begin{array}{l}\text { Ciências } \\
\text { Contábeis }\end{array}$ & 32 & $\begin{array}{c}29 \\
(90,6 \%)\end{array}$ & $\begin{array}{c}3 \\
(9,4 \%)\end{array}$ & $\begin{array}{c}19 \\
(59,4 \%)\end{array}$ & $\begin{array}{c}13 \\
(40,6 \%)\end{array}$ & $\begin{array}{c}22 \\
(68,8 \%)\end{array}$ & $\begin{array}{c}10 \\
(31,3 \%)\end{array}$ & $\begin{array}{c}28 \\
(87,5 \%)\end{array}$ & $\begin{array}{c}4 \\
(12,5 \%)\end{array}$ \\
\hline Psicologia & 42 & $\begin{array}{c}25 \\
(59,5 \%)\end{array}$ & $\begin{array}{c}17 \\
(40,5 \%)\end{array}$ & $\begin{array}{c}19 \\
(45,2 \%)\end{array}$ & $\begin{array}{c}23 \\
(54,8 \%)\end{array}$ & $\begin{array}{c}14 \\
(33,3 \%)\end{array}$ & $\begin{array}{c}28 \\
(66,7 \%)\end{array}$ & $\begin{array}{c}26 \\
(61,9 \%)\end{array}$ & $\begin{array}{c}14 \\
(33,3 \%)\end{array}$ \\
\hline História & 32 & $\begin{array}{c}22 \\
(68,8 \%)\end{array}$ & $\begin{array}{c}9 \\
(28,1 \%)\end{array}$ & $\begin{array}{c}21 \\
(65,6 \%)\end{array}$ & $\begin{array}{c}11 \\
(34,4 \%)\end{array}$ & $\begin{array}{c}18 \\
(56,3 \%)\end{array}$ & $\begin{array}{c}14 \\
(43,8 \%)\end{array}$ & $\begin{array}{c}18 \\
(56,3 \%)\end{array}$ & $\begin{array}{c}14 \\
(43,8 \%)\end{array}$ \\
\hline Pedagogia & 33 & $\begin{array}{c}25 \\
(75,8 \%)\end{array}$ & $\begin{array}{c}8 \\
(24,2 \%)\end{array}$ & $\begin{array}{c}13 \\
(39,4 \%)\end{array}$ & $\begin{array}{c}20 \\
(60,6 \%)\end{array}$ & $\begin{array}{c}22 \\
(66,7 \%)\end{array}$ & $\begin{array}{c}11 \\
(33,3 \%)\end{array}$ & $\begin{array}{c}25 \\
(75,8 \%)\end{array}$ & $\begin{array}{c}8 \\
(24,2 \%)\end{array}$ \\
\hline Engenharia Civil & 28 & $\begin{array}{c}21 \\
(75,0 \%)\end{array}$ & $\begin{array}{c}7 \\
(25,0 \%)\end{array}$ & $\begin{array}{c}24 \\
(85,7 \%)\end{array}$ & $\begin{array}{c}4 \\
(14,3 \%)\end{array}$ & $\begin{array}{c}13 \\
(46,4 \%)\end{array}$ & $\begin{array}{c}15 \\
(53,6 \%)\end{array}$ & $\begin{array}{c}17 \\
(60,7 \%)\end{array}$ & $\begin{array}{c}11 \\
(39,3 \%)\end{array}$ \\
\hline Total & 352 & $\begin{array}{c}276 \\
(100 \%)\end{array}$ & $\begin{array}{c}75 \\
(100 \%)\end{array}$ & $\begin{array}{c}226 \\
(100 \%)\end{array}$ & $\begin{array}{c}124 \\
(100 \%)\end{array}$ & $\begin{array}{c}203 \\
(100 \%)\end{array}$ & $\begin{array}{c}147 \\
(100 \%)\end{array}$ & $\begin{array}{c}239 \\
(100 \%)\end{array}$ & $\begin{array}{c}110 \\
(100 \%)\end{array}$ \\
\hline
\end{tabular}

A fim de avaliar se as diferenças entre os estilos de cada dimensão são estatisticamente significantes foi utilizada a estatística do qui-quadrado para cada curso separadamente. Nas Tabelas 10, 11, 12 e 13 serão apresentados os 
resultados das análises estatísticas que revelaram diferença significante em cada dimensão.

Considerando o número de relações significantes, houve grande distinção dos resultados quanto às dimensões. A dimensão sensorial-intuitivo (Tabela 10) foi a que apresentou o maior número de cursos que diferem significantemente quanto aos estilos de seus participantes: oito cursos, com exceção apenas dos cursos de Enfermagem e Psicologia. Houve predominância do estilo sensorial em todos os cursos que apresentaram diferença significante na escolha entre o estilo sensorial e o intuitivo.

Tabela 10. Comparação entre os estilos sensorial e intuitivo em função dos cursos

\begin{tabular}{lcccc}
\hline Estilos de & \multicolumn{3}{c}{ Estatística } \\
Aprendizagem & $\mathbf{g . I}$ & $\mathbf{X}^{2}$ crítico & $\mathbf{X}^{2}$ observado & Sig. \\
\hline Educação Física & 1 & 10,83 & 22,27 & 0,000 \\
Nutrição & 1 & 10,83 & 24,34 & 0,000 \\
Ciências da Computação & 1 & 10,83 & 19,89 & 0,000 \\
Matemática & 1 & 9,56 & 9,84 & 0,002 \\
Ciências Contábeis & 1 & 10,83 & 21,13 & 0,000 \\
História & 1 & 3,84 & 4,50 & 0,034 \\
Pedagogia & 1 & 7,88 & 8,76 & 0,003 \\
Engenharia Civil & 1 & 6,64 & 7,00 & 0,008 \\
\hline
\end{tabular}

As análises realizadas com as demais dimensões revelaram número bem menor de cursos com diferenças significantes entre os estilos. Na dimensão referente à retenção da informação (Tabela 11) apenas três cursos (Educação Física, Ciências da Computação e Engenharia Civil) e em todos foi grande a diferença na escolha pelos estilos, sendo forte a predominância do estilo visual sobre o verbal. 
Tabela 11. Comparação entre os estilos visual e verbal em função dos cursos

\begin{tabular}{lcccc}
\hline Estilos de & \multicolumn{3}{c}{ Estatística } \\
Aprendizagem & g.I & $\mathbf{X}^{2}$ crítico & $\mathbf{X}^{2}$ observado & Sig. \\
\hline Educação Física & 1 & 10,83 & 17,04 & 0,000 \\
Ciências da Computação & 1 & 5,41 & 9,53 & 0,002 \\
Engenharia Civil & 1 & 10,83 & 14,29 & 0,000 \\
\hline
\end{tabular}

Na Tabela 12 visualiza-se a comparação entre os estilos ativo e reflexivo em razão do curso dos sujeitos. Nesta dimensão, três cursos apresentaram relação significante entre os estilos (Educação Física, Ciências Contábeis e Psicologia), sendo que em Educação Física e Ciências Contábeis predomina o estilo ativo sobre o reflexivo, já em Psicologia o inverso acontece: o estilo reflexivo é o predominante.

Tabela 12. Comparação entre os estilos ativo e reflexivo em função dos cursos

\begin{tabular}{lcccc}
\hline Estilos de & \multicolumn{3}{c}{ Estatística } \\
Aprendizagem & $\mathbf{g . l}$ & $\mathbf{X}^{2}$ crítico & $\mathbf{X}^{2}$ observado & Sig. \\
\hline Educação Física & 1 & 10,83 & 12,52 & 0,000 \\
Ciências Contábeis & 1 & 3,84 & 4,50 & 0,034 \\
Psicologia & 1 & 3,84 & 4,67 & 0,031 \\
\hline
\end{tabular}

Por fim, na dimensão seqüencial-global (Tabela 13) quatro cursos (Educação Física, Enfermagem, Ciências Contábeis e Pedagogia) apresentaram diferença significante quanto aos estilos sequencial e global, e em todos houve predomínio do estilo sequencial. 
Tabela 13. Comparação entre os estilos sequencial e global em função dos cursos

\begin{tabular}{lcccc}
\hline $\begin{array}{l}\text { Estilos de } \\
\text { Aprendizagem }\end{array}$ & $\mathbf{g . I}$ & $\mathbf{X}^{2}$ crítico & $\mathbf{X}^{2}$ observado & Sig. \\
\hline Educação Física & 1 & 6,64 & 7,04 & 0,008 \\
Enfermagem & 1 & 9,55 & 9,76 & 0,002 \\
Ciências Contábeis & 1 & 10,83 & 18,00 & 0,000 \\
Pedagogia & 1 & 7,88 & 8,76 & 0,003 \\
\hline
\end{tabular}

Em resumo, Educação Física é único curso onde comprovadamente há a predileção por quatro estilos de aprendizagem. Em Ciências Contábeis foi possível a verificação de três e nos demais somente um ou dois estilos apresentaram diferenças significantes. Com base na análise realizada, infere-se que, com exceção da dimensão sensorial-intuitivo, são poucas as diferenças significantes nas comparações entre os estilos de cada dimensão em função do curso do sujeito.

\subsubsection{Estilos de aprendizagem em função do gênero}

A Tabela 14 apresenta os dados referentes às frequências em cada estilo de aprendizagem em função do sexo. Vale ressaltar que o número total da amostra dividida por gênero e estilo é diferente da amostra por estilo, pois um dos participantes não relatou o gênero. 
Tabela 14. Frequência em cada estilo de aprendizagem por sexo

\begin{tabular}{lllllll}
\hline \multirow{2}{*}{ Dimensão } & \multicolumn{1}{c}{ Estilo } & \multicolumn{2}{c}{ Masculino } & Feminino & Total \\
& & N & \% & N & $\%$ & \\
\hline Percepção & Sensorial & 101 & $76 \%$ & 174 & $80 \%$ & 275 \\
& Intuitivo & 32 & $24 \%$ & 43 & $20 \%$ & 75 \\
Retenção & Visual & 102 & $77 \%$ & 123 & $57 \%$ & 225 \\
& Verbal & 30 & $23 \%$ & 94 & $43 \%$ & 124 \\
Processamento & Ativo & 81 & $61 \%$ & 121 & $56 \%$ & 202 \\
& Reflexivo & 52 & $39 \%$ & 95 & $44 \%$ & 147 \\
Compreensão & Sequencial & 86 & $65 \%$ & 152 & $70 \%$ & 238 \\
& Global & 45 & $34 \%$ & 65 & $30 \%$ & 110 \\
\hline
\end{tabular}

A partir da inspeção visual da Tabela 14 percebe-se que o estilo sensorial recebe a maior concentração do sexo feminino (80\%), já o sexo masculino apresenta sua maior representatividade, de forma similar, no estilo visual $(77 \%)$ e sensorial (76\%). Considerando a menor concentração dos gêneros, o intuitivo é o estilo com menor proporção de mulheres (20\%), novamente os homens apresentam duas concentrações similares: verbal (23\%) e intuitivo (24\%).

Para identificação de diferenças significantes entre os estilos de aprendizagem e o gênero dos estudantes foi utilizada a estatística do qui-quadrado. Os resultados encontrados são apresentados na Tabela 15. 
Tabela 15. Comparações entre os estilos de cada dimensao em função do sexo

\begin{tabular}{llcccc}
\hline Dimensão & Estilos de & \multicolumn{3}{c}{ Estatística } \\
& Aprendizagem & $\mathbf{g . I}$ & $\mathbf{X}^{2}$ crítico & $\mathbf{X}^{2}$ observado & Sig. \\
\hline Percepção & Sensorial & 1 & 10,83 & 19,38 & 0,000 \\
& Intuitivo & 1 & 1,64 & 1,61 & 0,204 \\
Retenção & Visual & 1 & 2,70 & 1,96 & 0,162 \\
& Verbal & 1 & 10,83 & 33,03 & 0,000 \\
Processamento & Ativo & 1 & 7,88 & 7,92 & 0,005 \\
& Reflexivo & 1 & 10,83 & 12,58 & 0,000 \\
& Sequencial & 1 & 10,83 & 18,30 & 0,000 \\
& Global & 1 & 3,84 & 3,64 & 0,057 \\
\hline
\end{tabular}

Como pode ser inferido, em apenas três estilos os sexos não se diferenciaram estatisticamente: intuitivo, visual e global. Observe-se, todavia, que no estilo global os valores são muito próximos do grau de significância. Nas demais comparações o número de mulheres foi significativamente maior do que o dos homens. Assim, neste estudo, as mulheres se caracterizaram como mais sensoriais, verbais, ativas, reflexivas e sequenciais do que os homens e com tendência a compreensão global.

\subsection{ESTRATÉGIAS DE APRENDIZAGEM}

As estratégias de aprendizagem foram identificadas por meio da Escala de Avaliação de Estratégias de Aprendizagem em Universitários (EAP - U). Nesta escala as estratégias são agrupadas em três grupos distintos: autorregulação cognitiva e metacognitiva; autorregulação dos recursos internos e contextuais e autorregulação social (SANTOS, informação pessoal ${ }^{15}$ ).

\footnotetext{
${ }^{15}$ SANTOS, A.A.A. Explicação dos fatores da EAP-U. Mensagem recebida por lislie.silva@usp.br
} em 19 out. 2011. 


\subsubsection{Estratégias de aprendizagem da amostra total}

Na Tabela 16 são apresentadas as medias e os desvios padrão dos escores na EAP-U para cada uma das estratégias.

Tabela 16. Estratégias de aprendizagem: médias e desvios padrão de cada fator

\begin{tabular}{|c|c|c|c|c|c|c|}
\hline & Estratégias de Aprendizagem & $\mathrm{N}$ & Mínimo & Máximo & Média & $\begin{array}{l}\text { Desvio } \\
\text { Padrão }\end{array}$ \\
\hline $\mathrm{F} 1$ & Autorregulação cognitiva e metacognitiva & 307 & 1,67 & 3,88 & 2,95 & 0,39 \\
\hline $\mathrm{F} 2$ & $\begin{array}{l}\text { Autorregulação dos recursos internos e } \\
\text { contextuais }\end{array}$ & 339 & 1,75 & 4,00 & 3,15 & 0,42 \\
\hline F3 & Autorregulação social & 345 & 1,00 & 4,00 & 2,87 & 0,54 \\
\hline
\end{tabular}

Como se pode observar a média da estratégia autorregulação dos recursos internos e contextuais foi a mais alta e a autorregulação social a mais baixa.

Cabe ressaltar que foram utilizados apenas os dados dos participantes que responderam a todas as questões referentes ao grupo de estratégias analisado.

A fim de verificar se as diferenças entre as médias são estatisticamente significantes, foi utilizado o teste $\mathrm{t}$ para uma única amostra. Os resultados são apresentados na Tabela 17.

Tabela 17. Estratégias de aprendizagem: comparações entre os três fatores

\begin{tabular}{lccc}
\hline Comparações & \multicolumn{3}{c}{ Estatística } \\
& g.I & $\mathbf{t}$ & Sig. (bicaudal) \\
\hline F1 x F2 & 306 & $-8,97$ & 0,000 \\
F1 x F3 & 306 & 3,65 & 0,000 \\
F2 x F3 & 338 & 12,37 & 0,000 \\
& & \\
\hline F1= Autorregulação cognitiva e metacognitiva \\
F2= Autorregulação dos recursos internos e contextuais \\
F3= Autorregulação social
\end{tabular}


De acordo com tais resultados, é possível rejeitar a hipótese nula e inferir que os resultados diferem significantemente quanto ao emprego das estratégias. Ou seja, com base nos resultados apresentados, é possível deduzir que há uma ordem hierárquica no uso preferencial das estratégias de aprendizagem pelos participantes. As mais utilizadas são as destinadas à autorregulação dos recursos internos e contextuais, seguidas pelas estratégias de autorregulação cognitiva e metacognitiva e, por fim, as referentes à autorregulação social

\subsubsection{Estratégias de aprendizagem: comparações entre as áreas de conhecimento}

A Tabela 18 apresenta a frequência, médias e desvios padrão em função da área de conhecimento na qual os cursos foram agrupados.

Tabela 18. Estratégias de aprendizagem: frequência, médias e desvios padrão em função da área de conhecimento

\begin{tabular}{llrrr}
\hline Estratégias de Aprendizagem & \multicolumn{1}{c}{$\begin{array}{c}\text { Áreas de } \\
\text { conhecimento }\end{array}$} & N & Média & Desvio Padrão \\
\hline Autorregulação cognitiva e & Ciências da Saúde & 105 & 2,94 & 0,43 \\
metacognitiva & Ciências Exatas & 82 & 2,92 & 0,42 \\
& Ciências Humanas & 93 & 3,00 & 0,32 \\
& Engenharias & 27 & 2,92 & 0,35 \\
& Total & 307 & 2,95 & 0,39 \\
Autorregulação dos recursos & Ciências da Saúde & 119 & 3,10 & 0,39 \\
internos e contextuais & Ciências Exatas & 87 & 3,04 & 0,44 \\
& Ciências Humanas & 105 & 3,25 & 0,41 \\
& Engenharias & 28 & 3,33 & 0,36 \\
& Total & 339 & 3,15 & 0,42 \\
Autorregulação social & Ciências da Saúde & 121 & 2,90 & 0,58 \\
& Ciências Exatas & 92 & 2,89 & 0,50 \\
& Ciências Humanas & 105 & 2,79 & 0,53 \\
& Engenharias & 27 & 3,02 & 0,48
\end{tabular}


Observando-se a tabela 18, percebe-se que as médias mais altas se concentraram na estratégia autorregulação dos recursos internos e contextuais em que todas as médias foram superiores a 3,00. Nos dois outros fatores, apenas duas áreas apresentaram valores superiores a 3,00: Ciências Humanas na autorregulação cognitiva e metacognitiva e Engenharias, na estratégia autorregulação social. Considerando-se os três fatores, a maior média foi obtida pela área de Engenharias ( $\overline{\mathrm{X}}=3,33$ ) na estratégia autorregulação dos recursos internos e contextuais.

Com o objetivo de comparar as áreas de conhecimento quanto ao uso de estratégias foi realizada uma análise multifatorial de variância (ANOVA), cujos resultados são apresentados na tabela 19.

Tabela 19. Análise de variância referente ao uso de estratégias de aprendizagem em função da área de conhecimento

\begin{tabular}{llcc}
\hline \multicolumn{1}{c}{$\begin{array}{c}\text { Estratégias de Aprendizagem } \\
\text { (F1/F2/F3) }\end{array}$} & gl & Fstatística & Sig. \\
\hline $\begin{array}{l}\text { Autorregulação dos recursos internos e } \\
\text { contextuais }\end{array}$ & 3 & 6,31 & 0,000 \\
\hline
\end{tabular}

Os resultados da ANOVA indicam diferenças estatisticamente significantes entre as áreas apenas na estratégia autorregulação dos recursos internos e contextuais $(p=0,000)$.

Para identificar quais grupos apresentam diferenças significantes quanto ao uso das estratégias de aprendizagem, aplicou-se a análise estatística Tukey H.S.D. que compara as áreas duas a duas. Os resultados desta análise indicaram que, quanto à estratégia de autorregulação dos recursos internos e contextuais, o grupo Ciências Exatas $(\bar{x}=3,04)$ diferiu significantemente de Ciências Humanas $(\bar{x}=3,25)$ e Engenharias $(\bar{x}=3,33)$ no sentido de se utilizar menos desta estratégia.

Com base na análise realizada é possível se inferir que houve muito poucas diferenças estatisticamente significantes entre as áreas de conhecimento. De maneira geral, elas não diferem entre si. 


\subsubsection{Estratégias de aprendizagem: médias e desvios padrão em função dos}

cursos

As médias e os desvios padrão dos sujeitos são apresentados na Tabela 20.

Tabela 20. Estratégias de aprendizagem: médias e desvios padrão em função dos cursos

\begin{tabular}{|c|c|c|c|c|}
\hline $\begin{array}{l}\text { Estratégias de } \\
\text { Aprendizagem }\end{array}$ & Curso & Média & Desvio Padrão & $\mathbf{N}$ \\
\hline \multirow{11}{*}{$\begin{array}{l}\text { Autorregulação cognitiva } \\
\text { e metacognitiva }\end{array}$} & Educação Física & 2,87 & 0,456 & 30 \\
\hline & Enfermagem & 2,95 & 0,46 & 34 \\
\hline & Nutrição & 2,97 & 0,41 & 37 \\
\hline & Ciências da computação & 2,67 & 0,45 & 26 \\
\hline & Matemática & 3,20 & 0,38 & 21 \\
\hline & Ciências contábeis & 2,93 & 0,32 & 31 \\
\hline & Psicologia & 3,06 & 0,29 & 33 \\
\hline & História & 2,97 & 0,31 & 27 \\
\hline & Pedagogia & 2,97 & 0,35 & 30 \\
\hline & Engenharia Civil & 2,93 & 0,34 & 26 \\
\hline & Total & 2,95 & 0,39 & 295 \\
\hline
\end{tabular}




\begin{tabular}{|c|c|c|c|c|}
\hline $\begin{array}{l}\text { Estratégias de } \\
\text { Aprendizagem }\end{array}$ & Curso & Média & Desvio Padrão & $\mathbf{N}$ \\
\hline \multirow{11}{*}{$\begin{array}{l}\text { Autorregulação dos } \\
\text { recursos internos e } \\
\text { contextuais }\end{array}$} & Educação Física & 3,09 & 0,36 & 30 \\
\hline & Enfermagem & 3,14 & 0,42 & 34 \\
\hline & Nutrição & 3,07 & 0,41 & 37 \\
\hline & Ciências da computação & 2,85 & 0,40 & 26 \\
\hline & Matemática & 3,29 & 0,42 & 21 \\
\hline & Ciências contábeis & 3,04 & 0,42 & 31 \\
\hline & Psicologia & 3,24 & 0,44 & 33 \\
\hline & História & 3,29 & 0,33 & 27 \\
\hline & Pedagogia & 3,16 & 0,40 & 30 \\
\hline & Engenharia Civil & 3,34 & 0,35 & 26 \\
\hline & Total & 3,15 & 0,42 & 295 \\
\hline \multirow[t]{11}{*}{ Autorregulação social } & Educação Física & 2,97 & 0,516 & 30 \\
\hline & Enfermagem & 2,96 & 0,60 & 34 \\
\hline & Nutrição & 2,80 & 0,65 & 37 \\
\hline & Ciências da computação & 2,77 & 0,46 & 26 \\
\hline & Matemática & 3,02 & 0,54 & 21 \\
\hline & Ciências contábeis & 2,90 & 0,49 & 31 \\
\hline & Psicologia & 2,90 & 0,52 & 33 \\
\hline & História & 2,61 & 0,43 & 27 \\
\hline & Pedagogia & 2,76 & 0,57 & 30 \\
\hline & Engenharia Civil & 3,0288 & 0,49 & 26 \\
\hline & Total & 2,87 & 0,54 & 295 \\
\hline
\end{tabular}

A observação da Tabela 20 revela que, semelhantemente ao resultado da análise por áreas de conhecimento, as médias mais altas se concentraram na estratégia autorregulação dos recursos internos e contextuais em que todas as 
médias, com exceção da de Ciências da Computação, apresentaram valores superiores a 3,00. Nos dois outros fatores, apenas dois cursos apresentaram valores superiores a 3,00: Matemática e Psicologia na autorregulação cognitiva e metacognitiva, e Matematica e Engenharia Civil na estratégia autorregulação social.

A fim de identificar a existência de diferenças significantes entre os cursos quanto ao uso de estratégias foi realizada uma análise multifatorial de variância (ANOVA). Os resultados são apresentados na tabela 21.

Tabela 21. Análise de variância referente ao uso de estratégias de aprendizagem em função dos cursos

\begin{tabular}{lccc}
\hline \multicolumn{1}{c}{$\begin{array}{c}\text { Estratégias de Aprendizagem } \\
\text { (F1/F2/F3) }\end{array}$} & gl & Fstatística & Sig. \\
\hline Autorregulação cognitiva e metacognitiva & 9 & 3,13 & 0,001 \\
$\begin{array}{l}\text { Autorregulação dos recursos internos e } \\
\text { contextuais }\end{array}$ & 9 & 3,56 & 0,000 \\
Autorregulação social & 9 & 1,69 & 0,091 \\
\hline
\end{tabular}

Os resultados da ANOVA indicam diferenças estatisticamente significantes entre os cursos nas estratégias autorregulação cognitiva e metacognitiva $(p=0,001)$ e autorregulação dos recursos internos e contextuais $(p=0,000)$, mas não na estratégia autorregulação social $(p=0,091)$.

Com o objetivo de verificar quais grupos diferem estatisticamente quanto ao uso das estratégias de aprendizagem, os dados foram analisados por meio do Tukey H.S.D., que compara os cursos dois a dois. Os resultados desta análise indicaram que: a) no tocante à estratégia de autorregulação cognitiva e metacognitiva o grupo Ciência da Computação $(\overline{\mathrm{X}}=2,67)$ difere significantemente dos grupos Psicologia $(\overline{\mathrm{X}}$ $=3,06)$ e Matemática $(\bar{X}=3,20)$ no sentido de se utilizar menos desta estratégia; $b) 0$ grupo de Educação Física ( $\overline{\mathrm{x}}=2,87$ ), neste mesmo fator considerado, difere significantemente de Ciência da Computação $(\bar{x}=2,67)$ e de Matemática $(\bar{x}=3,20)$; c) no que se refere à autorregulação dos recursos internos e contextuais o grupo de Ciências da Computação $(\overline{\mathrm{X}}=2,85)$ difere significantemente dos cursos de Psicologia 
$(\bar{x}=3,24)$, História $(\bar{x}=3,29)$, Matemática $(\bar{x}=3,29)$ e Engenharia Civil $(\bar{x}=3,34)$, mais uma vez no sentido de usar menos a estratégia em consideração.

Como se pode inferir da análise realizada foram muito poucas as diferenças estatisticamente significantes entre os cursos. De maneira geral eles não diferem entre si.

\subsubsection{Estratégias de aprendizagem: comparações entre os gêneros}

As médias e os desvios padrão dos sujeitos divididos por sexo são apresentados na Tabela 22. A inspeção visual da tabela revela que nos três fatores, autorregulação cognitiva e metacognitiva, autorregulação dos recursos internos e contextuais e autorregulação social, as mulheres obtiveram médias superiores a 3,00, enquanto os homens não alcançaram esta média em nenhuma das estratégias.

Tabela 22. Estratégias de aprendizagem: médias e desvios padrão em função do sexo

\begin{tabular}{|c|c|c|c|c|}
\hline Estratégias de Aprendizagem & Gênero & $\mathbf{N}$ & Média & Desvio Padrão \\
\hline \multirow{2}{*}{$\begin{array}{l}\text { Autorregulação cognitiva e } \\
\text { metacognitiva }\end{array}$} & Masculino & 114 & 2,83 & 0,44 \\
\hline & Feminino & 192 & 3,02 & 0,34 \\
\hline \multirow{2}{*}{$\begin{array}{l}\text { Autorregulação dos recursos } \\
\text { internos e contextuais }\end{array}$} & Masculino & 124 & 3,13 & 0,45 \\
\hline & Feminino & 214 & 3,16 & 0,40 \\
\hline \multirow[t]{2}{*}{ Autorregulação social } & Masculino & 129 & 2,78 & 0,50 \\
\hline & Feminino & 215 & 2,92 & 0,55 \\
\hline
\end{tabular}

Com objetivo de verificar se as estratégias de aprendizagem diferem significantemente em função do gênero do participante, as diferenças de média entre os sexos foram analisadas pelo teste $t$. As comparações que se mostraram significantes são apresentadas na Tabela 23. 
Tabela 23. Resultado do test t para a comparação entre o uso de estratégias de aprendizagem e o gênero dos participantes

\section{Teste $\mathbf{t}$}

Estratégias de Aprendizagem

gl Sig. (bicaudal) Diferença média

\begin{tabular}{lllll}
\hline $\begin{array}{l}\text { Autorregulação cognitiva e } \\
\text { metacognitiva }\end{array}$ & $\begin{array}{l}\text { Não suposição de } \\
\text { igualdade das } \\
\text { variâncias }\end{array}$ & 190,351 & 0,000 & $-0,19$
\end{tabular}

$\begin{array}{lllll}\text { Autorregulação social } & \begin{array}{l}\text { Suposição de igualdade } \\ \text { das variâncias }\end{array} & 0,021 & -0,14\end{array}$

Os resultados obtidos através do teste $t$ (tabela 23) constataram relações significantes entre o gênero dos participantes e as estratégias de aprendizagem autorregulação cognitiva e metacognitiva e autorregulação social, indicando que, em comparação com seus colegas do sexo masculino, as estudantes empregam com maior frequência estas estratégias.

\subsection{INTERAÇÃO ENTRE ESTILOS E ESTRATÉGIAS DE APRENDIZAGEM}

Com o intuito de examinar uma possível relação entre os estilos e as estratégias utilizadas pelo aprendiz, foi utilizado o Teste $t$ para amostras independentes, por meio do qual se avaliou a significância das diferenças entre as médias dos participantes nos três tipos de estratégias de aprendizagem. Esta análise foi realizada para cada tipo de estilo: os sujeitos foram divididos em dois grupos, sendo o primeiro formado por aqueles pertencentes ao estilo investigado e o outro pelo par da mesma dimensão.

Todas as comparações entre os estilos de uma mesma dimensão foram realizadas, contudo apenas nas dimensões visual-verbal e ativo-reflexivo foram identificadas diferenças significantes quanto ao uso preferencial de estratégias de aprendizagem. Nas Tabelas 24 e 25 estes resultados podem ser visualizados. 
Tabela 24. Comparação entre o uso de estratégias de aprendizagem e os estilos visual-verbal

\begin{tabular}{|c|c|c|c|c|c|c|c|}
\hline \multirow{2}{*}{$\begin{array}{l}\text { Estratégias de } \\
\text { Aprendizagem }\end{array}$} & \multirow{2}{*}{$\begin{array}{l}\text { Estilos de } \\
\text { Aprendizagem }\end{array}$} & \multicolumn{3}{|c|}{ Estatística } & \multicolumn{3}{|c|}{ Teste $t$} \\
\hline & & $\mathbf{N}$ & Média & $\begin{array}{l}\text { Desvio } \\
\text { Padrão }\end{array}$ & gl & Sig. (bicaudal) & $\begin{array}{c}\text { Diferença } \\
\text { média }\end{array}$ \\
\hline $\begin{array}{l}\text { Autorregulação } \\
\text { cognitiva e }\end{array}$ & Visual & 207 & 2,92 & 0,40 & 219,48 & 0,025 & 0,10 \\
\hline metacognitiva & Verbal & 100 & 3,02 & 0,35 & 305 & 0,031 & 0,10 \\
\hline
\end{tabular}

Conforme visto na tabela anterior, os estilos visual e verbal diferem significantemente indicando que os estudantes considerados como de estilo verbal manifestam maior preferência pela estratégia de autorregulação cognitiva e metacognitiva do que os visuais.

Tabela 25. Comparação entre o uso de estratégias de aprendizagem e os estilos ativoreflexivo

\begin{tabular}{|c|c|c|c|c|c|c|c|}
\hline \multirow[t]{2}{*}{$\begin{array}{l}\text { Estratégias de } \\
\text { Aprendizagem }\end{array}$} & \multirow[t]{2}{*}{$\begin{array}{l}\text { Estilos de } \\
\text { Aprendizagem }\end{array}$} & \multicolumn{4}{|c|}{ Estatística } & \multicolumn{2}{|l|}{ Teste $t$} \\
\hline & & $\mathbf{N}$ & Média & $\begin{array}{l}\text { Desvio } \\
\text { Padrão }\end{array}$ & gl & $\begin{array}{c}\text { Sig. } \\
\text { (bicaudal) }\end{array}$ & $\begin{array}{c}\text { Diferença } \\
\text { média }\end{array}$ \\
\hline \multirow{3}{*}{$\begin{array}{l}\text { Autorregulação } \\
\text { Social }\end{array}$} & Ativo & 200 & 2,94 & 0,535 & 312,310 & 0,004 & $-0,16711$ \\
\hline & & & & & & & \\
\hline & Reflexivo & 145 & 2,77 & 0,53 & 343 & 0,004 & $-0,16711$ \\
\hline
\end{tabular}

$\mathrm{Na}$ dimensão ativo-reflexivo (Tabela 25), foram identificadas diferenças significantes entre os estilos ativo e reflexivo, indicando que os estudantes considerados ativos tendem a empregar com maior frequência a estratégia de autorregulação social do que estudantes reflexivos.

$\mathrm{Na}$ tabela 26 é possível visualizar a síntese de todo os resultados deste trabalho que apresentaram diferenças estatisticamente significantes.

Tabela 26. Síntese dos resultados que apresentaram diferenças estatisticamente significantes 


\begin{tabular}{|c|c|}
\hline Variáveis & Resultados significantes \\
\hline $\begin{array}{l}\text { Estilos de aprendizagem } \\
\text { predominantes na amostra total }\end{array}$ & sensorial, visual, ativo e sequencial \\
\hline $\begin{array}{l}\text { Estilos de aprendizagem } \\
\text { predominantes por área do } \\
\text { conhecimento }\end{array}$ & $\begin{array}{l}\text { Ciências da Saúde: sensorial, visual, ativo e sequencial } \\
\text { Ciências Exatas: sensorial, visual, ativo e sequencial } \\
\text { Ciências Humanas: sensorial e sequencial } \\
\text { Engenharias: sensorial e visual }\end{array}$ \\
\hline $\begin{array}{l}\text { Estilos de aprendizagem } \\
\text { predominantes por curso }\end{array}$ & $\begin{array}{l}\text { Educação Física: sensorial, visual, ativo e sequencial } \\
\text { Enfermagem: sequencial } \\
\text { Nutrição: sensorial } \\
\text { Ciências da computação: sensorial, visual } \\
\text { Matemática: sensorial } \\
\text { Ciências contábeis: sensorial, ativo e sequencial } \\
\text { Psicologia: reflexivo } \\
\text { História: sensorial } \\
\text { Pedagogia: sensorial e sequencial } \\
\text { Engenharia Civil: sensorial, visual }\end{array}$ \\
\hline $\begin{array}{l}\text { Estilos de aprendizagem de } \\
\text { acordo com o gênero }\end{array}$ & $\begin{array}{l}\text { As mulheres apresentaram maior tendência em serem } \\
\text { sensoriais, verbais, ativas, reflexivas e sequenciais }\end{array}$ \\
\hline $\begin{array}{l}\text { Estratégias de aprendizagem da } \\
\text { amostra total }\end{array}$ & $\begin{array}{l}\text { Utilizadas em uma ordem hieráquica preferencial: } \\
\text { 1. autorregulação dos recursos internos e contextuais; } \\
\text { 2. autorregulação cognitiva e metacognitiva; } \\
\text { 3. autorregulação social. }\end{array}$ \\
\hline $\begin{array}{l}\text { Estratégias de aprendizagem } \\
\text { predominantes por área de } \\
\text { conhecimento }\end{array}$ & $\begin{array}{l}\text { O grupo de Ciências Exatas utiliza menos a estratégia } \\
\text { autorregulação dos recursos internos e contextuais do que o } \\
\text { de Ciências Humanas. }\end{array}$ \\
\hline $\begin{array}{l}\text { Estratégias de aprendizagem } \\
\text { predominantes por curso }\end{array}$ & $\begin{array}{l}\text { Autorregulação cognitiva e metacognitiva: Ciências da } \\
\text { Computação utiliza com menor frequência que Psicologia e } \\
\text { Matemática; Educação Física utiliza menos que Ciências da } \\
\text { Computação e de Matemática. } \\
\text { Autorregulação dos recursos internos e contextuais: Ciências } \\
\text { da Computação utiliza menos do que Psicologia, História, } \\
\text { Matemática e Engenharia Civil. }\end{array}$ \\
\hline $\begin{array}{l}\text { Estratégias de aprendizagem de } \\
\text { acordo com o gênero }\end{array}$ & $\begin{array}{l}\text { As mulheres empregam com maior frequência as estratégias } \\
\text { de autorregulação cognitiva e metacognitiva e de } \\
\text { autorregulação social. }\end{array}$ \\
\hline $\begin{array}{l}\text { Interação entre estilos e } \\
\text { estratégias de aprendizagem }\end{array}$ & $\begin{array}{l}\text { Dimensão visual-verbal: aprendizes verbais possuem } \\
\text { maior preferência pela estratégia de autorregulação } \\
\text { cognitiva e metacognitiva do que os visuais. } \\
\text { Dimensão ativo-reflexivo: aprendizes ativos tendem a } \\
\text { empregar com maior frequência a estratégia de } \\
\text { autorregulação social do que os reflexivos. }\end{array}$ \\
\hline
\end{tabular}




\section{CAPÍTULO 4}

\section{DISCUSSÃO}

Este trabalho buscou investigar os estilos e estratégias de aprendizagem de universitários brasileiros com o objetivo de avaliar uma possível interação entre os dois constructos e também comparar o tipo de estilo e de estratégia de aprendizagem dos participantes da amostra em função da área de conhecimento, do curso e sexo dos participantes. Os resultados mostraram algumas relações significantes entre as variáveis.

Antes da discussão dos resultados, todavia, vale resgatar os conceitos de estilos e estratégias de aprendizagem. Coerente com o instrumento utilizado, esta pesquisa adota a definição proposta por Felder e Silverman (1988) que compreendem os estilos de aprendizagem como a maneira preferencialmente escolhida pelo estudante para lidar com as demandas da própria aprendizagem. Já estratégias de aprendizagem são definidas por técnicas e procedimentos utilizados pelo aprendiz com a intenção de armazenar e, posteriormente, utilizar a informação.

Em resumo, os resultados indicaram que, quanto aos estilos de aprendizagem, a amostra como um todo se revelou predominantemente sensorial, visual, ativa e sequencial. A área de conhecimento diferiu de acordo com os estilos dos estudantes, mas o curso pareceu não ter a mesma relação. O gênero exerceu influência significante nos estilos dos sujeitos, pois os resultados indicaram diferentes tendências entre os estudantes do sexo feminino e masculino.

No tocante às estratégias de aprendizagem, constatou-se que há uma ordem hierárquica no uso das mesmas: os universitários tenderam a utilizar preferencialmente as estratégias de autorregulação dos recursos internos e contextuais, seguidas pelas de autorregulação cognitiva e metacognitiva e, por último, às destinadas à autorregulação social. De maneira geral, as estratégias não diferem nem quanto à área de conhecimento e nem quanto ao curso dos sujeitos investigados. Contudo, quanto ao gênero, os resultados indicaram que homens e mulheres fazem diferente uso das estratégias durante o processo de aprendizagem. 
A discussão destes resultados se dará na mesma ordem de apresentação do capítulo anterior, ou seja, primeiramente serão considerados os dados da análise descritiva e, em seguida, os da inferencial, divididos em tópicos referentes aos estilos, estratégias e à interação entre eles.

\subsection{ESTILOS DE APRENDIZAGEM}

Em função dos resultados, o instrumento utilizado no levantamento dos estilos, o Índice de Estilos de Aprendizagem de Felder-Soloman (ILS - Index of Learning Styles), mostrou-se bastante eficaz na discriminação dos estilos, uma vez que, em todas as comparações realizadas na amostra como um todo foi possível identificar diferenças significantes entre eles e, também, em três quartos das comparações realizadas em função da área de conhecimento dos participantes.

Considerando o perfil dominante, os resultados revelaram que a amostra como um todo tende a ser sensorial, visual, ativa e sequencial. Estes resultados confirmam os encontrados em outros estudos realizados com estudantes universitários brasileiros (KURI, 2004; BELHOT, 2005; PEREIRA, 2005; ROSÁRIO, 2006; DINIZ, 2007; FREITAS, 2007; TREVELIN, 2007; KALATZIZ, 2008; LINDEMAN, 2008; PERNOMIAN, 2008; PIMENTEL, 2009; SANTOS; MOGNON, 2010) e também com universitários estrangeiros (HUGHES ET. AL., 2009; NEEL; GRINDEM, 2010; PRAJAPATI ET. AL, 2011). Isso indica que os universitários demonstram predileção por determinada forma de perceber, reter, processar e compreender a informação durante o processo de aprendizagem.

Quanto à percepção, os universitários tendem a ser sensoriais, apegando-se preferencialmente a fatos e dados, elegendo a praticidade para a resolução de problemas. No tocante à retenção do conteúdo a ser aprendido, declararam utilizar o canal visual com maior frequencia, preferindo os estímulos que incidem de maneira imagética. Já quanto ao processamento demonstraram preferência pela extroversão e dinamismo no trato com a informação, evitando situações passivas e procurando aquelas que privilegiem experimentações. Por último, no que se refere à organização do pensamento para a 
compreensão da informação, os universitários preferem aprender por meio de uma sequência lógica de etapas, ao invés de ter uma visão geral sobre o conteúdo.

Em resumo, os estilos dominantes da amostra parecem indicar a preferência dos estudantes universitários pelas formas menos trabalhosas de se lidar com a informação a ser aprendida. Em termos de desenvolvimento cognitivo este dado está de acordo com os ensinamentos de alguns dos grandes teóricos do desenvolvimento humano, tais como Piaget, Vigotsky, Bruner etc que pressupõem o conhecimento como um processo que parte das estruturas sensoriais básicas, ligadas a situações e estímulos concretos, e evolui em direção à capacidade de abstração/formalização que exige um progressivo desligamento do concreto, do aqui e do agora, por parte do aprendiz. Neste sentido, os estilos sensorial, visual, ativo e sequencial parecem exigir menor desafio cognitivo de reflexão e abstração. Para Willingham (2011) é natural a tendência humana de evitar atividades mentais que requeiram maior esforço.

Vale ressaltar, todavia, que, ainda que Felder $(1998,1996)$ não tenha valorizado mais um estilo em detrimento dos outros, uma vez que, segundo o autor, todos eles apresentam pontos fortes e pontos fracos, o autor afirma que os estudantes só desenvolverão a destreza mental de que necessitam se forem instruídos a exercitar todos os tipos de estilos e não só aqueles pelos quais possuem prefência.

Outra possível justificativa para a frequente predileção dos universitários brasileiros pelos estilos sensorial, visual, ativo e sequencial seriam os fatores culturais. $\mathrm{O}$ trabalho de Zhang e Lambert (2008) com estudantes chineses aponta para diferenças do perfil dominante destes em relação ao encontrado em estudantes ocidentais. Os orientais preferem os estilos reflexivo e global em detrimento do ativo e sequencial preferidos pelos ocidentais. É possível que a valorização da reflexão e introspecção, como também o pensamento direcionado, em primeiro lugar, para o coletivo em detrimento do individual, sejam características tão arraigadas ao modo de vida de sociedades orientais coletivistas, que transpareçam também na forma preferencial de aprender de seus estudantes. Assim sendo, o mesmo princípio se aplicaria aos estudantes brasileiros. A preferência por uma maneira ativa e sequencial de aprender pode ser o reflexo de uma sociedade ocidental individualista, na qual a prática e a ação são constantemente mais exaltadas do que a tranquilidade da reflexão. E o incentivo ao sucesso individual, promove uma tendência de 
partir sempre do que é particular. Esta suposição pode ser endossada por téoricos dos estilos de aprendizagem, como Kolb e Dunn, que acreditam ser os estilos formados por elementos ambientais, emocionais, sociológicos, fisiológicos e psicológicos. (DUNN; DEBELLO, 1999; KOLB; KOLB, 2005)

Com relação às quatro áreas de conhecimento investigadas: Ciências da Saúde, Ciências Exatas, Ciências Humanas e Engenharias, os resultados apontaram relação significante com os estilos de aprendizagem. Assim sendo, é possível afirmar que os estilos diferem de acordo com a área de conhecimento dos universitários.

No que se refere à dimensão sensorial-intuitivo, em todas as quatro áreas houve predomínio do estilo sensorial sobre o intuitivo. Quanto à dimensão visual-verbal, com exceção de Ciências Humanas que não apresentou diferença significante, as demais áreas demonstraram preferência pelo estilo visual. Já para a dimensão ativo-reflexivo, duas das áreas demonstraram diferença significante quanto à predominância do estilo ativo sobre o reflexivo: Ciências da Saúde e Ciências Exatas. Por fim, na dimensão sequencial-global, o estilo sequencial foi dominante em três áreas, com exceção apenas de Engenharias. Não foi possível comparar estes resultados com os de outros estudos que se utilizaram do ILS, pois dentre os encontrados não houve nenhum que analisou a amostra por área de conhecimento, apenas por curso.

Em face de tais resultados é legítimo perguntar: seria o estilo de aprendizagem influenciado pela escolha profissional do sujeito ou seriam os indíviduos portadores de determinados estilos de aprendizagem que escolheriam determinados cursos ou áreas de conhecimento? De acordo com Curry (1991) que, com base em 14 teóricos de estilos de aprendizagem, sintetizou os principais elementos na formação destes, a saber: preferências por condições do ambiente, preferências por condições sociais, nível de compromisso com a tarefa e as preferências no processamento cognitivo da informação, o estudante constrói suas preferências e compromisso com as tarefas de aprendizagem ao longo de sua carreira estudantil. Sendo assim os estilos iniciariam sua formação a partir do momento em que o aprendiz começa a aprender, bem antes do início do curso profissional. Cerqueira (2000) endossa esta suposição ao declarar a possibilidade de que fatores sociais e culturais atuem na formação do estilo de aprendizagem do universitário antes que ingressem no ensino superior. No entanto, os resultados de Kuri (2004) em pesquisa realizada com estudantes de 
Engenharia apontam para diferença nos estilos dos alunos iniciantes em comparação aos dos concluíntes do curso, levando à crença de que os estilos de aprendizagem dos estudantes tendem a se modificar para atender às exigências do curso escolhido.Com base nestes pressupostos, é possível extrair duas suposições: a) a de que os estilos de aprendizagem se formam antes ou mesmo concomitante ao processo de escolha profissional. De acordo com Levenfus e Soares (2010), a escolha profissional também é consequência de fatores psicológicos, sociais e culturais. Assim sendo, ambos, estilo e escolha profissional podem influenciar-se mutuamente; b) a de que os estilos são passíveis de mudança; logo, adaptamse à natureza do curso escolhido em prol da aprendizagem.

Quanto às comparações realizadas entre os estilos e os cursos realizados pelos sujeitos, foram encontradas poucas diferenças significantes. Parece que, à medida que ocorre uma maior especificação e redução da amostra, também diminuem as diferenças em função destas duas variáveis. Assim como esta, a pesquisa de Santos e Mognom (2010) realizada em vários cursos superiores também não encontrou diferenças significantes em todas as dimensões e cursos, quando a amostra foi reduzida. Em função do curso, estas pesquisadoras localizaram diferenças somente na dimensão ativo-reflexivo e visual-verbal.

O presente estudo verificou na dimensão sensorial-intuitivo, com exceção do curso de Enfermagem e Psicologia, que os demais cursos investigados (Educação Física, Nutrição, Ciências da Computação, Matemática, Ciências Contábeis, História, Pedagogia e Engenharia Civil) apresentam diferença significante na escolha entre o estilo sensorial e o intuitivo: nestes cursos predomina o estilo sensorial. Na dimensão visual-verbal há predileção comprovada pelo estilo visual nos cursos de Educação Física, Ciências da Computação e Engenharia Civil. Quanto à dimensão ativo-reflexivo, Educação Física e Ciências Contábeis preferem o estilo ativo, ao contrário de Psicologia, cujo estilo dominante é o reflexivo. Já na dimensão sequencial-global, Educação Física, Enfermagem, Ciências Contábeis e Pedagogia foram os únicos cursos que apresentaram diferença significante entre os estilos, sendo o sequencial o dominante. De forma geral, estes resultados confirmam os de outras pesquisas que também relacionaram os estilos de aprendizagem aos cursos dos participantes (KURI, 2004; BELHOT, 2005; PEREIRA, 2005; ROSÁRIO, 2006; DINIZ, 2007; FREITAS, 2007; TREVELIN, 2007; KALATZIZ, 2008; PERNOMIAN, 2008; PIMENTEL, 2009; SANTOS; MOGNON, 2010). 
Faz-se necessário explicar que este trabalho não se propõe a realizar considerações exaustivas sobre as peculiaridades de cada curso investigado e suas possíveis influências nos estilos preferencialmente escolhidos por cada um deles, visto o conhecimento limitado da autora sobre o contexto de ensino e aprendizagem de cursos distintos à sua área de especialização. Assim, a discussão ficará mais restrita aos cursos de Psicologia e Pedagogia.

Os estudantes de Pedagogia são predominantemente sensoriais e sequenciais, preferem perceber a informação de maneira prática, concreta e metódica. Apreciam fatos, dados e experimentações. Importam-se com os detalhes. Quanto à compreensão do conteúdo, privilegiam a organização sequencial do pensamento. Compreendem melhor se a informação for exposta em uma progressão contínua de complexidade e dificuldade. Esse resultado talvez seja decorrente das exigências feitas e das atividades de ensino propostas ao estudante desta graduação. Esta pesquisa foi realizada com estudantes do 4ㅇ․ Semestre, portanto já bastante conhecedores do perfil do curso e adaptados às atividades requeridas por este. De acordo com as diretrizes do Conselho Nacional de Educação para a formação do professor de educação básica (BRASIL, 2001), características de intenso relacionamento humano e experimentações diversas são inerentes à atividade docente. É exigida do professor das séries iniciais capacidade de elaborar e desenvolver atividades e projetos voltados a diversos fins: enriquecimento cultural, repeito à diversidade e cumprimento do currículo escolar. Consequentemente, o curso de Pedagogia privilegia situações de aprendizagem e estágios em que as competências exigidas dos futuros educadores sejam promovidas. E parece que as atividades exigidas pelo curso requerem características bem semelhantes àquelas próprias aos estilos sensorial e sequencial. Para a elaboração e execução de projetos, voltados ao ensino de crianças, se faz necessário: atenção aos detalhes, gosto por experimentações, capacidade de apresentar o conteúdo de maneira concreta e em etapas, partindo do mais simples para o complexo. É possível que o exercício das atividades propostas no curso de Pedagogia para construir a futura prática de ensino destes futuros educadores tenham também influenciado sua maneira preferencial de lidar com a própria aprendizagem.

Os estudantes do curso de Psicologia têm preferência pelo estilo reflexivo, diferindo do estilo ativo dominante na amostra geral. Não foi encontrado nenhum outro estudo que tenha se utilizado do ILS para pesquisar os estilos de aprendizagem de estudantes de 
Psicologia. Contudo, acredita-se que, a distinção deste curso em relação aos demais se deva à natureza do curso. Mesmo que não seja possível responder com absoluta certeza se os estilos influenciam a escolha pelo curso ou vice-versa, as duas suposições serviriam para justificar esta preferência, já que parece óbvio que futuros psicólogos caracterizem-se como aprendizes reflexivos, ou seja, tenham preferência por processar a informação de forma reflexiva, levantando alternativas e hipóteses, considerando que estas habilidades são exigidas durante o curso e também no exercício da profissão.

No tocante ao gênero, os resultados da amostra como um todo apontam para relação significante entre os estilos de aprendizagem e o gênero do estudante. Observandose a amostra dividida por gênero (ver tabela 14), não há diferença quanto aos estilos preferenciais. Ambos os sexos coincidem quanto ao perfil dominante: sensorial, visual, ativo e sequencial, resultado idêntico ao encontrado por Diniz (2007) e Lindeman (2008). Todavia, quando se realiza comparações entre os sexos (ver tabela 15), verifica-se diferenças significantes, pois, em comparação aos homens, as mulheres possuem maior tendência a serem sensoriais, verbais, ativas, reflexivas e sequenciais. Esses resultados são convergentes com os encontrados por outros pesquisadores: Rosário (2006), que também aponta o sexo feminino como o mais proeminente no estilo verbal; Diniz (2007) e Dee et. al. (2011), que verificaram maior tendência nas mulheres em serem ativas e sensoriais, e Prajapati et. al (2011), que indicou maior preferência do gênero feminino pelo estilo reflexivo do que o masculino. 


\subsection{ESTRATÉGIAS DE APRENDIZAGEM}

Utilizou-se neste estudo a classificação de estratégias feita pelas autoras do intrumento de coleta, Santos e Boruchovitch: autorregulação cognitiva e metacognitiva; autorregulação dos recursos internos e contextuais e autorregulação social. A autorregulação cognitiva e metacognitiva se subdivide em dois tipos de estratégias: as cognitivas, relacionadas às técnicas destinadas a organizar, elaborar e integrar a informação; e as metacognitivas referentes ao controle da própria motivação e compreensão. Já a autorregulação dos recursos internos e contextuais engloba as estratégias orientadas ao controle dos sentimentos e das variáveis relacionadas ao contexto da aprendizagem. Por fim, as estratégias de autorregulação social referem-se aos procedimentos que envolvem a interação social em prol da aprendizagem (SANTOS, informação pessoal ${ }^{16}$ ). Ressalta-se, todavia, que as estratégias de autorregulação dos recursos internos e contextuais são consideradas pela literatura também como estratégias metacognitivas, já que por metacognição compreende-se a capacidade do aprendiz de tomar consciência do próprio conhecimento, refletir sobre ele e os fatores que o influenciam. (BORUCHOVITCH, 1999, 2007; POZO, 2002, 2004; RIBEIRO, 2003).

$\mathrm{O}$ intrumento utilizado, Escala de Avaliação de Estratégias de Aprendizagem em Universitários (EAP-U) mostrou-se eficaz para discriminar a frequência no uso dos três tipos de estratégias pela amostra total. De acordo com os resultados desta pesquisa, os participantes tendem a impor uma ordem preferencial no uso das estratégias de aprendizagem, sendo que as mais utilizadas são as de autorregulação dos recursos internos e contextuais, seguidas pelas de autorregulação cognitiva e metacognitiva, e por último, utilizadas com menor frequência, as voltadas à autorregulação social. Ou seja, os participantes preocupam-se com maior frequência em controlar a ansiedade, em planejar 0 próprio tempo e o ambiente de estudo, de forma a atender as demandas da aprendizagem. Em segundo lugar, preferem empregar as estratégias voltadas à informação em si: ler, reler, anotar, resumir, criar questionários etc.; e também aquelas voltadas a se automotivar para os estudos e monitorar a própria

\footnotetext{
${ }^{16}$ SANTOS, A.A.A. Explicação dos fatores da EAP-U. Mensagem recebida por lislie.silva@usp.br em 19 out. 2011.
} 
compreensão sobre o conteúdo, como parar a leitura para verificar se realmente está compreendendo. As ações menos frequentes são as que promovem a relação com o outro objetivando o próprio aprendizado, como por exemplo, o estudo em grupo.

Estes resultados são contrários aos encontrados por Silva (2006), Galvão (2007) e Muneiro (2008) que apontam as estratégias cognitivas como as mais frequentemente utilizadas pelos estudantes universitários. E, também, diverge dos encontrados por Pereira (2007) que indicou grande dificuldade dos estudantes em organizar o tempo para o estudo individual. É neste aspecto que os resultados da presente pesquisa surpreendem, não por apontar a utilização de estratégias consideradas mais complexas, pois isto outros estudos também o fizeram (PEREIRA, 2007; DEMOLINER, 2008), mas pela frequência da utilização destas estratégias, já que aponta a autorregulação dos recursos internos e contextuais como a mais utilizada pelos universitários.

A literatura indica que este tipo de estratégia exige metacognição por parte do aprendiz, tarefa mais complexa do que a cognitiva, considerando a necessidade de reflexão sobre o próprio conhecimento (WEINSTEIN; MAYER, 1985; DEMBO, 1991). Segundo Boruchovitch (2007, p.50), é a metacognição ... que permite às pessoas o planejamento, monitoramento e controle das atividades cognitivas. Estudos como de Viana Junior (2006), Sossai (2009) e Magalhães (2009), apontam para a falta de metacognição nos estudantes universitários e para a necessidade de programas de intervenção para o ensino da metacognição. O fato dos participantes desta pesquisa utilizarem com maior frequência uma estratégia mais complexa, ao contrário dos participantes de outros estudos, pode indicar a influência de um programa de ensino de estratégias de aprendizagem desenvolvido pela IES investigada. Como é de conhecimento da pesquisadora, a referida instituição, através do PROAD, Programa de Apoio ao Discente, desenvolve um projeto de hábitos de estudos para seus universitários, constituído de palestras, oficinas e intervenções individuais para o uso das estratégias de aprendizagem. Contudo, considerando que a pontuação máxima de 4 pontos na EAP-U indica que o estudante usa sempre aquele tipo de estratégia e que 3 pontos indica às vezes, 2 pontos raramente e 1 ponto nunca, as médias obtidas pela amostra geral: $\bar{x}=2,95$ para autorregulação cognitiva e metacognitiva, $\overline{\mathrm{x}}=3,15$ para a autorregulação dos recursos internos e contextuais e $\overline{\mathrm{x}}=2,87$ para autorregulação, indicam ainda necessidade de continuidade e investimento no ensino para aquisição de melhor prática de estratégias por parte dos universitários. 
Quanto às comparações realizadas entre as estratégias de aprendizagem e as áreas de conhecimentos dos participantes, houve apenas uma diferença estatisticamente significante. O grupo de Ciências Exatas mostrou utilizar menos a estratégia autorregulação dos recursos internos e contextuais do que o de Ciências Humanas. Estes resultados endossam os de Bartalo (2006) que também encontrou distinção no uso de estratégias por parte de alunos de Ciências Exatas, sendo que estes utilizaram menos estratégias voltadas à organização do tempo do que os de Ciências Humanas.

Resultado semelhante às comparações por área foi encontrado nas comparações em função do curso. Houve poucas diferenças significantes. Quanto à estratégia autorregulação cognitiva e metacognitiva, os estudantes de Ciências da Computação a utilizam com menor frequência que os de Psicologia e Matemática, já os de Educação Física utilizam menos estas estratégias do que os alunos de Ciências da Computação e de Matemática. No tocante à autorregulação dos recursos internos e contextuais o grupo de Ciências da Computação utiliza menos frequentemente estas estratégias do que os cursos de Psicologia, História, Matemática e Engenharia Civil.

De forma geral, os resultados parecem indicar que o uso de estratégias não está relacionado à natureza da área de conhecimento ou do curso do estudante. $\mathrm{A}$ influência maior parece estar relacionada ao conhecimento que o estudante possui sobre as estratégias de aprendizagem. Estudos realizados indicam que os universitários fazem pouco uso das estratégias por desconhecer a importância destas e a maneira adequada de aplicá-las (ANDRADE, 2007; LOPES, 2007; RABELLO, 2007; SILVA, 2008B). Outras pesquisas, de caráter interventivo, endossam esta suposição ao comprovarem que um programa elaborado para o ensino de estratégias mostrou-se eficaz para aumentar o repertório e a prática de estratégias de aprendizagem por parte de alunos do ensino superior (FONSECA, 2006; GAIGNOUX, 2006; CARVALHO, 2007; VILAÇA, 2009; MAGALHÃES, 2009; TAKEUCHI, 2009; ALVES, 2010).

No que se refere ao gênero e o uso de estratégias de aprendizagem, os resultados indicaram que homens e mulheres apresentam diferenças estatisticamente significantes em seu uso de estratégias. Em comparação aos homens, as mulheres empregam com maior frequência tanto as estratégias de autorregulação cognitiva e metacognitiva quanto de autorregulação social. Estes 
resultados corroboram os encontrados por Bartalo (2006) que verificou serem as estudantes aquelas que mais frequentemente utilizam as estratégias metacognitivas para a manutenção da motivação.

Este dado parece refletir a realidade encontrada nos ambientes educacionais. Comumente as estudantes são mais automotivadas para os estudos e demonstram possuir maior empenho em realizar as tarefas de aprendizagem. Indício disso é que as mulheres conseguem frequentar a escola por mais tempo, atingindo maior nível de escolarização do que os homens. De acordo com a Síntese de Indicadores Sociais, divulgada em 2010 pelo Instituto Brasileiro de Geografia e Estatística (IBGE), da população entre 18 e 24 anos e com 11 anos de escolaridade, 40,6\% são mulheres e 35,2 são homens.

\subsection{INTERAÇÃO ENTRE ESTILOS E ESTRATÉGIAS DE APRENDIZAGEM}

O principal objetivo deste trabalho foi o de investigar se a diferentes estilos de aprendizagem corresponderiam escolhas preferenciais quanto ao uso de estratégias. A suposição sobre a interação entre estes constructos adveio das ideias de autores como Schmeck (1988), Entwistle (1988) e Berings et. al (2005) que definem os estilos como uma propensão para se utilizar determinada estratégia com o intuito de aprender. Outro endosso para a interação entre estilos e estratégias veio dos resultados de duas pesquisas (AGUADO; FALCHETI, 2009; HALBERT et. al., 2011) que apontaram correlação entre os estilos de universitários e as estratégias utilizadas por estes para aprender.

Os resultados desta pesquisa apontaram para diferenças estatisticamente significantes em duas das quatro dimensões dos estilos de aprendizagem. Contudo, apesar das diferenças encontradas, os resultados não são suficientemente robustos para que se possa postular, com base neste estudo, uma efetiva relação entre estilos e estratégias de aprendizagem.

$\mathrm{Na}$ dimensão referente à recepção da informação, os aprendizes verbais preferem utilizar mais as estratégias de autorregulação cognitiva e metacognitiva do que os aprendizes visuais. Esse resultado parece indicar coerência entre essas duas características do aprendiz verbal, pois quanto ao estilo apresentam predileção pelo 
trato com a palavra, escrita ou falada, e quanto às estratégias utilizam com maior frequência as estratégias cognitivas, ou seja, justamente aquelas destinadas maiormente à palavra: anotações, leitura e releitura de texto, mapas conceituais etc. Felder (1988; 1996) também ressalta a preferência dos aprendizes verbais pelas anotações.

Outra diferença significante foi encontrada na dimensão ativo-reflexivo: o aprendiz ativo tende a empregar com maior frequência a estratégia de autorregulação social do que estudantes reflexivos. Novamente o resultado parece indicar coerência entre as características do aprendiz ativo e a natureza da estratégia de autorregulação social, já que, segundo Felder (1988; 1996), o aprendiz ativo demonstra uma forma extrovertida de processar a informação, apresentando predileção para atividades que privilegiem as interações sociais, que são justamente o foco principal das estratégias de autorregulação social.

A falta de maiores evidências da interação entre estilos e estratégias de aprendizagem talvez se deva à incompatibilidade entre os modelos de estilos e estratégias escolhidos para esta pesquisa. As pesquisas que encontraram relação significante entre estilo e estratégia de aprendizagem utilizaram outros instrumentos de coleta de dados e outras formas de comparação. Aguado e Falcheti (2009) aplicaram o CHAEA - Cuestionario Honey-Alonso de Estilos de Aprendizaje, que avalia o modelo proposto por Honey-Alonso formado pelos estilos: ativo, reflexivo, teórico e pragmático. Já para avaliar as estratégias de aprendizagem utilizaram o CEPEA - Cuestionario de Evaluación de Procesos, construído com base no modelo de estratégias proposto por J. Biggs, que classifica as estratégias de acordo com a sua função na abordagem da aprendizagem: superficial, profunda e de alto rendimento. Dessa forma conseguiram comprovar que determinados estilos possuem uma propensão a abordar a aprendizagem de maneira superficial, profunda ou de alto rendimento. Por sua vez, Halbert et. al. (2011) compararam os resultados do ILS com o desempenho estratégico dos sujeitos em situação específica de aprendizagem e não com os dados de outro instrumento psicométrico destinado a avaliar suas estratégias.

Como pode ser percebido, os estudos que obtiveram sucesso em correlacionar estilos e estratégias foram realizadas em condições diferentes das da presente pesquisa. Aguado e Falcheti (2009) utilizaram um modelo mais simples de denominar as estratégias do que o aqui adotado, já que Biggs apresenta apenas três funções para as estratégias. Santos e 
Boruchovitch (SANTOS, informação pessoal ${ }^{17}$ ) classificam as estratégias de aprendizagem em fatores mais complexos, compostos por estratégias de várias funções distintas. Por exemplo, só na categoria autorregulação cognitiva e metacognitiva são compreendidas estratégias com a função de organizar, elaborar e integrar a informação além das destinadas ao controle da própria motivação e compreensão. É possível que uma diversidade tão grande de estratégias em uma mesma categoria tenha dificultado a correlação com o modelo de estilos de Felder-Silverman (1988), que por sua vez, propõe a existência de oito estilos distintos, número considerado alto, já que outros importantes modelos como de Kolb, Dunn-Dunn e Honey-Alonso apresentam no máximo cinco opções de estilos (DEBELLO, 1990; GARCIA, 2008).

Em suma, este trabalho buscou contribuir para uma melhor compreensão dos estilos e estratégias de aprendizagem dos estudantes universitários. De acordo com os resultados e discussões, é possível concluir que estes dois constructos não apresentam alta correlação entre si. Contudo, as comparações realizadas, considerando cada um separadamente, indicaram diferenças significantes quanto às variáveis área de conhecimento, curso e gênero do participante.

Tendo em vista o caráter exploratório deste estudo, faz-se necessário salientar as limitações desta pesquisa e sugerir novos estudos aos interessados no mesmo tema.

A primeira limitação encontrada foi quanto ao tamanho da amostra. Apesar de seu tamanho poder ser considerado como aceitável, se contado o número total de 352 participantes, quando reduzida por grupos específicos, como área de conhecimento e curso, o número total por subgrupos mostrou-se bastante reduzido em muitos dos casos. Como, por exemplo, o curso de Matemática que tinha apenas 26 sujeitos. Esta redução pode ter dificultado à análise estatística a captação de outras prováveis diferenças significantes. Sugere-se a futuros estudos que trabalhem com uma amostra maior ou com maior número de sujeitos em cada curso.

A segunda limitação se refere à circunscrição da amostra, já que o estudo foi realizado tão somente em uma instituição de ensino superior, particular e

\footnotetext{
${ }^{17}$ SANTOS, A.A.A. Explicação dos fatores da EAP-U. Mensagem recebida por lislie.silva@usp.br em 19 out. 2011.
} 
confessional, da região sudeste do país. Esta especificidade da amostra pode impedir generalizações mais amplas. É sugerido, portanto, que futuras pesquisas sejam realizadas com diferentes instituições, públicas e privadas, de diferentes regiões brasileiras para que achados sobre estilos e estratégias dos universitários possam ser generalizados com maior segurança.

Não obstante estas limitações reconhecidas, acredita-se que os resultados encontrados serão úteis para os interessados no processo de aprendizagem de estudantes do ensino superior.

Salienta-se que os resultados encontrados quanto aos estilos de aprendizagem, indicando a preferência pelos estilos sensorial, visual, ativo e sequencial, poderão auxiliar ao professor a conhecer melhor as inclinações de seus estudantes. Contudo, o conhecimento sobre os estilos preferenciais de aprendizagem não deve objetivar rótulos e limitações, mas promover diversidade na proposta de ensino. O professor obterá maior êxito no ensino se promover atividades que exijam as capacidades dos diferentes tipos de estilos, pois dessa forma atingirá a todos os estilos e também fará com que os estudantes lidem com as situações de aprendizagem de forma diferente daquela usada preferencialmente por ele, desenvolvendo assim maiores habilidades intelectuais.

No tocante às estratégias de aprendizagem, os resultados indicam que os estudantes universitários não fazem um bom uso de estratégias de aprendizagem. Possivelmente por falta de conhecimento e incentivo para o uso delas em prol de sua aprendizagem. Há uma urgente necessidade de que programas de ensino para o uso de estratégias de aprendizagem sejam inseridos no currículo, ou incorporados ao ensino do professor concomitante ao conteúdo da disciplina, ou mesmo de forma extracurricular promovidos pela própria IES.

Por fim, o conhecimento sobre estilos e estratégias de aprendizagem poderá auxiliar também o próprio estudante a refletir sobre sua forma individual de aprender e a incorporar à sua prática maneiras e procedimentos que tornem sua aprendizagem mais eficaz. 


\section{REFERÊNCIAS}

AGUADO, M. L.; FALCHETTI, E. S. Estilos de aprendizaje. Relacion com motivación e estratégias. Revista Estilos de Aprendizaje, Espanha, v. 4, n.4, p.36-55, 2009.

ALLEN, E.; MOURTOS, N. Using learning styles preferences data to inform classroom teaching and assessment activities. In.: $30^{\text {th }}$ ASEE/IEEE Frontiers in Education Conference, 2000, Kansas City. Proceedings... Kansas City:IEEE Frontiers in Education Conference, 2000. p.1821.

ALONSO, C. Estilos de aprendizaje. Presente y futuro. Revista Estilos de Aprendizaje, Espanha, v. 1, n.1, p.4-15, 2008.

ALVES, S. M. L. Estratégias de compreensão leitora e de produção de resumo do gênero científico: aspectos textuais e cognitivos. Porto Alegre. Tese (Doutorado). Pontifícia Universidade Católica do Rio Grande do Sul. 2010.

AMARAL, M. A. Modelo RHA - Retroalimentação em Hipermídia Adaptativa. Florianópolis. 189f. Tese (Doutorado). Programa de Pós-Graduação em Engenharia e Gestão do Conhecimento.Universidade Federal de Santa Catarina. 2008.

ANDRADE, J. D. Estratégias de aprendizagem dos alunos dos cursos de especialização do Instituto Nacional de Câncer - INCA. Rio de janeiro. 187f. Dissertação (mestrado). Núcleo de Tecnologia Educacional para a Saúde. Universidade Federal do Rio de Janeiro. 2007.

BAKER, A; JENSEN, P; KOLB, D. Conversation as experiential learning. Management Learning, London, v. 36, n.4, p. 411-427, 2005.

BANDURA, A. Self-Efficacy: the exercise of control. 8.ed. New York: W.H.Freeman and Company, 1997.

BANDURA, A.; AZZI, R.; POLYDORO, S. et al. Teoria Social Cognitiva. 1 ed. São Paulo: Artmed, 2008.

BARTALO, L. Mensuração de estratégias de estudo e aprendizagem de alunos universitários: Learning and Study Strategies Inventory (LASSI) adaptação e validação para o Brasil. Marília. 213f. Tese (doutorado) Programa de Pós-Graduação em Educação. Universidade Estadual Paulista "Julio de Mesquita Filho". 2006.

BELHOT, R.V.; FREITAS, A.A.; DORNELLAS, D.V. Requisitos profissionais do estudante de engenharia de produção: uma visão através dos estilos de aprendizagem. In: Simpósio de Engenharia de Produção, 7., 2005, Bauru-SP. Anais... Bauru: SIMPEEP, 2005. Disponível em: <http://www.simpep.feb.unesp.br/anais_simpep_aux.php?e=12>. Acesso em: 07 de novembro de 2011.

BENCKE, D. B. Estratégias de compreensão leitora em português brasileiro e em inglês como segunda língua: um estudo comparativo sobre transferência lingüística no âmbito da 
metacognição. Santa Cruz do Sul. 212f. Dissertação (mestrado). Programa de Pós-Graduação em Letras. Universidade de Santa Cruz do Sul. 2008.

BERINGS, M. G. M. C.; POELL, R. F.; SIMONS, P. R. Conceptualizing on-the-job learning styles. Human Resource Development Review, v. 4, p.373-400, 2005.

BISQUERRA, R.; SARRIERA, J.C.; MARTÍNEZ, F. Introdução à estatística. São Paulo: Artmed, 2004.

BORUCHOVITCH, E. A identificação e o estudo das variáveis associadas ao fracasso escolar brasileiro. Projeto de pesquisa realizado na qualidade de bolsista de recém doutor da CNPQ. Faculdade de Educação, Departamento de Psicologia Educacional, UNICAMP.1995.

BORUCHOVITCH, E. Estratégias de aprendizagem e desempenho escolar: considerações para a prática educacional. Psicologia: Reflexão e Crítica. Porto Alegre. v. 12, n.2., p. 361376, 1999.

BORUCHOVITCH, E.; SANTOS, A. Estratégias de aprendizagem: conceituação e avaliação. In: NORONHA, A.; SANTOS, A.; SISTO, F. (orgs.). Facetas do fazer em avaliação psicológica. São Paulo: Vetor, p.108-123, 2006.

BORUCHOVITCH, E. Dificuldades de aprendizagem, problemas motivacionais e estratégias de aprendizagem. In: SISTO, F.; BORUCHOVITCH, E; FINI, L.; BRENELLI, R.; MARTINELLI, S. Dificuldades de aprendizagem no contexto psicopedagógico. 5 ed. Petrópolis, RJ: Vozes, p.40-59, 2007.

BRANDÃO, M. Associação entre a interação e a metacognição: características e perspectivas de uma comunidade virtual de enfermagem. Rio de janeiro. 187f. Tese (doutorado). Escola de Enfermagem Ana Nery. Universidade Federal do Rio de Janeiro. 2006.

BRASIL. Ministério da Educação. Diretrizes Curriculares Nacionais para a Formação de Professores da Educação Básica, em nível superior, curso de licenciatura, de graduação plena. Brasília, DF: MEC, 2001.2 Disponível em: <http://portal.mec.gov.br/cne/arquivos/pdf/009.pdf> Acesso em 27 de fevereiro de 2012.

BRUNER, J. S. Acts of meaning. Cambridge: Harvard University Press, 1990.

BZUNECK, J.A. O esforço nas aprendizagens escolares: mais do que um problema motivacional do aluno. Revista Educação e Ensino - USF, v. 6, n.1, p.07-18, 2001.

BZUNECK, J. A. Aprendizagem por processamento da informação: uma visão construtivista. In: BORUCHOVITCH, E; BZUNECK, J. A. (Orgs.). Aprendizagem: processos psicológicos e o contexto social na escola. Petrópolis: Vozes, 2004.

CARVALHO, F. A. H. Reaprender a aprender: a pesquisa como alternativa metacognitiva. Porto Alegre. 152 f. Tese (doutorado). Faculdade de Educação. Universidade Católica do Rio Grande do Sul. 2007.

CASTEÑON, G. O que é cognitivismo? Fundamentos Filosóficos. São Paulo: EPU, 2007. 
CATHOLICO, R. Estratégia de ensino em curso técnico a partir dos estilos de aprendizagem de Felder-Soloman. São Carlos. 130f. Dissertação (mestrado). Escola de Engenharia de São Carlos (EESC). Universidade de São Paulo. 2009.

CASSIDY, S. Learning Styles: an overview of theories, models, and measures. Educational Psychology, v. 24, n. 4 , p. 419-444, 2004.

CERQUEIRA, T. Estilos de aprendizagem em universitários. Campinas. $202 f$. Tese (doutorado). Faculdade de Educação. Universidade Estadual de Campinas. 2000.

CERQUEIRA, T. Estilos de aprendizagem de Kolb e sua importância na educação. Revista Estilos de Aprendizaje, v. 1, n.1, p. 109-123, 2008.

CLAXTON, C.S.; MURRELL, P.H. Learning styles implications for improving educational practices. Washington: Association for the Study of Higher Education, 1987.

COCCO, A. Modelo de adaptação de ensino utilizando agentes pedagógicos. Porto Alegre. 113f. Tese (doutorado). Faculdade de Educação. Programa de Pós-Graduação em Informática na Educação. Universidade Federal do Rio Grande do Sul. 2004.

COFFIELD, F. D. et. al. Learning styles and pedagogy in post-16 education: a systematic and critical review. London: LSRC, 2004. Disponível em: <http://www.hull.ac.uk/php/edskas/learning\%20styles.pdf>. Acesso em: 28 de outubro de 2010.

COOK, D. A. Validity of index of learning styles scores: multitrait-multimethod comparison with three cognitive / learning style instruments. Medical Education. EUA, v.40, n. 9, p. $900-907,2006$.

COOK, D. A.; SMITH, A. J. Reliability and validity of scores from the Index of Learning Styles. Academic Medicine, v. 80, n. 10, p. 97-101, october 2005.

COKER, C. A.; PEDERSEN, S. J. Context and test-retest reliability of Kolb's learning style inventory. Psychological Reports, v. 95, n.1, p. 180-182, 2004.

CUÉ, J.; RINCÓN, J.; GARCIA, C. Instrumentos de medicion de estilos de aprendizaje. Revista Estilos de Aprendizaje, vol. 4, n.4, pp.3-21, 2009.

CURY, A. C. H. Uma análise holística do perfil pedagógico de docentes e suas estratégias de ensino e relacionamento: uma aplicação no ensino de engenharia de produção. São Carlos. 307f. Tese (doutorado). Escola de Engenharia de São Carlos (EESC). Universidade de São Paulo. 2008.

CURRY, L. Patterns of learning style across selected medical specialties. Educational Psychology, vol. 11, n. 3/4, pp. 247 - 278, 1991. Disponível em: <http://web.ebscohost.com/ehost/detail?vid=3\&hid=13\&sid=f5d2eae3-2b6d-4008-899247a3ca891a96\%40sessionmgr112\&bdata=JnNpdGU9ZWhvc3QtbGI2ZQ\%3d\%3d\#db=aph\&A $\mathrm{N}=9707160496>$. Acesso em: 28 de outubro de 2010. 
DEBELLO, T.C. Comparison of eleven major learning styles models: variables, appropriate populations, validity of instrumentation and the research behind them. Journal of Reading, Writing and Learning Disabilities, n.6, p. 203-222, 1990.

DEE K.C.; NAUMAN E.A.; LIVESAY G.A.; RICE J. Research report: learning styles of biomedical engineering students. Annals of Biomedical Engineering, v. 30, n. 8, p.1100-6, 2002.

DEMBO, M.H. Applying educational psychology. 5 ed. New York: Longman, 1991.

DEMOLINER, V. L. Estratégias de estudo e percepções sobre o ensino em contexto universitário dos aprendizes de pedagogia. Brasília. 104f. Dissertação (mestrado). Programa de Pós-Graduação em Educação. Universidade Católica de Brasília. 2008.

DINIZ, D.. A interação no ensino a distância sob a ótica dos estilos de aprendizagem. São Carlos. 108f. Dissertação (mestrado). Escola de Engenharia de São Carlos (EESC). Universidade de São Paulo. 2007.

DUNN, R.; DEBELLO, T. C. Improved test scores, attitudes, and behaviors in America's schools: supervisors success stories. Santa Barbara: Greenwood Publishing Group, 1999.

ENTWISTLE, N. Motivacional factors in students aproaches to learning. In: SCHMECK, R. R. (org.). Learning and strategies and learning styles. New York: Plenum Press, 1988.

FELDER, R. M. Matters of Style. AEEE Prism, December Issue, p.18-23, 1996.

FELDER, R. M. Richard Felder's responses to frequenly asked questions about the ILS, 2001. Disponível em:

$<$ http://www2.ncsu.edu/unity/lockers/users/f/felder/public/ILSdir/ILS-faq.htm>. Acesso em: 03 de junho de 2010.

FELDER, R. M; HENRIQUES, R. Learning and teaching styles in foreign and second. Foreign Language Annals. EUA, v. 28, n. 1, p.21-31, 1995.

FELDER, R.M.; BRENT, R. Understanding students differences. Journal of Engineering Education, v. 94, n.1, p. 57-72, 2005.

FELDER, R.M.; SILVERMAN, L.K. Learning and teaching styles in engineering education. Journal of Engineering Education, v. 78, n. 7, p. 674-681, 1988. Disponível em: <http://www.ncsu.edu/felder-public/Papers/FLAnnals.pdf>. Acesso em: 30 de maio de 2010.

FELDER, R.M.; SILVERMAN, L.K. Learning and Teaching styles in engineering education. Journal of Engineering Education, v. 78, n. 7, p. 674-681, (prefácio de 2002). Disponível em: <http://www4.ncsu.edu/unity/lockers/users/f/felder/public/Papers/LS-1988.pdf>. Acesso em: 25 de maio de 2010.

FELDER, R. M.; SOLOMAN, B. A. Index of Learning Styles Questionnaire. North Carolina State University, 2001. Disponível em: 
<http://www2.ncsu.edu/unity/lockers/users/f/felder/public/ILSdir/ILS-a.htm>. Acesso em: 25 de maio de 2010.

FERRAZ, A. P. C. M. Instrumento para facilitar o processo de planejamento e desenvolvimento de materiais instrucionais para a modalidade à distância. São Carlos. 234f. Tese (doutorado). Escola de Engenharia de São Carlos (EESC). Universidade de São Paulo. 2008.

FONSECA, G. M. R. Estratégias metacognitivas de leitura e consolidação da memória de longo prazo. Uberlândia. 142f. Dissertação (mestrado). Pós-Graduação em Lingüística. Universidade Federal de Uberlândia, 2006.

FREITAS, J. R. Mapas conceituais: estratégia pedagógica para construção de conceitos na disciplina química orgânica. Ciências \& Cognição, v. 12, dez. 2007.

FREITAS, A.. Aplicação dos estilos de aprendizagem na formação de equipes: um estudo de caso. São Carlos. 108f. Dissertação (mestrado). Escola de Engenharia de São Carlos (EESC). Universidade de São Paulo. 2007.

FUTER, M. J. K. A relação entre os estilos de aprender e os estilos de ensinar em uma sala de aula multicultural de português como língua estrangeira: um estudo de caso. Brasília. 181f. Dissertação (mestrado). Instituto de Letras. Universidade de Brasília. 2007.

GAGNÉ, E. D. The cognitive psychology of school learning. Boston: Litle, Brown and Company, 1985.

GARDNER, H. A nova ciência da mente: uma história da revolução cognitiva. 3ạ. ed. São Paulo: Edusp, 2003.

GAIGNOUX, K.. C. M. O efeito da instrução de estratégias de aprendizagem no desenvolvimento da produção oral de alunos de inglês da universidade do Pará: um estudo de caso. Belém. 194 f. Dissertação (mestrado). Universidade Federal do Pará. 2006.

GALEGO, D. J.; GARCIA, C. M. A. Estilos de aprender em el siglo XXI. Revista Estilos de Aprendizaje, v. 2, n. 2, p. $23-34,2008$.

GALVÃO, V. F. Estratégias de estudo deliberado e percepções sobre o contexto de ensino na perspectiva de estudantes do curso de letras-inglês. Brasília. 141f. Dissertação (mestrado). Programa de Pós Graduação Stricto Senso em Educação. Universidade Católica de Brasília, 2007.

GARCIA, C. M. A. Estilos de aprendizaje. Presente y futuro. Revista Estilos de Aprendizaje, v. 1, n. 1, p. $04-15,2008$.

GARNER, I. Problems and inconsistencies with Kolb's Learning Styles. Educational Psychology, v.20, p. 341-348, 2000.

GIL, A. C. Como elaborar projetos de pesquisa. 4. ed. São Paulo: Atlas, 2002. 
GRANITO, R. Educação a distância e estilos de aprendizagem: elaboração de um protocolo de qualidade para ambientes virtuais de ensino. Ribeirão Preto. 202f. Dissertação (mestrado). Faculdade de Economia, Administração e Contabilidade de Ribeirão Preto (FEARP). Universidade de São Paulo. 2008.

HALBERT C.; KRIEBEL R.; CUZZOLINO R.; COUGHLIN P.; FRESA-DILLON K. Self-assessed learning style correlates to use of supplemental learning materials in an online course management system. Medical Teacher, v. 33, n. 4, p. 331-3, 2011.

HATTIE, J.; BIGGS, J.; PURDIE, N. Effects of learning skills interventions on students: a meta analysis. Review of Educational Research, v. 66, p. 99-136, 1996.

HOLTZCLAW J.D.; EISEN A.; WHITNEY E.M.; PENUMETCHA M.; HOEY J.J.; KIMBRO K.S. Incorporating a new bioinformatics component into genetics at a historically black college: outcomes and lessons. CBE - Life Sciences Education, v. 5, n. 1, p. 52-64, 2006.

HOSFORD, C.C; SIDERS, W. A . Felder-Soloman's Index of Learning Styles: internal consistency, temporal stability, and factor structure. Teaching and Learning in Medicine, $\mathrm{v}$. 22, n. 4, p. 298-303, 2010.

HUGHES J.M.; FALLIS D.W.; PEEL J.L. Murchison DF learning styles of orthodontic residents. Journal of Dental Education, v. 73, n. 3, p. 319-27, 2009.

Instituto Brasileiro de Geografia e Estatística. Síntese de indicadores sociais. Brasília, DF: IBGE, 2010.Disponível em:

<http://www.ibge.gov.br/home/estatistica/populacao/condicaodevida/indicadoresminimos /sinteseindicsociais2010/default_tab.shtm> Acesso em 20 de fevereiro de 2012.

JACOBSOHN, L. V. A contribuição do e-learning no desenvolvimento de competências do administrador: considerando o estilo de aprendizagem do aluno de graduação. São Paulo. 232f. Dissertação (mestrado). Faculdade de Economia, Administração e Contabilidade (FEA). Universidade de São Paulo. 2003.

KALATZIS, A. Aprendizagem baseada em problemas em uma plataforma de ensino a distância com o apoio dos estilos de aprendizagem: uma análise do aproveitamento dos estudantes de engenharia. São Carlos. 113f. Dissertação (mestrado). Escola de Engenharia de São Carlos (EESC). Universidade de São Paulo. 2008.

KAYES, D. C. Internal validity and reliability of Kolb's learning style inventory version 3 (1999). Journal of Business and Psychology, v. 20, n. 2, p.249-257, 2005.

KEEFE, J. W.; JENKINS, J. M. Instruction and the learning environment. New York: Eye on Education, 1997.

KOLB, D.A.; BOYATZIS, R.E.; MAINEMELIS, C. Experiential learning theory: previous research and new directions. In: Sternberg, R. J.; Zhang, L. F. (orgs.). Perspectives on cognitive, learning, and thinking styles. $\mathrm{NJ}$ : Lawrence Erlbaum, 2000. 
KOLB. A.; KOLB, D.A. Learning styles and learning spaces: enhancing experiential learning in higher education. Academy of Management Learning \& Education, v. 4, n. 2, p.193-212, 2005.

KURI, N. P. Tipos de personalidade e estilos de aprendizagem: proposições para o ensino de engenharia. $334 \mathrm{f}$. Tese (doutorado). Curso de Pós-graduação em Engenharia da Produção. Universidade Federal de São Carlos, São Carlos, 2004.

LAGO, B.; COLVIN, L.; CACHEIRO, M. Estilos de aprendizaje. Presente y futuro. Revista Estilos de Aprendizaje, v. 2, n. 2, p. $02-21,2008$.

LAZARTE, L. Ecologia cognitiva na sociedade da informação. Ciência da Informação. Brasília, v. 29, n. 2, maio/agosto. 2000.

LEFRANÇOIS, G. R. Teorias de Aprendizagem. São Paulo: Cengage Learning, 2008.

LEVENFUS, R. S.; SOARES, D. H. P. e cols. Orientação Vocacional Ocupacional. 2a.ed. Porto Alegre: Artmed, 2010.

LIMA, W. R. Estratégias de estudo deliberado e percepções sobre o ensino na perspectiva da graduação em psicologia. Brasília. 105 f. Dissertação (mestrado). Programa de PósGraduação Stricto Sensu em Psicologia. Universidade Católica de Brasilía. 2007.

LINDEMANN, V. Estilos de aprendizagem: buscando a sinergia. Porto Alegre. 165f. Tese (doutorado). Faculdade de Educação. Programa de Pós-Graduação em Informática na Educação. Universidade Federal do Rio Grande do Sul. 2008.

LITZINGER, T.; LEE, S.; WISE, J.; FELDER, R. A psychometric study of the Index of Learning Styles. Journal of Engineering Education, v.96, n.4, p. 309-319, 2007.

LOMÔNACO, J.F. B. A natureza dos conceitos: visões psicológicas. São Paulo, 1997. 213f. Tese (Livre Docência em Psicologia). Instituto de Psicologia. Universidade de São Paulo.

LOPES, G. Crenças em estratégias de aprendizagem de línguas (inglês) de alunos de cursos de letras. Brasília. 244 f. Dissertação (mestrado). Universidade de Brasília. 2007.

LOO, R. Kolb's learning styles and learning preferences: is there a linkage? In: Educational Psychology, v. 24, n. 1, p. 99-108, 2004.

LOPES, W. ILS - Inventário de Estilos de Aprendizagem de FelderSaloman: investigação de sua validade em estudantes universitários de Belo Horizonte. Dissertação (mestrado). Universidade Federal de Santa Catarina. Florianópolis, 2002.

MADRUGA, J.A.G.; LACASA, P. Processos cognitivos básicos nos anos escolares. In : COLL, C., MARCHESI, A., PALACIOS, J. (orgs.) Desenvolvimento psicológico e educação: psicologia evolutiva. 1 ed. v.1. Porto Alegre: Artmed, 1995. 
MAGALHAES, A. R. Mapas conceituais digitais como estratégias para o desenvolvimento da metacognição no estudo das funções. São Paulo. 257 f. Tese (doutorado). Pontifícia Universidade Católica de São Paulo, 2009.

MAYER, R.E. El futuro de la psicologia cognitiva. Madrid: Alianza Psicologia, 1985.

MANZINI, N. I. J. Roteiro pedagógico: um instrumento para a aprendizagem de conceitos de física. Ciência e educação, v.13, n.1, pp.201-217, 2007.

MARINI FILHO, R. L. Aprendizagem baseada em problemas e o desenvolvimento de habilidades para a aprendizagem auto-dirigida. Curitiba. 163f. Dissertação (mestrado). Programa de Pós Graduação em Educação. Universidade Federal do Paraná. 2006.

METALLIDOU, P.; PLATSIDOU, M. Kolb's Learning Style Inventory-1985: Validity issues and relations with metacognitive knowledge about problem-solving strategies. Learning and Individual Differences, v. 18, n. 1, pp. 114-119, 2008.

MONEREO, C. Ensinar a aprender e a pensar no ensino médio: estratégias de aprendizagem. In : COLL, C., GOTZENS, C., MONEREO, C.; ONRUBIA, J.; POZO, J.; TAPIA, A. (orgs) Psicologia da aprendizagem no ensino médio. Porto Alegre: Artmed, 2003.

MORITA, A. B. P. S. Estratégias de ensino aprendizagem na enfermagem - análise pela escala de coma de Gasgow. Guarulhos. 80f. Dissertação (mestrado). Centro de Pós Graduação, Universidade Guarulhos. 2006.

MOTTA, V. R. A.. Noticing e consciousness - raising na aquisição da escrita em língua materna. Santa Maria. 204f. Tese (doutorado). Centro de Artes de Letras. Universidade Federal de Santa Maria. 2009.

MUNEIRO, M. Estratégias de aprendizagem de alunos do ensino superior. Campinas. $144 \mathrm{f}$. Dissertação (mestrado). Faculdade de Educação. Universidade Estadual de Campinas. 2008.

MURAD, C. R. R. O. Descompasso entre estilo de ensino/aprendizagem e os objetivos dos alunos. Campinas. 100f. Dissertação (mestrado). Instituto de Estudos da Linguagem. Universidade Estadual de Campinas. 2004.

NAKASHIMA, R. H. R. A linguagem interativa da lousa digital e a teoria dos estilos de aprendizagem. Campinas. 160f. Dissertação (mestrado). Faculdade de Educação. Universidade Estadual de Campinas. 2008.

NEEL J.A.; GRINDEM C.B. Learning-style profiles of 150 veterinary medical students.

Journal of Veterinary Medical Education, v. 37, p. 4, p.347-52, 2010.

PRAJAPATI B.; DUNNE M.; BARTLETT H.; CUBBIDGE R. The influence of learning styles, enrollment status and gender on academic performance of optometry undergraduates. Ophthalmic and Physiological Optics, v. 31, n.1, p. 69-78, 2011. 
PENNA, A. G. Introdução à Psicologia Cognitiva. São Paulo: EPU - Editora Pedagógica e Universitária,1984.

PEREIRA, E. S. Estilos de aprender e ensino a distância: perfil de estudantes. Campinas. $114 \mathrm{f}$. Dissertação (mestrado). Programa de Pós-graduação em Psicologia. Pontifícia Universidade Católica de Campinas. 2007.

PEREIRA, M. A. Estratégias de estudo deliberado e percepções sobre o ensino de matemática no contexto universitário, Brasília. 154f. Dissertação (mestrado). Programa de Pós-Graduação Stricto Sensu em Educação. Universidade Católica de Brasília, 2007.

PEREIRA, M. Ensino-aprendizagem em um contexto dinâmico - o caso de planejamento de transportes. São Carlos. 147f. Tese (doutorado). Escola de Engenharia de São Carlos (EESC). Universidade de São Paulo. 2005.

PERNOMIAN, V. Visualização exploratória de dados do desempenho na aprendizagem em um ambiente adaptável. São Carlos. 124f. Tese (doutorado). Escola de Engenharia de São Carlos (EESC). Universidade de São Paulo. 2008.

PERRAUDEAU, M. Estratégias de aprendizagem. 1ed. Porto Alegre: Artmed, 2009.

PIMENTEL, A. Análise da influência do estilo de aprendizagem e da atitude em disciplinas de estatística da FEARP. Ribeirão Preto. 205f. Dissertação (mestrado). Faculdade de Economia, Administração e Contabilidade de Ribeirão Preto (FEARP). Universidade de São Paulo. 2009.

PLATÃO. A república. 6 ed. Editora Atena, 1956.

POZO, J.I. Aprendizes e mestres: a nova cultura da aprendizagem. 1ed. Porto Alegre: Artmed, 2002.

POZO, J.I., MONEREO, C., CASTELLÓ, M. O uso estratégico do conhecimento. In : COLL, C., MARCHESI, A., PALACIOS, J. (orgs) Desenvolvimento psicológico e educação: psicologia da educação escolar.. 2 ed. Vol.2.Porto Alegre: Artmed, 2004.

POZO, J.I.; CRESPO, M.A.G. A aprendizagem e o ensino de ciências - do conhecimento cotidiano ao conhecimento científico. 5 ed. São Paulo: Editora Artmed, 2009.

PUPO, E. A.; TORRES, E. O. Las invenstigaciones sobre los estilos de aprendizaje y sus modelos explicativos. Revista Estilos de Aprendizaje, vol. 4, n.4, pp. 22-35, 2009.

QUINTANA, M. M. S. A aprendizagem na percepção de alunos e professores do ensino superior. Curitiba. 148f. Dissertação (mestrado). Programa de Pós-Graduação em Educação. Pontifícia Universidade Católica do Paraná. 2006.

RABELLO, C. R. L. Aprendizagem na educação à distância: dificuldades dos discentes de licenciatura em ciências biológicas na modalidade semipresencial. Rio de Janeiro. $132 \mathrm{f}$. Dissertação (Mestrado). Universidade Federal do Rio de Janeiro. 2007. 
RENNIE, G. A. An investigation of the learning styles of undergraduate physical therapy students and practicing physical therapists. Dissertation Abstracts International Section $A$ : Humanities and Social Sciences, v.64, n. 7-A, p. 23-84. 2004.

RIBEIRO, C. Metacognição: um apoio ao processo de aprendizagem. Psicologia: Reflexão e Crítica, Porto Alegre, v. 16, n.1, p. 109-116, 2003.

RIDING, R. J.; CHEEMA, I. Cognitive styles: An overview and integration. Educational Psychology, v. 11,pp. 193-215, 1991.

ROSÁRIO, J. Estilos de aprendizagem de alunos de engenharia química e engenharia de alimentos da UFSC. Florianópolis. 102 f. Dissertação (mestrado). Programa de Pós-Graduação em Engenharia Química. Universidade Federal de Santa Catarina. 2006.

RUIZ, V. M. Aprendizagem em universitários: variáveis motivacionais. Campinas. $172 \mathrm{f}$. Dissertação (mestrado). Programa de Pós Graduação em Psicologia. Pontifícia Universidade Católica de Campinas Tese. 2005.

SALLES, T. J. Estilos de Aprendizagem no trabalho: análise e construção de medidas. Brasília. 149 f. Dissertação (mestrado). Instituto de Psicologia. Universidade de Brasília. 2007.

SANTOS, A.A.A.; BORUCHOVITCH, E.; PRIMI, R.; BUENO, J. M. H.; ZENORINI, R. P. C. Escala de Avaliação de Estratégias de Aprendizagem para Universitários (EAP-U): aplicação do modelo de Rasch de créditos parciais. Psicologia: Teoria, Investigação e Prática, v.9, n.2, p.227-243. Universidade do Minho, Portugal, 2004.

SANTOS, A.A.A.; MOGNON, J.F. Estilos de aprendizagem em estudantes universitários. Boletim de Psicologia, v.LX, n.133, p.229-241, 2010.

SANTOS, E. M. Avaliação da influência dos estilos cognitivos no perfil do aluno de educação a distância. São Carlos. 130f. Dissertação (mestrado). Escola de Engenharia de São Carlos (EESC). Universidade de São Paulo. 2007.

SANTOS, G. Aprendizagem do diagnóstico fonoaudiológico clínico na perspectiva metacognitiva. Rio de Janeiro. 189f. Dissertação (mestrado). Núcleo de Tecnologia Educacional para a Saúde. Universidade Federal do Rio de Janeiro. 2006.

SANTOS, L. A contribuição dos processos metacognitivos na formação do pedagogo. Curitiba. 202f. Dissertação (mestrado). Programa de Pós-graduação em Educação. Pontifícia Universidade Católica do Paraná. 2005.

SANTOS, O. O professor enquanto estudante: suas estratégias de aprendizagem. Campinas. 140f. Dissertação (mestrado). Faculdade de Educação. Universidade Estadual de Campinas. 2008.

SANTROCK, J. W. Educational Psychology. 2 ed. Dallas: Mc Graw Hill, 2004. 
SCHMECK, R. R. An introduction to strategies and styles of learning. In: SCHMECK, R. R.(org.) Learning and strategies and learning styles. New York: Plenum Press, 1988.

SCHULTZ, D. P.; SCHULTZ, S. E. História da Psicologia Moderna. São Paulo: Thomson Learning, 2007.

SENRA, C. M. S.; LIMA, G. F. C. A.; SILVA, F.W.O. A Relação entre os Estilos de Aprendizagem de Richard Felder e os Tipos Psicológicos de Carl Jung. In: SEMINÁRIO NACIONAL DE EDUCAÇÃO PROFISSIONAL E TECNOLÓGICA, 2008, Belo Horizonte. Anais... Belo Horizonte: SENEPT, 2008.

SILVA, D. O impacto dos estilos de aprendizagem no ensino de contabilidade na FEARP/USP. Ribeirão Preto. 108f. Dissertação (mestrado). Faculdade de Economia, Administração e Contabilidade de Ribeirão Preto (FEARP). Universidade de São Paulo. 2006.

SILVA. G. de A.(a) A autonomia do ensino-aprendizagem de língua inglesa: suas relações com a motivação e as estratégias. Salvador. 166f. Dissertação (mestrado). Programa de PósGraduação em Letras e Lingüística. Universidade Federal da Bahia. 2008.

SILVA, G. B. A. Estratégia de aprendizagem na aula de língua estrangeira: um estudo com formandos em letras. Santa Maria. 125f. Dissertação (mestrado). Programa de Pós graduação em Letras. Universidade Federal de Santa Maria. 2006.

SILVA, M. G. R. (b) Labirintos de espaços e tempos no cotidiano universitário: o acadêmico de administração. Porto Alegre. 152f. Tese (doutorado). Faculdade de Educação. Pontifícia Universidade Católica do Rio Grande do Sul. 2008.

SKINNER, B. F. Beyond freedom and dignity. Indianápolis: Hackett Publishing Company, 2002.

SOBRAL, D. T. Inventário de estilo de aprendizagem de Kolb: características e relaçäo com resultados de avaliaçäo no ensino pré-clínico. Psicologia: teoria e pesquisa, v.8, n. 3, p.293303, 1992.

SOSSAI, M. Um estudo em estratégias de compreensão leitora num curso de letras. São Paulo. 172f. Dissertação (Mestrado). Programa de Pós-Graduação em Educação (Psicologia da Educação). Pontifícia Universidade Católica de São Paulo. 2009.

SOUZA, L. Role-play aplicado ao ensino da contabilidade: um estudo à luz dos estilos de aprendizagem e percepções discentes. São Paulo. 202f. Dissertação (mestrado). Faculdade de Economia, Administração e Contabilidade (FEA). Universidade de São Paulo. 2006.

STERnBERG, R. Psicologia Cognitiva. 4 ed. Porto Alegre: Artmed, 2008.

TAKEUCHI, M. Y. Estudo do uso de mapa conceitual na promoção de aprendizagem significativa de conteúdo de neurociência na graduação. São Paulo. 94 f. Dissertação (Mestrado) Instituto de Psicologia. Universidade de São Paulo. 2009. 
TEIXEIRA, A.P.F. Estratégias de auto-regulação na aprendizagem em história: estudo no 2.을 C.E.B. Portugal. Dissertação (Mestrado). Instituto de Educação e Psicologia. Universidade do Minho, 2004.

TREVELIN, A. A relação professor aluno estudada sob a ótica dos estilos de aprendizagem: análise em uma Faculdade de Tecnologia - Fatec. São Carlos. 202f. Tese (doutorado). Escola de Engenharia de São Carlos (EESC). Universidade de São Paulo. 2007.

VAN ZWANENBERG, N; WILKINSON, L. J.;ANDERSON, A. Felder and Silverman's Index of Learning Styles and Honey and Mumford's Learning Styles Questionnaire: how do they compare and do they predict academic performance? Educational Psychology. v. 20, n.3, p. 365-381, 2000.

VIANA JÚNIOR, O. B. (RE) Construindo a noção de estratégias de aprendizagem em contexto interacional de sala de aula. Salvador. 185f. Dissertação (mestrado). Programa de Pós-Graduação em Letra e Linguística. Universidade Federal da Bahia. 2006.

VILAÇA, M. L. C. Estratégias de aprendizagem e materiais didáticos de língua estrangeira: elaboração, integração, ensino e percepção. Niterói. 249f. Tese (Doutorado). Instituto de Letras. Universidade Federal Fluminense. 2009.

VIOLA, S.R., GRAF, S., KINSHUK, LEO, T.: Analysis of Felder-Silverman Index of Learning Styles by a Data-driven Statistical Approach. In: 8th IEEE International Symposium on Multimedia, 2006, San Diego. Proceeding... San Diego: 2006 p. 959-964.

WEINSTEIN, C.E.; MAYER, R.E. The teaching of learning strategies. In: WITTROCK, M. (Org.). Handbook of research on teaching. 3a. ed. New York: Macmillan, 1985. pp.315-327.

WILLINGHAM, D. T. Por que os alunos não gostam da escola? Respostas da ciência cognitiva para tornar a sala de aula atrativa e efetiva. Porto Alegre: Artmed, 2011.

ZYWNO, M. S. A Contribution to Validation of Score Meaning for Felder-Soloman's Index of Learning Styles Ryerson University. In: AMERICAN SOCIETY FOR ENGINEERING EDUCATION ANNUAL CONFERENCE \& EXPOSITION COPYRIGHT. 2003, EUA. Proceedings... EUA: American Society for Engineering Education, 2003. 
Dados do Participante:

Curso:

Semestre:

Idade:

Sexo: Masculino ( ) Feminino ( )

\section{ÍNDICE DE ESTILOS DE APRENDIZAGEM - ILS}

(Felder \& Soloman, 1991)

Instruções:

Marque na letra "a" ou "b" para indicar sua resposta a cada uma das questões. Assinale apenas uma das alternativas para cada questão. Se as duas alternativas se aplicam a você, escolha aquela que é mais freqüente.

1. Eu compreendo melhor alguma coisa depois de

a) experimentar.

b) refletir sobre ela.

2. Eu me considero

a) realista.

b) inovador (a).

3.Quando eu penso sobre o que fiz ontem, é mais provável que aflorem

a) figuras.

b) palavras.

4. Eu tendo a

a) compreender os detalhes de um assunto, mas a estrutura geral pode ficar imprecisa.

b) compreender a estrutura geral de um assunto, mas os detalhes podem ficar imprecisos.

5. Quando estou aprendendo algum assunto novo, me ajuda

a) falar sobre ele.

b) refletir sobre ele.

6. Se eu fosse um professor, eu preferiria ensinar uma disciplina

a) que trate com fatos e situações reais.

b) que trate com ideias e teorias.

7. Eu prefiro obter novas informações através de

a) figuras, diagramas, gráficos ou mapas.

b) instruções escritas ou informações verbais.

8. Quando eu compreendo

a) todas as partes, consigo entender o todo.

b) o todo, consigo ver como as partes se encaixam.

9. Em um grupo de estudo, trabalhando um material difícil, eu provavelmente 
a) tomo a iniciativa e contribuo com ideias.

b) assumo uma posição discreta e escuto.

10. Acho mais fácil

a) aprender fatos.

b) aprender conceitos.

11. Em um livro com uma porção de figuras e desenhos, eu provavelmente

a) observo as figuras e desenhos cuidadosamente.

b) atento para o texto escrito.

12. Quando resolvo problemas de matemática, eu

a) usualmente trabalho de maneira a resolver uma etapa de cada vez.

b) frequentemente antevejo as soluções, mas tenho que me esforçar muito para conceber as etapas para chegar a elas.

13. Nas disciplinas que cursei eu

a) em geral fiz amizade com muitos dos colegas.

b) raramente fiz amizade com muitos dos colegas.

14. Em literatura de não-ficção, eu prefiro

a) algo que me ensine fatos novos ou me indique como fazer alguma coisa.

b) algo que me apresente novas ideias para pensar.

15. Eu gosto de professores

a) que colocam uma porção de diagramas no quadro.

b) que gastam bastante tempo estudando.

16. Quando estou analisando uma estória ou novela eu

a) penso nos incidentes e tento colocá-los juntos para identificar os temas.

b) tenho consciência dos temas quando termino a leitura e, então, tenho que voltar atrás para encontrar os incidentes que os confirmem.

17. Quando inicio a resolução de um problema para casa, normalmente eu

a) começo a trabalhar imediatamente na solução.

b) primeiro tento compreender completamente o problema.

18. Prefiro as ideias

a) objetivas.

b) teóricas.

19. Relembro melhor

a) o que vejo.

b) o que ouço.

20. É mais importante para mim que o professor

a) apresente a matéria em etapas sequenciais claras.

b) apresente um quadro geral e relacione a matéria com outros assuntos.

21. Eu prefiro estudar

a) em grupo.

b) sozinho(a). 
a) cuidadoso(a) com os detalhes do meu trabalho.

b) criativo(a) na maneira de realizar meu trabalho.

23. Quando busco orientação para chegar a lugar desconhecido, eu prefiro

a) um mapa.

b) instruções por escrito.

24. Eu aprendo

a) num ritmo bastante regular. Se estudar pesado, eu "chego lá".

b) em saltos. Fico totalmente confuso(a) por algum tempo e, então, repentinamente eu tenho um "estalo".

\section{Eu prefiro primeiro}

a) experimentar as coisas.

b) pensar sobre como é que eu vou fazer.

26. Quando estou lendo como lazer, eu prefiro escritores que

a) explicitem claramente o que querem dizer.

b) dizem as coisas de maneira criativa, interessante.

27. Quando vejo um diagrama ou esquema em uma aula, relembro mais facilmente

a) a figura.

b) o que o professor disse a respeito dela.

28. Quando considero um conjunto de informações, provavelmente eu

a) presto mais atenção nos detalhes e não percebo o quadro geral.

b) procuro compreender o quadro geral antes de atentar para os detalhes.

29. Relembro mais facilmente

a) algo que fiz.

b) algo sobre o qual pensei bastante.

30. Quando tenho uma tarefa para executar, eu prefiro

a) dominar uma maneira para a execução da tarefa.

b) encontrar novas maneiras para a execução da tarefa.

31. Quando alguém está me mostrando dados, eu prefiro

a) diagramas e gráficos.

b) texto sumarizando os resultados.

32. Quando escrevo um texto, eu prefiro trabalhar (pensar a respeito ou escrever)

a) a parte inicial do texto e avançar ordenadamente.

b) diferentes partes do texto e ordená-las depois.

33. Quando tenho que trabalhar em um projeto em grupo, eu prefiro que se faça primeiro

a) um debate (brainstorming) em grupo, onde todos contribuem com ideias.

b) um brainstorming individual, seguido de reunião do grupo para comparar as ideais.

34. Considero um elogio chamar alguém de

a) sensível.

b) imaginativo.

35. Das pessoas que conheço em uma festa, provavelmente eu me recordo melhor 
a) de sua aparência.

b) do que elas disseram de si mesmas.

36. Quando estou aprendendo um assunto novo, eu prefiro

a) concentrar-me no assunto, aprendendo o máximo possível.

b) tentar estabelecer conexões entre o assunto e outros com ele relacionados.

37. Mais provavelmente sou considerado(a)

a) expansivo(a).

b) resevado(a).

38. Prefiro disciplinas que enfatizam

a) material concreto (fatos, dados).

b) material abstrato (conceitos, teorias).

39. Para entretenimento, eu prefiro

a) assistir televisão.

b) ler um livro.

40. Alguns professores iniciam suas preleções com um resumo do que irão cobrir. Tais assuntos são
a) de alguma utilidade para mim.

b) muito úteis para mim.

41. A ideia de fazer o trabalho de casa em grupo, com a mesma nota para todos do grupo

a) me agrada.

b) não me agrada.

42. Quando estou fazendo cálculos longos,

a) tendo a repetir todos os passos e conferir meu trabalho cuidadosamente.

b) acho cansativo conferir o meu trabalho e tenho que me esforçar para fazê-lo.

43. Tendo a descrever os lugares onde estive

a) com facilidade e com bom detalhamento.

b) com dificuldade e sem detalhamento.

44. Quando estou resolvendo problemas em grupo, mais provavelmente eu

a) penso nas etapas do processo de solução.

b) penso nas possíveis conseqüências, ou sobre as aplicações da solução para uma ampla faixa de áreas. 


\section{ANEXO B - ESCALA DE AVALIAÇÃO DE ESTRATÉGIAS DE APRENDIZAGEM}

(Acácia Aparecida Angeli dos Santos \& Evely Boruchovitch, 2008)

As próximas questões referem-se às estratégias que você pode utilizar para aprender.

Pense na(s) forma(s) como você, em geral, costuma estudar ou se preparar para uma avaliação e assinale $(\mathbf{x})$ apenas uma alternativa de cada um dos itens apresentados a seguir:

\begin{tabular}{|c|c|c|c|c|}
\hline & sempre & às vezes & raramente & nunca \\
\hline \multicolumn{5}{|l|}{$\begin{array}{l}\text { 1. Repetir as informações oralmente na medida que vai } \\
\text { lendo o texto. }\end{array}$} \\
\hline \multicolumn{5}{|l|}{ 2. Anotar na íntegra as explicações do professor. } \\
\hline \multicolumn{5}{|l|}{$\begin{array}{l}\text { 3. Identificar suas dificuldades para aprender determinados } \\
\text { tópicos ou assuntos. }\end{array}$} \\
\hline \multicolumn{5}{|l|}{ 4. Resumir os textos indicados para estudo. } \\
\hline \multicolumn{5}{|l|}{ 5. Ler os textos indicados pelo professor. } \\
\hline \multicolumn{5}{|l|}{ 6. Fazer anotações no texto ou em folha à parte. } \\
\hline \multicolumn{5}{|l|}{ 7. Escrever com suas palavras o que entendeu do texto. } \\
\hline \multicolumn{5}{|l|}{$\begin{array}{l}\text { 8. Ler textos complementares, além dos indicados pelo } \\
\text { professor. }\end{array}$} \\
\hline \multicolumn{5}{|l|}{ 9. Motivar-se para as atividades de leitura e estudo. } \\
\hline \multicolumn{5}{|l|}{$\begin{array}{l}\text { 10. Elaborar perguntas e respostas sobre o assunto } \\
\text { estudado. }\end{array}$} \\
\hline \multicolumn{5}{|l|}{ 11. Selecionar as idéias principais do texto } \\
\hline \multicolumn{5}{|l|}{ 12.Controlar sua ansiedade em situações de avaliação } \\
\hline \multicolumn{5}{|l|}{$\begin{array}{l}\text { 13. Analisar os gráficos e as tabelas que você encontra nos } \\
\text { textos. }\end{array}$} \\
\hline \multicolumn{5}{|l|}{$\begin{array}{l}\text { 14. Identificar as idéias principais e relacioná-las através de } \\
\text { diagramas ou mapas conceituais. }\end{array}$} \\
\hline \multicolumn{5}{|l|}{ 15. Identificar o quanto você está ou não aprendendo } \\
\hline \multicolumn{5}{|l|}{ 16. Pedir auxílio ao professor sobre as dúvidas na matéria. } \\
\hline & sempre & às vezes & raramente & nunca \\
\hline
\end{tabular}




\begin{tabular}{|c|c|c|c|c|}
\hline 17. Rever as anotações feitas em sala de aula & & & & \\
\hline $\begin{array}{l}\text { 18. Procurar no dicionário o significado de palavras } \\
\text { desconhecidas. }\end{array}$ & & & & \\
\hline 19. Pedir ajuda aos colegas em caso de dúvidas. & & & & \\
\hline 20. Administrar seu tempo de estudo. & & & & \\
\hline 21. Organizar seu ambiente de estudo. & & & & \\
\hline 22. Manter a calma diante de tarefas difíceis. & & & & \\
\hline 23. Recorrer a outros textos e livros sobre o assunto. & & & & \\
\hline 24. Perceber quando não entende o que lê, parar e reler. & & & & \\
\hline 25. Planejar suas atividades de estudo. & & & & \\
\hline $\begin{array}{l}\text { 26. Separar todo o material necessário para a tarefa que ir } \\
\text { realizar. }\end{array}$ & & & & \\
\hline $\begin{array}{l}\text { 27. Conseguir ir até o final de uma tarefa mesmo quando } \\
\text { ela é difícil ou tediosa. }\end{array}$ & & & & \\
\hline $\begin{array}{l}\text { 28. Parar durante a leitura para saber se está } \\
\text { compreendendo o que leu. }\end{array}$ & & & & \\
\hline 29. Verificar seus erros após receber uma nota de prova & & & & \\
\hline 30. Escutar música enquanto estuda ou faz os trabalhos & & & & \\
\hline $\begin{array}{l}\text { 31. Criar perguntas sobre o assunto que está estudando e } \\
\text { tentar respondê-las }\end{array}$ & & & & \\
\hline $\begin{array}{l}\text { 32. Ficar muito nervoso quando está fazendo uma pro } \\
\text { difícil }\end{array}$ & & & & \\
\hline 33. Tentar refazer questões que errou em uma prova & & & & \\
\hline $\begin{array}{l}\text { 34. Ficar se levantando à toda hora enquanto está } \\
\text { estudando }\end{array}$ & & & & \\
\hline 35. Comer enquanto estuda ou faz os trabalhos & & & & \\
\hline & sempre & às vezes & raramente & nunca \\
\hline cer de fazer as coisas que os professores pede & & & & \\
\hline
\end{tabular}




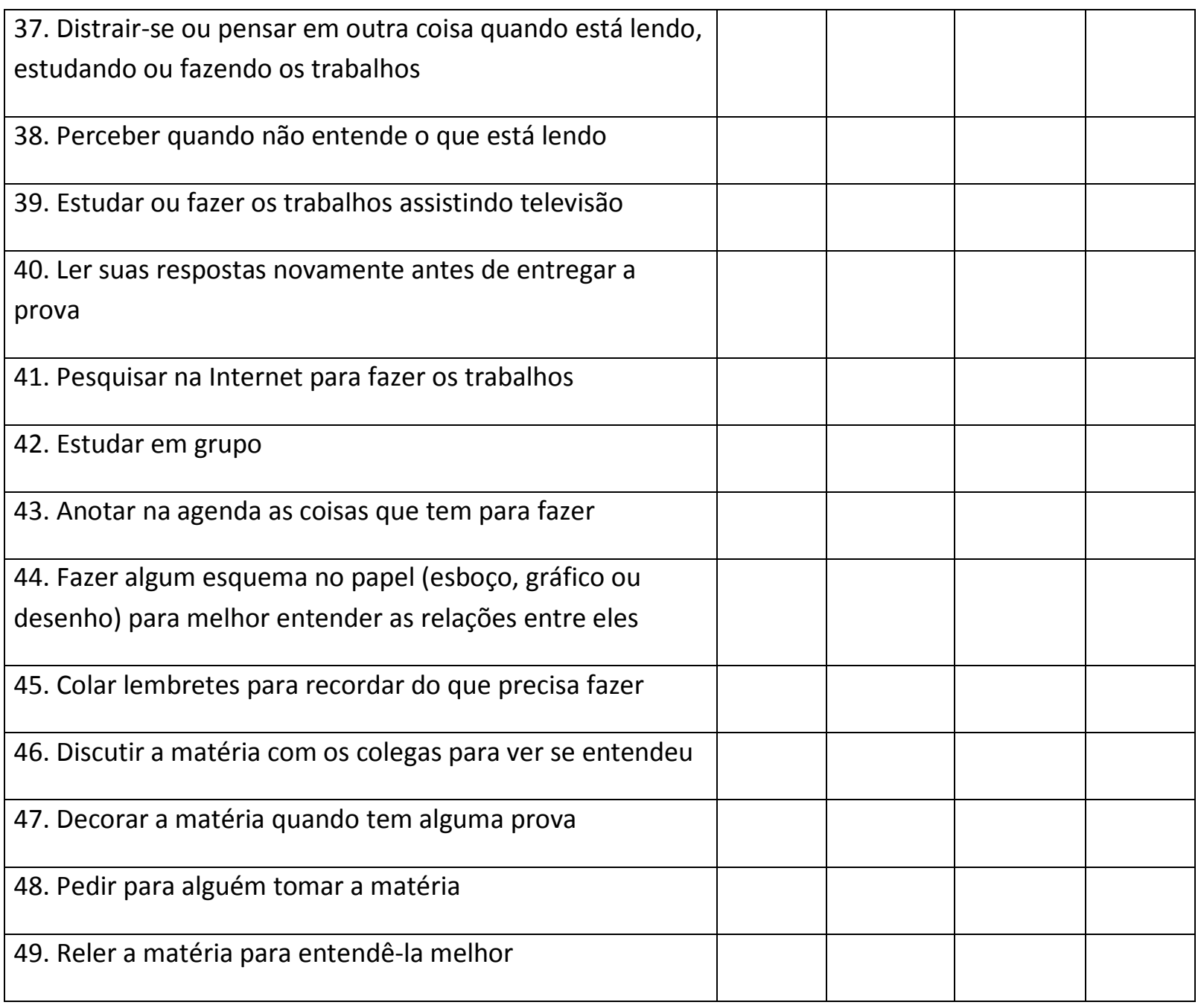


$\mathrm{Eu}$ concordo em participar do Trabalho de Pesquisa sob o título Estilos e estratégias de aprendizagem de estudantes universitários, cujos objetivos são identificar os estilos e estratégias de aprendizagem mais comuns entre os participantes e verificar se, a cada tipo de estilo de aprendizagem, correspondem preferencialmente certos tipos de estratégias.

Reconheço que os resultados dessa pesquisa poderão contribuir para um maior conhecimento sobre as diferenças individuais para aprender e auxiliar na orientação de futuras ações que visem a melhoria do processo de aprendizagem .

Fui informado que será mantido sigilo das minhas informações e que minha pessoa será mantida no anonimato.

Ressalto que minha participação é voluntária e autorizo a pesquisadora a utilizar, para fins científicos, os dados coletados através dos dois questionários que respondi.

Posso desistir da pesquisa a qualquer momento. E se desejar qualquer informação adicional ou ter acesso aos resultados da pesquisa poderei me dirigir à pesquisadora Lisliê Lopes Vidal Silva pelo telefone (19) 96095753 ou pelo e-mail lislie.silva@usp.edu.br

Este termo foi entregue em duas vias sendo uma para o participante e outra para a pesquisadora. 
